In Cooperation With the International Upper Great Lakes Study Board and U.S. Army Corps of Engineers

\title{
Statistical and Spatial Analysis of Bathymetric Data for the St. Clair River, 1971-2007
}

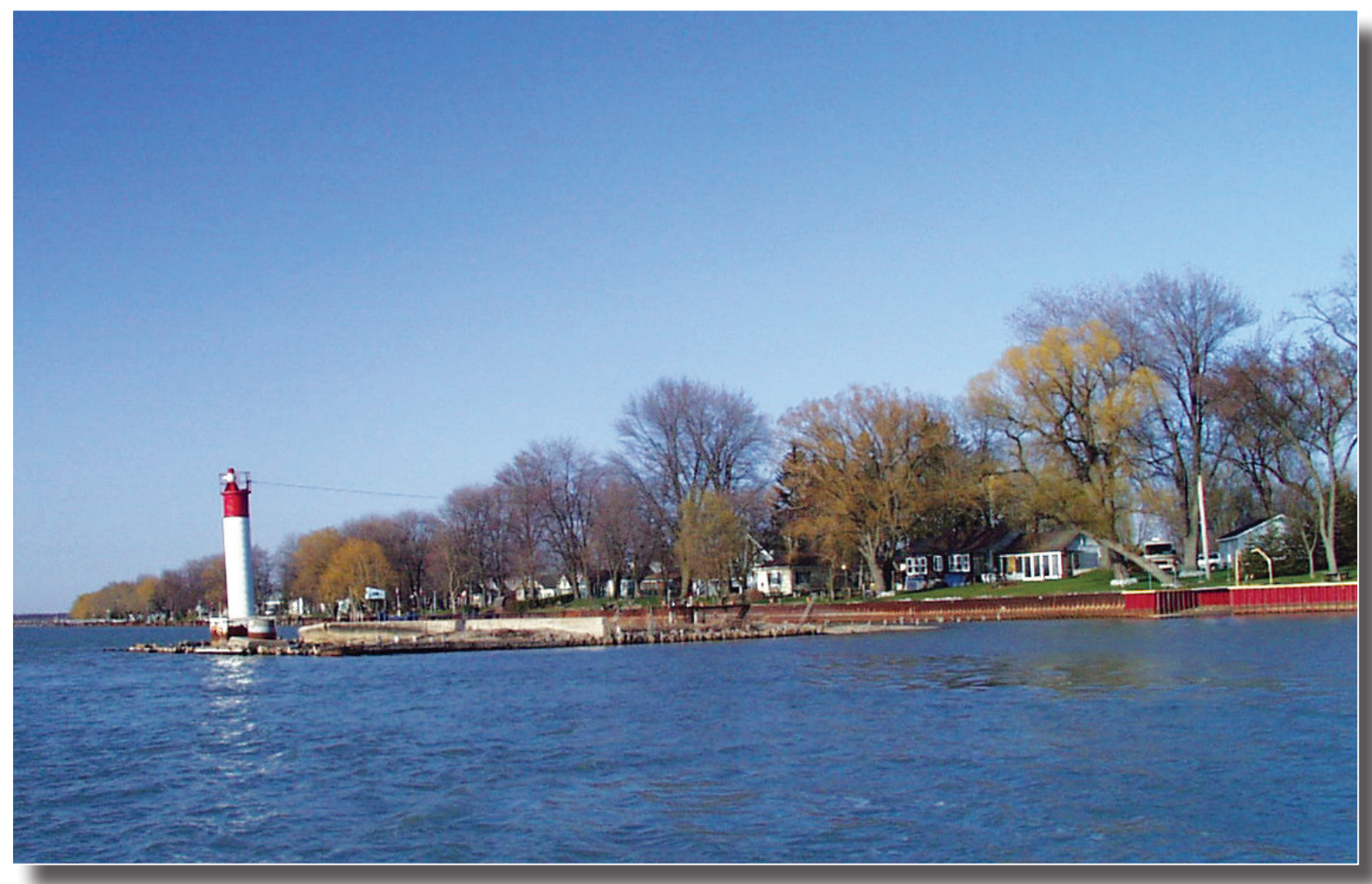

Scientific Investigations Report 2009-5044 
Cover Image. View of St. Clair River shoreline. (Photo by Greg Kennedy, U.S. Geological Survey). 


\section{Statistical and Spatial Analysis of Bathymetric Data for the St. Clair River, 1971-2007}

By David Bennion

In Cooperation With the International Upper Great Lakes Study Board and U.S. Army Corps of Engineers

Scientific Investigations Report 2009-5044 


\title{
U.S. Department of the Interior \\ KEN SALAZAR, Secretary
}

\author{
U.S. Geological Survey \\ Suzette M. Kimball, Acting Director
}

U.S. Geological Survey, Reston, Virginia: 2009

For more information on the USGS - the Federal source for science about the Earth, its natural and living resources, natural hazards, and the environment, visit http://www.usgs.gov or call 1-888-ASK-USGS

For an overview of USGS information products, including maps, imagery, and publications, visit http://www.usgs.gov/pubprod

To order this and other USGS information products, visit http://store.usgs.gov

Any use of trade, product, or firm names is for descriptive purposes only and does not imply endorsement by the U.S. Government.

Although this report is in the public domain, permission must be secured from the individual copyright owners to reproduce any copyrighted materials contained within this report.

Suggested citation:

Bennion, David, 2009, Statistical and spatial analysis of bathymetric data for the St. Clair River, 1971-2007: U.S.

Geological Survey Scientific Investigations Report 2009-5044, 58 p. 


\section{Contents}

Abstract
Introduction.
Dataset Properties
Full-River Datasets.
Inper-River Datasets
Interpolation Properties Summary
Interpolation Uncertainty
Remparative Analysis
Changes in Volume
Changes in Elevation
Acknowledgments
References.
Appendix 1. Images Showing Results From Volumetric- and Elevation-Change Analyses

\section{Figures}

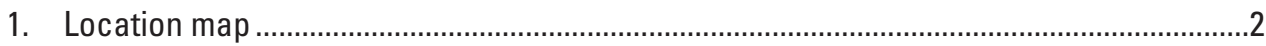

2. Prediction standard error maps ...................................................................................

3-5. Maps showing-

3. Regions where the sign of elevation change switches from the 2005-6 comparison to the 2006-7 comparison .................................................................. 10

4. The "sediment tongue" elevation-gain feature in the upper St. Clair River .............11

5. Areas of geomorphic change in the upper St. Clair River and associated

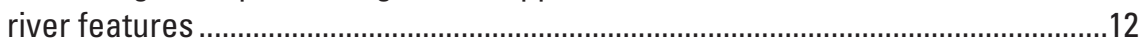

\section{Tables}

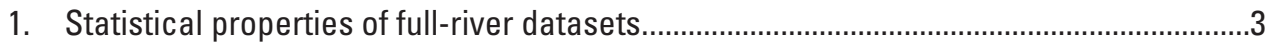

2. Statistical properties of upper-river datasets...........................................................

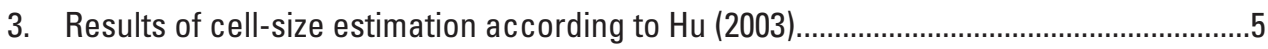

4. Interpolation error statements for 1-meter DEM surfaces..............................................

5. Statistics for 1-meter DEMs ..........................................................................................

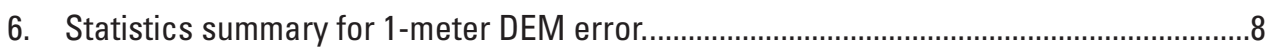

7. Results of selected upper-river-area Cut/Fill analysis ......................................................

8. Results of selected upper-river-area Cut/Fill with analysis mask ....................................9 


\section{Conversion Factors}

\begin{tabular}{lll}
\hline \multicolumn{1}{c}{ Multiply } & By & \multicolumn{1}{c}{ To obtain } \\
\hline & Length & \\
\hline meter $(\mathrm{m})$ & 3.281 & foot $(\mathrm{ft})$ \\
kilometer $(\mathrm{km})$ & 0.6214 & mile $(\mathrm{mi})$ \\
\hline & Area & \\
\hline square meter $\left(\mathrm{m}^{2}\right)$ & 0.0002471 & acre \\
square kilometer $\left(\mathrm{km}^{2}\right)$ & 0.3861 & square mile $\left(\mathrm{mi}^{2}\right)$ \\
\hline & Volume & \\
\hline cubic meter $\left(\mathrm{m}^{3}\right)$ & 35.31 & cubic foot $\left(\mathrm{ft}^{3}\right)$ \\
cubic meter $\left(\mathrm{m}^{3}\right)$ & 1.308 & cubic yard $\left(\mathrm{yd}^{3}\right)$ \\
\hline & Flow rate & \\
cubic meter per second $\left(\mathrm{m}^{3} / \mathrm{s}\right)$ & 35.31 & cubic foot per second $\left(\mathrm{ft}^{3} / \mathrm{s}\right)$ \\
\hline
\end{tabular}

Vertical coordinate information is referenced to the International Great Lakes Datum of 1985 (IGLD 85). 


\title{
Statistical and Spatial Analysis of Bathymetric Data for the St. Clair River, 1971-2007
}

\author{
By David Bennion
}

\section{Abstract}

To address questions concerning ongoing geomorphic processes in the St. Clair River, selected bathymetric datasets spanning 36 years were analyzed. Comparisons of recent high-resolution datasets covering the upper river indicate a highly variable, active environment. Although statistical and spatial comparisons of the datasets show that some changes to the channel size and shape have taken place during the study period, uncertainty associated with various survey methods and interpolation processes limit the statistical certainty of the results. The methods used to spatially compare the datasets are sensitive to small variations in position and depth that are within the range of measurement and interpolation uncertainty associated with the datasets. Characteristics of the data, such as the density of measured points and the range of values surveyed, can also influence the results of spatial comparison. With due consideration of these limitations, apparently active and ongoing areas of elevation change in the river are mapped and discussed.

\section{Introduction}

The St. Clair River, Lake St. Clair, and the Detroit River form a waterway within the Great Lakes Basin that is part of the international boundary between the United States and Canada (fig. 1). This waterway connecting Lake Huron and Lake Erie is commonly referred to as the "Huron-Erie Corridor" (HEC) and is part of the St. Lawrence Seaway. The HEC is a major navigational and recreational resource of the Great Lakes Basin over which more than $\$ 80$ billion in trade takes place each year. The St. Clair River constitutes approximately the northern third of the HEC; it extends about $68 \mathrm{~km}$ from its headwaters at the outlet of Lake Huron near Port Huron, Mich., to an extensive delta area at the northern end of Lake St. Clair. Throughout its length, water-surface elevations decrease about $1.5 \mathrm{~m}$ as it discharges an average of 5,154 $\mathrm{m}^{3} / \mathrm{s}$ from a drainage area of about 576,013 $\mathrm{km}^{2}$. Local tributaries to the St. Clair River include the Black River at Port Huron, the Pine River at St. Clair, and the Belle River at Marine City. The St. Clair River channel has undergone extensive modifications starting in the mid-1800s. Removal of bottom sediments from the river for commercial gravel production and dredging for the construction and maintenance of the deep-draft shipping channels has changed the system and affected the water levels of Lakes Michigan and Huron (Derecki, 1985).

Past studies have quantified changes in water levels in Lakes Michigan-Huron on the basis of manmade changes in riverbed size and shape (Baird, 2005; Derecki, 1985; International Great Lakes Levels Board, 1973; Brunk, 1968; Horton and Grunsky, 1927). The results of these studies were based on examination of changes in measured water levels and modeled changes in water flow. The study described in this report does not consider these hydraulic characteristics, examining only changes in riverbed elevation. As presented in the framework of the St. Clair River Task Team, part of the International Upper Great Lakes Study, this study addresses primary science question 2, "Has the morphology of the St. Clair River changed?" and secondary science questions 9 and 12, "Can the project establish zones of active erosion and deposition?” and "Can the project explain the impact of large object sinking?"

This study utilized six datasets spanning the years 1971 to 2007. Because past studies have focused on the historic changes in the river, this study focused primarily on the recent datasets of riverbed elevation from 1971, 2000, 2002, 2005, 2006, and 2007. Data for the entire river are available from the 1971, 2000, and 2007 datasets. The data from 2002, 2005, 2006, and 2007 provide high-density depth measurements for the upper $4 \mathrm{~km}$ of the river, from the head to just below the mouth of the Black River. The statistical characteristics of these datasets are discussed and comparative analyses performed on the data. Further, uncertainty associated with the survey methods used to collect the data and uncertainty associated with the process of creating digital elevation models (DEMs) are examined.

\section{Dataset Properties}

It is important to consider the statistical properties of the datasets before engaging in comparative analysis. The range of surveyed values varies greatly among some of the datasets. Not all surveys are done with the same aim in mind, and this 


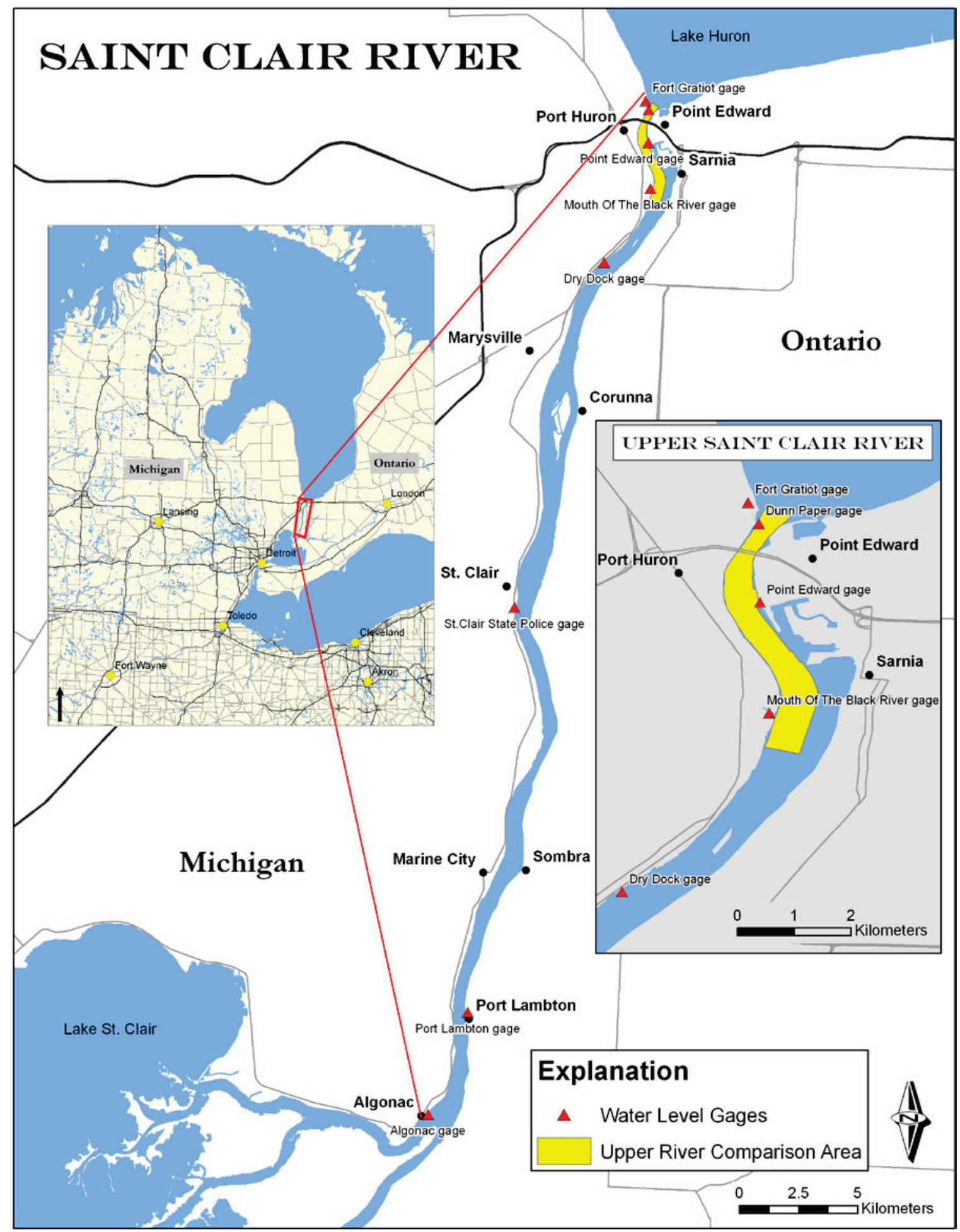

Figure 1. Location map. 
difference in aims can influence the area surveyed, the range of values surveyed, and the density of measured points. Methods used to process the surveyed values to reduce them to a common low water datum can also affect the final water-depth values. In this section, the statistical properties of the datasets are highlighted and discussed.

In order to allow direct comparison of the water-depth data, all measurements have been converted to the International Great Lakes Datum 1985 (IGLD 85) vertical datum, and computed river-bottom elevations are based on the step-down planes for the river. This process is relatively simple for surveys that reference the IGLD 85 . The methods used to convert values in the surveys that were referenced to other datums are explained in the discussions of the properties of the datasets.

\section{Full-River Datasets}

Data covering the entire St. Clair River approximately from the head to near Algonac are available from the 1971, 2000, and 2007 datasets. The range of surveyed values and the density of surveyed points vary greatly among these datasets. A summary of the statistical properties of the full-river datasets is given in table 1 .

The original 1971 single-beam survey was provided by the Corps of Engineers Detroit office and obtained from the National Oceanic and Atmospheric Administration (NOAA) Geophysical Data Management System (GEODAS) Web site (http://www.ngdc.noaa.gov/mgg/geodas/geodas.html). These data were referenced to the North American Datum 1983 (NAD 83) horizontal datum, and depths were adjusted to reference low water surface elevations on the International Great Lakes Datum 1955 (IGLD 55) vertical datum. The dataset was converted to the Michigan State Plane South (meters) projection. The depth values were converted to IGLD 85 by computing the changes in the differences of elevations of gaging stations between IGLD 55 and IGLD 85 for each set of stations. Comparison of the two datums showed an overall 0.03048-m increase in fall, but this difference was not evenly distributed along the course of the river. Analysis showed a 0.06096-m increase in fall between the Ft. Gratiot gage and the Dunn Paper gage. Between the mouth of the Black River gage and the Dry Dock gage, there was a 0.03048-m increase in fall. Between the St. Clair State Police gage and Algonac, there was a 0.03048-m increase in fall. Below Algonac through the delta, a 0.09144-m decrease in fall was calculated. The computed change in fall between gages was then divided by the number of step planes between the gages and applied incrementally to the measurements within each step plane. The 1971 dataset consists of 11,736 measurements, mostly along regularly spaced transects with the remaining points in various locations, resulting in a point density of $0.0003 / \mathrm{m}^{2}$ using an area of 38,556,363 $\mathrm{m}^{2}$ to represent the total area of the St. Clair River. The depth values in this dataset appear to have been rounded and binned together through an unknown process. For example, all values under $2 \mathrm{~m}$ are reported as 0.3 $\mathrm{m}, 0.6 \mathrm{~m}, 0.9 \mathrm{~m}, 1.2 \mathrm{~m}, 1.5 \mathrm{~m}$ and $1.8 \mathrm{~m}$. This trend continues throughout the dataset and is in stark contrast to the variability in values seen in more recent datasets.

The single-beam data acquired in 2000 were obtained directly from the National Oceanic and Atmospheric Administration (NOAA) Geophysical Data Management System (GEODAS) Web site (http://www.ngdc.noaa.gov/mgg/geodas/ geodas.html). The 2000 survey was referenced to NAD 83 and IGLD 85, and then was converted to the Michigan State Plane South (meters) projection. The survey is a series of transects with a line of data down the approximate river channel centerline. This dataset consists of 128,227 points, and, as noted in Baird (2005), required the removal of approximately 400 anomalous values. A subset of the data was extracted limiting the coverage from the head of the river to just below Algonac, resulting in 52,247 points. This yields an average point density of $0.0014 / \mathrm{m}^{2}$. As with the 1971 dataset, the values appear to have been rounded and binned. Unlike the 1971 dataset, the year 2000 depth values are reported to two decimal places and use different values for the bins: all values below $2 \mathrm{~m}$ are either $0.3 \mathrm{~m}, 0.61 \mathrm{~m}, 0.91 \mathrm{~m}, 1.22 \mathrm{~m}, 1.52 \mathrm{~m}$, or $1.83 \mathrm{~m}$, except for a single measurement at $1.93 \mathrm{~m}$. The number of bins used between whole numbers also differs from the 1971 dataset. For example, between $10 \mathrm{~m}$ and $11 \mathrm{~m}$ in the 1971 dataset, values are $10.1 \mathrm{~m}, 10.4 \mathrm{~m}$, and $10.7 \mathrm{~m}$, whereas in the 2000 dataset, the values are $10.06 \mathrm{~m}, 10.36 \mathrm{~m}, 10.67 \mathrm{~m}$, and $10.97 \mathrm{~m}$.

Table 1. Statistical properties of full-river datasets.

\begin{tabular}{|c|c|c|c|c|c|c|c|c|c|c|c|c|}
\hline \multirow[b]{2}{*}{ Year } & \multirow{2}{*}{$\begin{array}{l}\text { Number } \\
\text { of points }\end{array}$} & \multicolumn{5}{|c|}{ Depth, in meters } & \multicolumn{5}{|c|}{ Bottom elevation, in meters IGLD 85} & \multirow{2}{*}{\begin{tabular}{|c|} 
Point \\
density \\
per square \\
meter (full \\
river)
\end{tabular}} \\
\hline & & Minimum & Maximum & Mean & $\begin{array}{l}\text { Standard } \\
\text { deviation }\end{array}$ & Skew & Minimum & Maximum & Mean & $\begin{array}{l}\text { Standard } \\
\text { deviation }\end{array}$ & Skew & \\
\hline 1971 & 11,736 & 0.30 & 22.90 & 8.13 & 3.77 & -0.43 & 152.90 & 175.58 & 166.98 & 3.76 & 0.41 & 0.0003 \\
\hline 2000 & 52,247 & 0.30 & 21.34 & 8.92 & 3.40 & -0.44 & 154.33 & 175.03 & 166.17 & 3.40 & 0.40 & 0.0014 \\
\hline
\end{tabular}


The year 2007 multibeam dataset is the result of a survey by the USACE Detroit survey department. Coverage is from the head of the river to Algonac. The dataset contains $12,999,986$ measurements, resulting in an average point density of $0.3372 / \mathrm{m}^{2}$. The depth values are supplied on a $1.524-\mathrm{m}$ grid. Depth values were not rounded or binned and exhibit greater variability within the range of values than in the two previously discussed datasets.

Vertical uncertainty associated with the survey process for the 1971 and 2000 datasets is assumed to be $\pm 0.3 \mathrm{~m}$ (National Oceanic and Atmospheric Administration, 2003; Umbach, 1976). Minimum survey uncertainty for the 2007 dataset is reported as $\pm 0.1524 \mathrm{~m}$ (N. Noorbakhsh, U.S. Army Corps of Engineers, oral commun., 2007).

\section{Upper-River Datasets}

Multibeam data collected in 2002, 2005, and 2006 are limited to the upper $4 \mathrm{~km}$ of the river. All three datasets are the result of surveys by the USACE Detroit survey department and have a reported minimum survey uncertainty of \pm 0.1524 $\mathrm{m}$. All data in these sets are arranged on a 1.524-m grid. A summary of the statistical properties is shown in table 2 .

Subsets of the full-river datasets were extracted from the 1971, 2000, and 2007 datasets to facilitate comparison in the upper-river area. The statistical properties of these subsets are very similar to those for the full-river versions.

\section{Data Properties Summary}

Inferences can be made about the outcome of comparative analysis based on comparison of the dataset's statistical properties. It would be expected that comparison of the 1971 data to the 2000 data would indicate overall elevation loss based on the mean elevation values, wider distribution of the 1971 data (as indicated by the standard deviation), and the difference in minimum elevations. In addition to the uncertainty associated with the survey methods, the methods used to round and bin the measurement values in these two datasets are unknown. The effect of these uncertainties and unknowns cannot be quantified, but the outcome of comparative analysis is undoubtedly affected.
Assumptions about comparison with the 2007 dataset are more difficult to make. The vast difference in number of surveyed points, range of depth and elevation values, and smaller standard deviation make comparison of the dataset statistical properties difficult. The gridded distribution of the measured points in the 2007 dataset is significantly different from the transect arrangement of the 1971 and 2000 datasets. This difference is considered further in the discussion about creation of a DEM.

\section{Interpolation}

To allow direct comparison of the survey data, the riverbottom elevation values were used as input for an interpolation process to create a DEM surface. This process creates a gridded continuous surface, with each grid cell containing a bottom elevation value. Surveyed values are used as input, and various methods are applied to make educated guesses about elevation values where none were measured. All datasets except the 2007 set were interpolated by means of the ordinary kriging method as applied through the Geostatistical Analyst extension of ESRI's ArcGIS desktop software. Selection of this method was based on error comparison of test interpolation areas. The Inverse Distance Weighting (IDW) method of interpolation within Geostatistical Analyst was selected for the 2007 data to reduce the increased processing time that otherwise would have resulted due to the size and extent of this dataset. In all cases, the datasets were sectioned into smaller reach sections and interpolated, error tested, compiled into a final DEM surface, and error tested again. The sectioning of data and the use of the Geostatistical Analyst extension allowed the size, shape, and orientation of the interpolation search neighborhood to be adjusted to consider the directional nature of a particular river reach. Through error testing, this method was found to yield superior results when compared to attempting a full-dataset interpolation. In addition, the size of some of the datasets precluded a full-dataset interpolation, owing to computer processing limitations.

All interpolated surfaces were created with a 1-m cell size to mirror past studies (Baird, 2005) and to include as much detail as possible. An important consideration when choosing an interpolation resolution is the density of the

Table 2. Statistical properties of upper-river datasets.

\begin{tabular}{|c|c|c|c|c|c|c|c|c|c|c|c|c|}
\hline \multirow[b]{2}{*}{ Year } & \multirow[b]{2}{*}{$\begin{array}{c}\text { Number of } \\
\text { points }\end{array}$} & \multicolumn{5}{|c|}{ Depth, in meters } & \multicolumn{5}{|c|}{ Bottom elevation, in meters IGLD 85} & \multirow{2}{*}{$\begin{array}{c}\text { Point } \\
\text { density } \\
\text { per squar } \\
\text { meter }\end{array}$} \\
\hline & & Minimum & Maximum & Mean & $\begin{array}{l}\text { Standard } \\
\text { deviation }\end{array}$ & Skew & Minmum & Maximum & Mean & $\begin{array}{l}\text { Standard } \\
\text { deviation }\end{array}$ & Skew & \\
\hline 2005 & 992,730 & 1.65 & 24.12 & 10.57 & 2.86 & 0.68 & 151.61 & 173.93 & 165.07 & 2.84 & -0.65 & 0.2018 \\
\hline 2006 & 989,502 & 1.30 & 24.16 & 10.59 & 2.87 & 0.65 & 151.57 & 174.28 & 165.06 & 2.85 & -0.62 & 0.2011 \\
\hline
\end{tabular}


original dataset. For an ideal resolution, the number of grid cells should equal the number of measured points (McCullagh, 1988). As stated in Liu and others (2007), "It is inappropriate to generate a high-resolution Digital Elevation Model (DEM) with very sparse terrain data: any surface so generated is more likely to represent the shape of the specific interpolator used than that of the target terrain because interpolation artifacts will abound.” Further, to thin a high-density dataset to a larger cell size will devalue the accuracy of the data and negatively influence comparison results. A DEM grid size estimator proposed by $\mathrm{Hu}$ (2003) uses the equation

DEM cell size $=$ square root (area / \# of points $)$

The results of the application of this equation (using the standardized areas used to compute point density) to each of the datasets used in this study are shown in table 3 . From these calculations, it is evident that the 1971 and 2000 datasets do not have the needed point density to be reliably interpolated to a $1-\mathrm{m}$ cell size.

Table 3. Results of cell-size estimation according to $\mathrm{Hu}$ (2003).

\begin{tabular}{ccc}
\hline \multirow{2}{*}{ Year } & \multicolumn{2}{c}{ Cell size, in square meters } \\
\cline { 2 - 3 } & Full-river area & Upper-river area \\
\hline 1971 & 57.32 & 54.37 \\
2000 & 27.14 & 29.19 \\
2002 & $\mathrm{n} / \mathrm{a}$ & 2.52 \\
2005 & $\mathrm{n} / \mathrm{a}$ & 2.23 \\
2006 & $\mathrm{n} / \mathrm{a}$ & 2.23 \\
2007 & 1.72 & 1.98 \\
\hline
\end{tabular}

\section{Interpolation Uncertainty}

Assessment of the error associated with the interpolation process is essential to maintain an understanding of the uncertainty in the comparative analysis. To facilitate error analysis in this study, the bottom-elevation datasets for each section of river were subset into training and test sets through the use of the "Create Subsets" tool in the ArcGIS Geostatistical Analyst extension. The test sets consisted of a random sample of 10 percent of the original dataset that were withheld from the interpolation process. A measure of accuracy was attached to each DEM by means of the 95th-percentile method. This methodology adheres to current National Standard for Spatial Data Accuracy (NSSDA), U.S. Geological Survey (USGS), and Federal Emergency Management Agency (FEMA) standards for DEM creation. The method provides a means of examining the error datasets for statistical outliers, allowing the best 95-percent of the points in the error dataset to be used for quantifying the vertical accuracy of the interpolated surface. The standard deviation of the error datasets is computed and then multiplied by 3 to obtain a 3 sigma value. The absolute values of the errors are ranked in descending order, and if none of the errors are outliers larger than the 3 sigma value, accuracy at the 95th percentile may be stated as 1.96 * Root-Mean-Square error (RMSE ) because the data are close to normal distribution. If data meet this requirement, accuracy is stated as "Tested xx (units) vertical accuracy at 95-percent confidence level using RMSE procedures with no outliers." If the error datasets do not meet the requirement of normal distribution, a further step of percentile ranking the errors and excluding all errors above the 95th percentile is employed. The standard deviation is then recomputed and a new 3 sigma value obtained. The ranked errors are then examined to see whether they exceed the new 3 sigma value. If no error values exceed this threshold, accuracy is reported by completing the statement "Tested xx (units) vertical accuracy at 95-percent confidence level, determined by the 95th-percentile method." The phrase "compiled to meet" is used in place of "tested" when an independent source of quality control data of higher accuracy is not available for error analysis, as is the case with the data in this study. The accuracy value is determined by the error value at the 95th-percent ranking. If points in the dataset exceed the recomputed 3 sigma value, the process may be repeated for the 90th percentile (Daniel and Tennant, 2001). For this study, outputs that did not meet the 95-percent requirements were not tested further but were discarded, and the data were reinterpolated until the 95 -percent standard was met. The skew coefficient is used as an indicator of deviation from a normal distribution in the error dataset. FEMA guidelines advise that the absolute value of the skewness should not be larger than 0.5 to ensure a near-normal distribution of the errors at 95 percent (Maune and others, 2001). The interpolation error statements for the data used in this study appear in table 4. It is important to consider that the test points were withheld from the original data, precluding any error analysis outside the extent of the original dataset or in areas between measured points.

Table 4. Interpolation error statements for 1-meter DEM surfaces.

\begin{tabular}{cl}
\hline Year & \multicolumn{1}{c}{ Interpolation error statement } \\
\hline 1971 & Compiled to meet 1.7-meter vertical accuracy at 95-percent confidence level \\
2000 & Compiled to meet 0.7 -meter vertical accuracy at 95-percent confidence level \\
2002 & Compiled to meet 0.2-meter vertical accuracy at 95-percent confidence level \\
2005 & Compiled to meet 0.2-meter vertical accuracy at 95-percent confidence level \\
2006 & Compiled to meet 0.3-meter vertical accuracy at 95-percent confidence level \\
2007 & Compiled to meet 0.3-meter vertical accuracy at 95-percent confidence level \\
\hline
\end{tabular}


In addition to the 95th-percentile method outlined, several other statistics were considered when assessing DEM accuracy. The root-mean-square error was examined as a comparative tool. Attempts were made to keep the mean prediction error and mean standardized prediction error close to zero. A close relation of the mean standard error value to the rootmean-square error value indicates that bias is low. This assessment of prediction variability can be confirmed by inspecting the root-mean-squared standardized error for its closeness to 1. Mean error, mean absolute error, minimum and maximum error, and the standard deviation of the error set also are used to assess the fitness of the interpolation procedure. A summary of select DEM statistics is given in table 5 .

As an additional assessment of interpolator fitness, maps of the kriging prediction standard errors were created when possible. This indicator of error is generated as part of the kriging interpolation process. It is a unitless value with an ideal of zero that represents how good an estimation the interpolation process is likely to make at a given location. This tool is useful when assessing potential interpolation error outside of or in between the measured points. The images in figure 2 are representative excerpts from the 1971, 2000, 2002, 2005, and 2006 prediction standard error maps. They clearly show that interpolator accuracy diminishes quickly as distance away from a measured point increases. Also indicated is the relation of point density to interpolator accuracy. In comparing the images of the 1971 and 2000 prediction standard errors with the 2002-6 images, a much greater distance from the ideal value of zero is evident among the measured data points in the less dense datasets.

\section{Uncertainty Summary}

The total statistical uncertainty associated with a dataset is plus and minus the sum of the survey and interpolation error. Which value to choose to represent interpolator error is flexible, but the choice must be applied consistently to all datasets. As expected, the high-density datasets are associated with significantly lower interpolation uncertainty. The survey uncertainty values for the NOAA and USACE survey represent minimum estimated values. A summary of error statistics is shown in table 6 .

\section{Comparative Analysis}

Two main types of comparisons were done among the various datasets. Change in elevation of the river bottom and change in volume of the river channel were both examined. Comparisons were done between all available datasets rather than restricting the output to a time-series analysis. Uncertainty was then assessed and accounted for in presenting the results of the comparison.

Volumetric-change analysis was examined through the use of the Cut/Fill tool as part of ESRI's Spatial Analyst extension. This type of analysis is very sensitive to small changes in elevation values and extent. It is imperative that the comparison area be limited to the smallest combined spatial extent of the employed datasets to ensure the most statistically certain results. An upper-river standard extent and full-river standard extent that fit this requirement were used for all comparisons. Uncertainty can have a significant influence on the overall results of the analysis. The equation that is used to calculate the volumetric change at each set of grid cells is

$$
\text { Cell Volume }=\text { Cell Area } *(\text { Zbefore }- \text { Zafter }) \text {. }
$$

Total potential Cut/Fill error is represented by the equation

$$
\text { Cell Count * Cell Area * (Ebefore - Eafter), }
$$

where Ebefore and Eafter are the total error values of each dataset. Cell Count is the number of cells in the analysis extent and therefore the number of times the potential error could be repeated. A very optimistic example is comparison of the high-density datasets from 2005 and 2006, assuming that combined survey error results are zero. If the mean absolute error of the interpolation errors is selected as an estimation of interpolation error, then total error is reported as $\pm 0.08 \mathrm{~m}$ for each dataset. The standardized upper-river comparison extent has an area of 1,578,716 $\mathrm{m}^{2}$, and the DEM files use a 1-m grid size. Potential error is then represented by $1,578,716 * 1 *$ $(0.08--0.08)$ or $252,595 \mathrm{~m}^{3}$. This value represents maximum error in the respect that the error values are assumed to be oppositely signed throughout both datasets. In order to minimize this rather large impact on results, the Cut/Fill DEM was

Table 5. Statistics for 1-meter DEMs.

\begin{tabular}{cccc|ccccc}
\hline \multirow{2}{*}{ Year } & \multicolumn{2}{c|}{ Bottom elevation, in meters IGLD 85 } & \multicolumn{5}{c}{ Error, in meters } \\
\cline { 2 - 9 } & Minimum & Maximum & Mean & Mean & Minimum & Maximum & $\begin{array}{c}\text { Mean } \\
\text { absolute }\end{array}$ & $\begin{array}{c}\text { Standard } \\
\text { deviation }\end{array}$ \\
\hline 1971 & 152.86 & 178.44 & 167.26 & -0.01 & -4.83 & 7.89 & 0.53 & 0.85 \\
2000 & 154.34 & 176.75 & 166.85 & -0.0069 & -4.1 & 2.69 & 0.21 & 0.33 \\
2002 & 151.65 & 173.49 & 164.92 & -0.0034 & -1.98 & 1.99 & 0.05 & 0.08 \\
2005 & 151.62 & 173.78 & 166.40 & -0.0082 & -2.04 & 2.68 & 0.08 & 0.13 \\
2006 & 151.59 & 174.27 & 165.59 & -0.0062 & -3.04 & 2.44 & 0.08 & 0.15 \\
2007 & 151.61 & 175.66 & 166.74 & -0.0076 & -3.29 & 3.22 & 0.08 & 0.14 \\
\hline
\end{tabular}



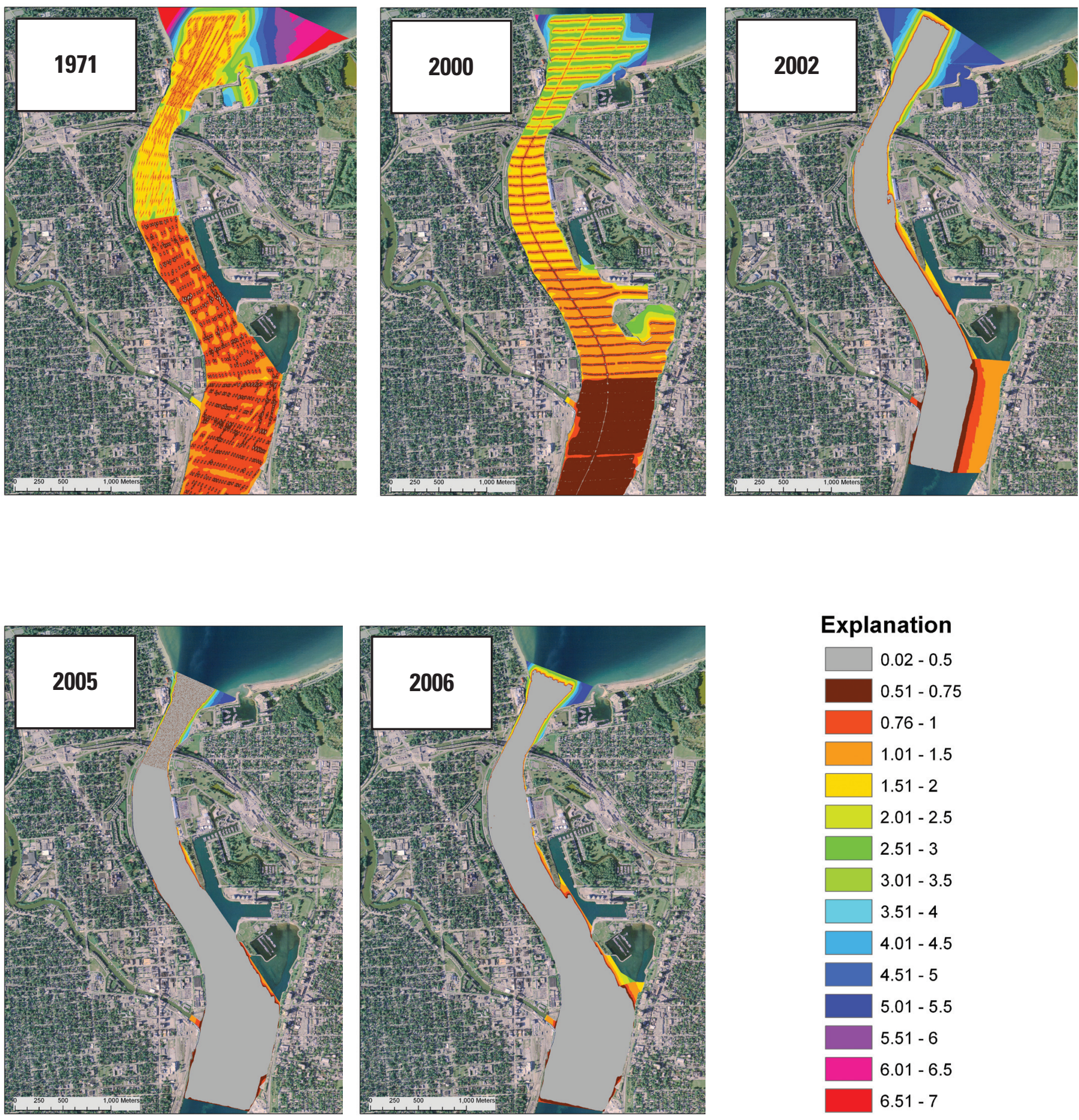

Figure 2. Prediction standard error maps for the Upper St. Clair River. The same classification is used on each image. Lower values indicate less predicted interpolation error. 
Table 6. Statistics summary for 1-meter DEM error.

\begin{tabular}{|c|c|c|c|c|c|c|c|c|c|c|c|}
\hline \multirow[b]{2}{*}{ Year } & \multicolumn{3}{|c|}{$\begin{array}{c}\text { Bottom elevation, in meters } \\
\text { IGLD } 85\end{array}$} & \multicolumn{8}{|c|}{ Error, in meters } \\
\hline & Minmum & $\begin{array}{c}\text { Maxi- } \\
\text { mum }\end{array}$ & Mean & $\begin{array}{c}\text { At } \\
95 \\
\text { pecent }\end{array}$ & Mean & Minmum & $\begin{array}{c}\text { Maxi- } \\
\text { mum }\end{array}$ & $\begin{array}{l}\text { Mean } \\
\text { absolute }\end{array}$ & $\begin{array}{c}\text { Stan- } \\
\text { dard } \\
\text { devia- } \\
\text { tion }\end{array}$ & $\begin{array}{c}\text { Root } \\
\text { mean } \\
\text { square }\end{array}$ & Survey \\
\hline 1971 & 152.86 & 178.44 & 167.26 & 1.70 & -0.0100 & -4.83 & 7.89 & 0.53 & 0.8500 & 0.854 & 0.3000 \\
\hline 2000 & 154.34 & 176.75 & 166.85 & 0.70 & -0.0069 & -4.10 & 2.69 & 0.21 & 0.3300 & 0.334 & 0.3000 \\
\hline 2002 & 151.65 & 173.49 & 164.92 & 0.20 & -0.0034 & -1.98 & 1.99 & 0.05 & 0.0790 & 0.079 & 0.1524 \\
\hline 2005 & 151.62 & 173.78 & 166.40 & 0.20 & -0.0082 & -2.04 & 2.68 & 0.08 & 0.1300 & 0.141 & 0.1524 \\
\hline 2006 & 151.59 & 174.27 & 165.59 & 0.30 & -0.0062 & -3.04 & 2.44 & 0.08 & 0.1500 & 0.148 & 0.1524 \\
\hline 2007 & 151.61 & 175.66 & 166.74 & 0.30 & -0.0076 & -3.29 & 3.22 & 0.08 & 0.1400 & 0.189 & 0.1524 \\
\hline
\end{tabular}

compared to an elevation-change DEM, and the Cut/Fill areas that coincided with areas where elevation change was statistically indicated were extracted. This method effectively limited volumetric comparison to areas where bathymetric change was statistically certain. The elevation comparison was a less complicated process. Three types of comparisons were used where appropriate. In comparing the high-density upper-river datasets, the interpolated DEM surfaces were used. In comparing the full-river datasets, elevation values were extracted from the 2007 DEM to the measured points in the 1971 and 2000 datasets. This was done to exclude the high interpolation error associated with the lower density datasets, which must be considered in DEM or cross-sectional comparisons. The third comparison method was a direct point-to-point comparison of the 0.0696-m gridded 2005, 2006, and 2007 data. These three datasets contain an area of approximately $1,900,000$ points that directly coincide in xy location. No interpolation is needed, and therefore, no interpolation error was considered in analyzing uncertainty. These comparisons yield the smallest range of uncertainty and the most statistically accurate indication of geomorphic change in a limited area of the upper river.

\section{Results}

\section{Changes in Volume}

None of the results of overall volumetric analysis exceeded the error threshold and therefore are statistically uncertain. This threshold was calculated using potential survey error and the mean absolute interpolation error. The $1,578,716-\mathrm{m}^{2}$ upper-river analysis area limits the extent to areas of data overlap. Table 7 shows the results of analysis of this area. An analysis mask was created and applied, limiting comparison areas. This process resulted in comparison areas of varying sizes based on excluding regions where elevation change between the two datasets was statistically uncertain. The results of these analyses are shown in table 8 . It should be noted that the overall magnitude of volumetric change indicated by the masked analyses is still subject to variation within the error range. The mean change per year without the analysis mask is $1,955 \mathrm{~m}^{3}$ of volume loss; with the analysis masks applied, the mean becomes $2,759 \mathrm{~m}^{3}$ of volume gain. If the results are limited to the high-density datasets of 2002 , 2005, 2006 and 2007, the mean is $14,820 \mathrm{~m}^{3}$ of volume gain; with the analysis masks applied, the mean is $2,610 \mathrm{~m}^{3}$ of volume loss. No clear pattern emerges from the data. Identifying trends is further complicated by the large variations in average per year cut, average per year fill, and average overall per year change. The large amounts of volume gain indicated in the comparisons to the 1971 data can be partially explained by the difference in range of surveyed values. This large gain is expected also in comparisons with the 2000 dataset but is not reflected in the results. The significant difference in minimum elevation of the 2000 dataset when compared to other datasets influences the prediction of large-scale volume loss. Even in the high-density datasets, areas of volume gain were seen to switch to areas of volume loss within a year, highlighting the very small tolerances for error in this type of analysis. When the map images of these results are visually inspected, certain areas do consistently indicate ongoing processes. These images are shown in Appendix 1, figures 1-15.

\section{Changes in Elevation}

Comparison of elevation changes does not allow a quantification of overall change in volume, but it can indicate location, magnitude, and trends of elevation differences. The analysis extent was slightly limited along the nearshore areas for this method to allow inspection of areas where overlap may exist among some, but not all, datasets and to account for the exclusion of nearshore data in the high-resolution datasets. Where available, data were analyzed along the entire river from the head to Algonac. The results were examined with prior knowledge of dataset extents and statistical properties to yield meaningful results. Results of three types of comparison 
Table 7. Results of select upper-river-area Cut/Fill analysis.

$\left[\mathrm{m}^{3}\right.$, cubic meters]

\begin{tabular}{|c|c|c|c|c|c|c|c|c|}
\hline $\begin{array}{l}\text { Before } \\
\text { year }\end{array}$ & After year & $\begin{array}{c}\text { Amount fill } \\
\qquad\left(\mathrm{m}^{3}\right)\end{array}$ & $\begin{array}{c}\text { Amount cut } \\
\left(\mathrm{m}^{3}\right)\end{array}$ & $\begin{array}{c}\text { Overall change } \\
\left(\mathrm{m}^{3}\right) \text { (negative = } \\
\text { volume loss) }\end{array}$ & $\begin{array}{c}\text { Average } \\
\text { change per } \\
\text { year }\left(\mathbf{m}^{3}\right)\end{array}$ & $\begin{array}{c}\text { Average per } \\
\text { year fill } \\
\left(\mathrm{m}^{3}\right)\end{array}$ & $\begin{array}{l}\text { Average per } \\
\text { year cut }\left(\mathrm{m}^{3}\right)\end{array}$ & $\begin{array}{l}\text { Error thresh- } \\
\text { old }\end{array}$ \\
\hline 1971 & 2000 & 514,496 & $1,495,656$ & 981,160 & 33,833 & 17,741 & 51,574 & $2,115,479$ \\
\hline 2000 & 2002 & 490,472 & 227,950 & $-262,522$ & $-131,261$ & 245,236 & 113,975 & $1,120,888$ \\
\hline 2002 & 2005 & 94,044 & 130,436 & 36,392 & 12,131 & 31,348 & 43,479 & 678,848 \\
\hline 2005 & 2006 & 112,869 & 112,178 & -691 & -691 & 112,869 & 112,178 & 726,209 \\
\hline 1971 & 2002 & 649,740 & $1,346,630$ & 696,890 & 22,480 & 20,959 & 43,440 & $1,626,077$ \\
\hline 1971 & 2005 & 671,423 & $1,359,164$ & 687,741 & 20,228 & 19,748 & 39,975 & $1,673,439$ \\
\hline 1971 & 2006 & 690,092 & $1,383,217$ & 693,125 & 19,804 & 19,717 & 39,520 & $1,673,439$ \\
\hline 1971 & 2007 & 685,407 & $1,413,303$ & 727,896 & 20,219 & 19,039 & 39,258 & $1,673,439$ \\
\hline 2000 & 2007 & 452,252 & 263,454 & $-188,798$ & $-26,971$ & 64,607 & 37,636 & $1,168,250$ \\
\hline 2002 & 2006 & 110,542 & 146,242 & 35,700 & 8,925 & 27,636 & 36,561 & 678,848 \\
\hline 2002 & 2007 & 84,080 & 157,802 & 73,722 & 14,744 & 16,816 & 31,560 & 678,848 \\
\hline 2005 & 2007 & 96,330 & 133,658 & 37,328 & 18,664 & 48,165 & 66,829 & 726,209 \\
\hline
\end{tabular}

Table 8. Results of select upper-river-area Cut/Fill with analysis mask.

$\left[\mathrm{m}^{3}\right.$, cubic meters]

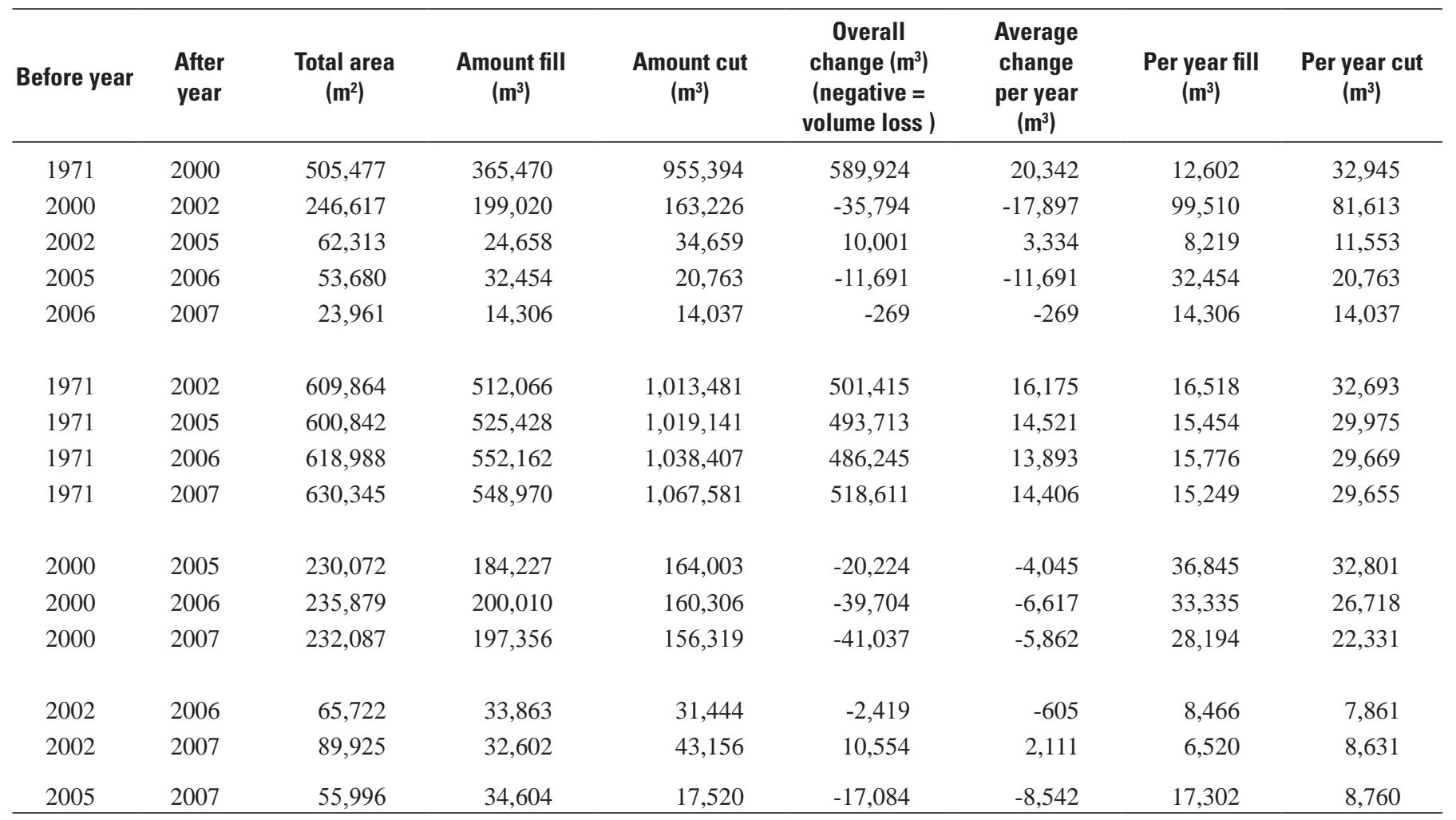


are offered here. DEM-to-DEM, point-to-DEM, and direct point-to-point comparisons were made where appropriate, and resulting location and magnitude patterns were examined.

DEM-to-DEM comparisons were made by subtracting the coincident values of the later DEM from the values of the earlier DEM. From this equation, positive values indicate elevation gain, and negative values indicate elevation loss. These comparisons were made for the upper river from approximately the Ft. Gratiot gage to the Black River. The amount of uncertainty associated with the interpolation of the 1971 and 2000 datasets precludes these datasets from producing statistically meaningful results from this type of analysis along the full river course. In place of DEM-to-DEM and cross-section comparison, the 1971 and 2000 dataset points were compared with the 2007 DEM data. This eliminated the need to consider interpolation uncertainty associated with the 1971 and 2000 DEM datasets and minimized overall uncertainty. The pointto-point comparisons of the $0.0696-\mathrm{m}$-spaced 2005, 2006, and 2007 datasets yielded the smallest range of uncertainty and the most statistically accurate indication of geomorphic change in a limited area of the upper river.

The DEM-to-DEM comparison images are shown in Appendix 1, figures 16-30. A generally consistent pattern of limited elevation loss and elevation gain areas can be seen in the high-density data for the upper river. Although the areas of change seem rather constant, certain areas switch from elevation gain to elevation loss within the analysis timeframes. In examining the 2002 to 2005 analysis (Appendix 1, fig. 25) and the 2005 to 2007 analysis (Appendix 1, fig. 29), an example of this switching is apparent. In the upper northeast corner of the analysis area (outlined in white) on the 2002 to 2005 image, one can see a large swath of elevation gain area with an elevation-loss area below. When these same areas are inspected on the 2005 to 2007 image, this pattern is reversed, indicating a large elevation loss area with an elevation-gain area below. These changes indicate that a highly variable process is at work in the upper river, that an unknown bias exists in the survey data, or that uncertainty in the survey data was underestimated. All comparisons with the 1971 dataset indicated large areas of elevation gain and elevation loss. These areas became much more limited in comparisons with the 2000 dataset. This pattern would indicate that the ongoing process in these areas changed around 2000 from mainly elevation loss to a mainly elevation gain. This is supported by comparison of the volumetric analysis per-year-change amounts (tables 7 and 8) and the comparisons of the 1971 and 2000 point data to the 2007 DEM.

The point-to-DEM comparison shows widespread elevation loss from 1971 to 2007 (Appendix 1, figs. 31, 32, 33). This trend is largely reversed in the 2000 to 2007 comparison (Appendix 1 fig. 34, 35, 36). It is expected to some extent to see indications of elevation loss close to the nearshore areas
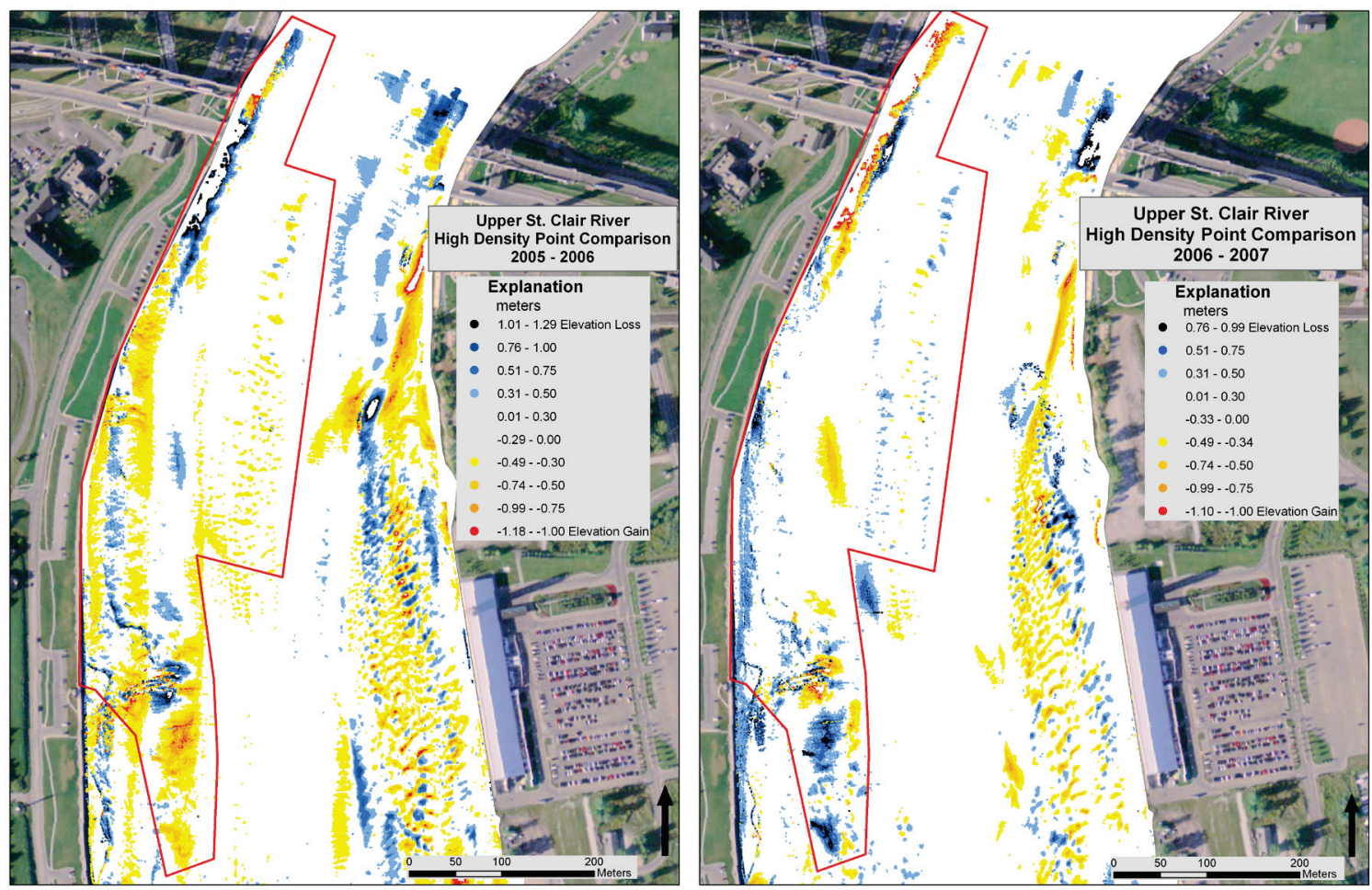

Figure 3. Region (highlighted with the red line) where the sign of elevation change switches from the 2005-6 comparison to the 2006-7 comparison. Blues and black indicate elevation loss, and yellows, orange and red indicate elevation gain. 
in both comparisons due to the differences in the range of surveyed values. Areas that were consistently indicated as elevation loss such as the head of Fawn Island, the shoals at St. Clair, and the head and tail of Stag Island were areas of no data coverage in the 2007 dataset. An area of consistent elevation gain was indicated in the upper river along the east shore between the Blue Water Bridge and Point Edward.

The very high density point-to-point comparisons indicated that dynamic processes were at work in the upper river. Again, areas were found that changed from elevation loss to elevation gain from year to year. These areas tended to be associated with high change values, indicating close to $1 \mathrm{~m}$ of elevation loss one year and close to $1 \mathrm{~m}$ of elevation gain the next (Appendix 1, figs. 37 and 39) These areas are highlighted in figure 3 (on preceding page). Within these comparisons, and supported by most other comparisons made for this study, a "sediment tongue" (fig. 4) can be seen progressing through the system with a trailing area of variable elevation loss and elevation gain. Also consistently indicated in these analyses and supported by other comparisons is the general pattern of elevation loss and elevation gain within the flow-recirculation zone along the eastern shore of the upper river.

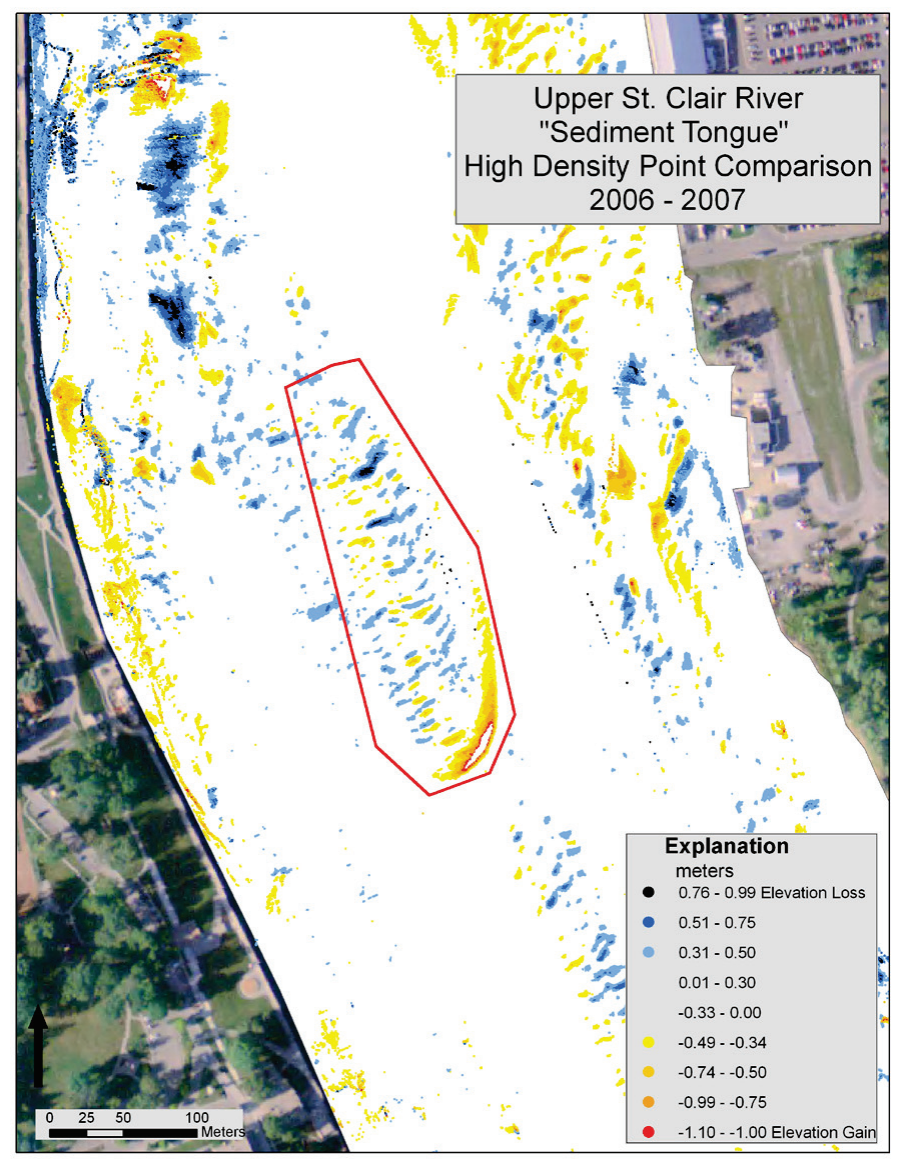

Figure 4. The "sediment tongue" elevation-gain feature in the upper St. Clair River.

\section{Conclusions}

The accuracy of available data was not great enough to reliably detect widespread geomorphic change throughout the St. Clair River at the scale required. The issue of how data values were rounded and binned in the 1971 and 2000 datasets and the differences in the density, location, and range of surveyed values contribute to the uncertainty. Even among the high-density datasets, the processes that are indicated are unusual or are a result of an unknown error in one of the employed datasets. Because minimum estimations of error were used, refining the error values could be expected to further restrict the amount of area available for analysis, leaving fewer areas of statistical certainty. None of the results from volumetric analysis exceeded the error threshold associated with the dataset comparisons. Because of this, volumetricanalysis results should be used only qualitatively and not as firm measurement of change. To continue to monitor geomorphic change in the river, high-resolution survey datasets, like the 2007 dataset, will be required in the future.

Comparisons of the datasets did provide indication of geomorphic processes at work. The analyses of the comparison results discussed herein indicated highly variable areas of elevation loss and elevation gain. Figure 5 highlights areas of the upper river where change was consistently indicated and illustrates the proximity of these areas to other river features. Visual inspection confirms a spatial relationship between areas of change and sunken large objects. Bottom materials appear to be moving in the system, although whether this is due to direct action of the river or other forces such as propeller wash from passing freighters or gouging from ice jams is unknown. The analyses of the area of the "sediment tongue" showed an advancing elevation gain feature.

\section{Acknowledgments}

This study was supported by the International Upper Great Lakes Study Board and U.S. Army Corps of Engineers. The author wishes to acknowledge the assistance of Bruce Manny, Sandy Morrison, Christine Schmuckal, Greg Kennedy and Kurt Kowalski from the USGS Great Lakes Science Center; Jim Nicholas from the USGS Michigan Water Science Center; Mike Eberle from the USGS Columbus Publishing Service Center; Nanette Noorbakhsh, Eric Tauriaine, and Tony Eberhardt from the U.S. Army Corps of Engineers; Jacob Bruxer and Aaron Thompson from Environment Canada; Christine Geddes from Great Lakes GIS; and Syed Moin from the International Joint Commission. This report is Contribution 1515 of the USGS Great Lakes Science Center. 


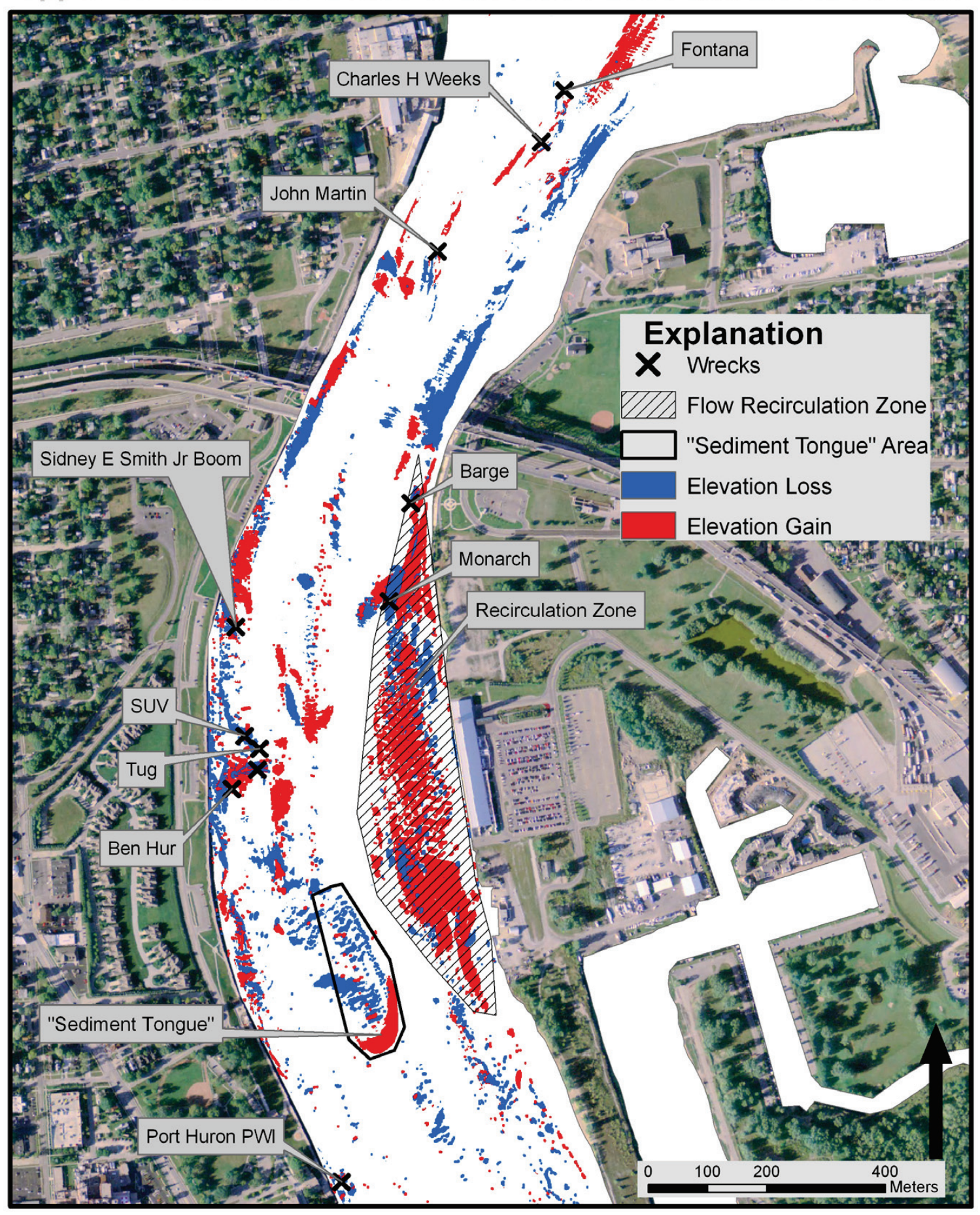

Figure 5. Areas of geomorphic change in the upper St. Clair River and associated river features. 


\section{References}

Baird, W.F., \& Associates Coastal Engineers Ltd., 2005, Regime change (man made intervention) and ongoing erosion in the St. Clair River and impacts on Lake MichiganHuron lake levels: Oakville, Ontario, prepared for the Georgian Bay Association Foundation [variously paged].

Brunk, I.W., 1968, Evaluation of channel changes in St. Clair and Detroit Rivers: Water Resources Research, v. 4, no. 6, p. 1335-1346.

Daniel, C., and Tennant, K., 2001, DEM quality assessment, in Maune, D.F., ed., Digital elevation model technologies and applications - The DEM users manual: Bethesda, Md., American Society for Photogrammetry and Remote Sensing, chap. 12, p. 395-440.

Derecki, J.A., 1985, Effect of channel changes in the St. Clair River during the present century: Journal of Great lakes Research, v. 11, no. 3, p. 201-207.

Horton, R., and Grunsky, C., 1927, Hydrology of the Great Lakes: Report of the Engineering Board of Review of the Sanitary District of Chicago on the lowering controversy and a program of remedial measures, part III, Appendix II.

Hu, Yong, 2003, Automated extraction of digital terrain models, roads and buildings using airborne LiDAR data: University of Calgary, Canada, Department of Geomatics Engineering, UCGE report 20187 (Ph.D. thesis), 206 p.
International Great Lakes Levels Board, 1973, Regulation of Great Lakes water levels: Report to the International Joint Commission, International Levels Board, p. 43-49.

Liu, X., Zhang, Z., Peterson, J., and Chandra, S., 2007, The effect of LiDAR data density on DEM accuracy, in MODSIM07 International Congress on Modelling and Simulation, December 10-13, 2007, Christchurch, New Zealand: [Proceedings] p. 1363-1369.

Maune, D., Maitra, J., and McKay, E., 2001, Accuracy standards, in Maune, D.F., ed., Digital elevation model technologies and applications - The DEM users manual: American Society for Photogrammetry and Remote Sensing, chap. 3, p. 61-82.

McCullagh, M.J., 1988, Terrain and surface modelling systems - Theory and practice: Photogrammetric Record, v. 12, no. 72 , p. 747-779.

National Oceanic and Atmospheric Administration, 2003, National Ocean Service, hydrographic surveys specifications and deliverables: Silver Spring, Md.

Umbach, M.J., 1976, Hydrographic manual (4th ed.): U.S. Department of Commerce, National Oceanic and Atmospheric Administration [variously paged]. 


\section{Appendix 1. Images Showing Results From Volumetric- and Elevation-Change Analyses}

\section{Figures}

1-1 through 1-15. Volumetric-change analysis of the upper St. Clair River, with uncertainty removed:

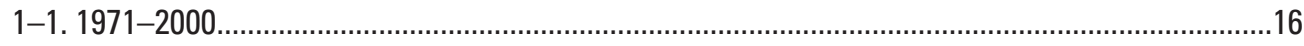

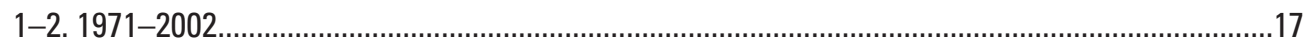

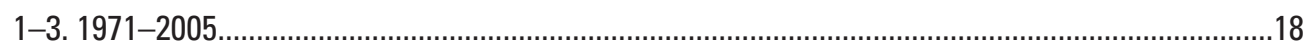

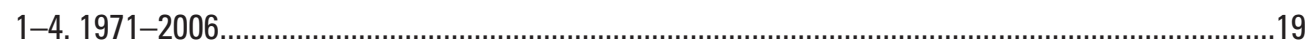

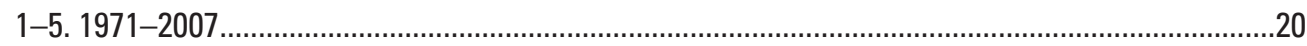

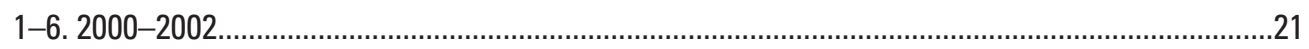

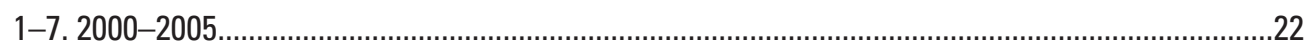

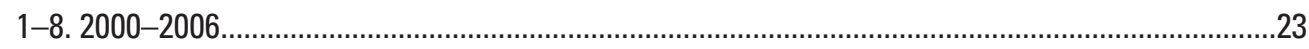

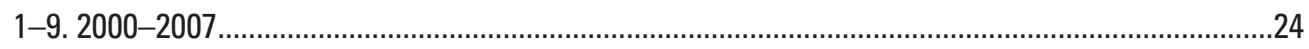

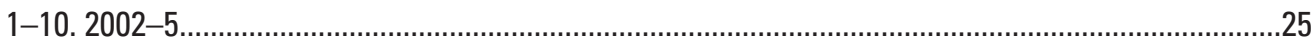

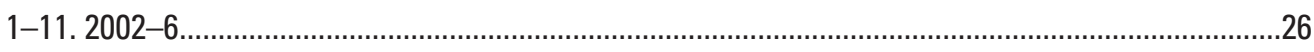

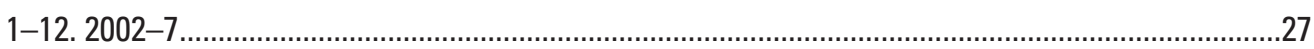

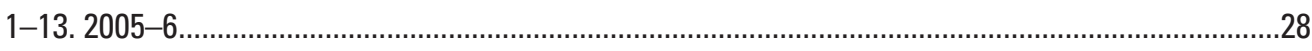

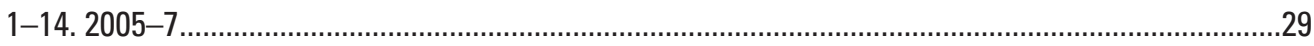

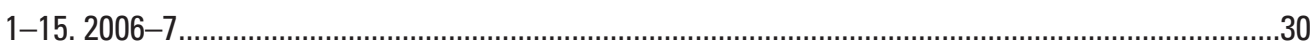

1-16. through 1-30. DEM file comparison indicating change in riverbed elevation in the upper St. Clair River, with uncertainty removed:

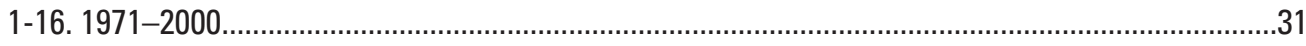

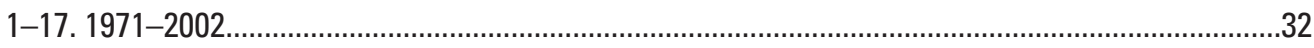

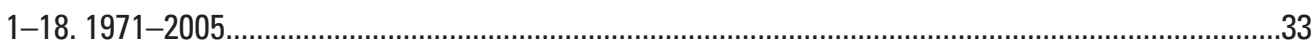

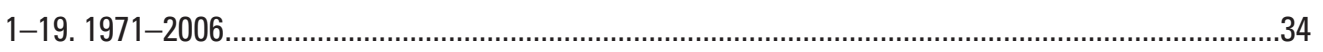

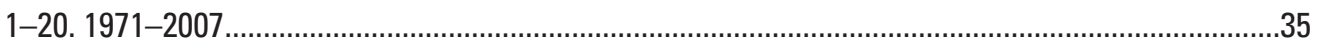

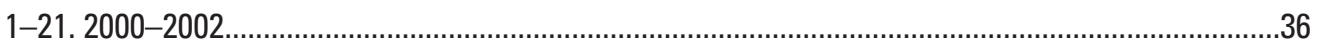

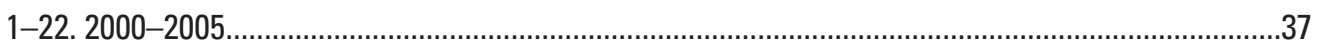

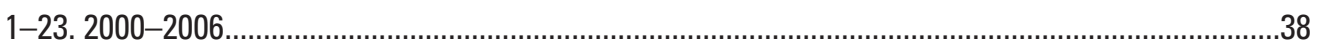

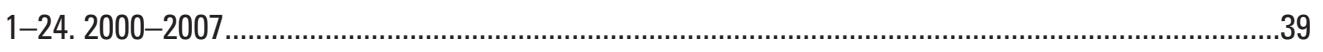

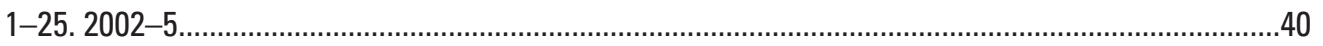


1-26. 2002-6

1-27. 2002-7

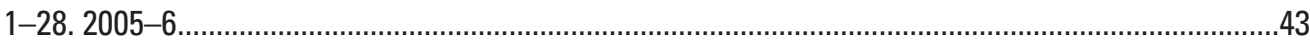

1-29. 2005-7

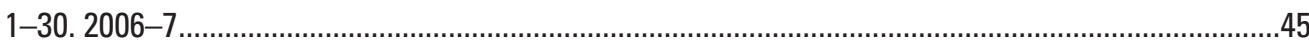

1-31. 1971 point bathymetry compared to 2007 DEM data in the upper St. Clair River, with uncertainty removed ................................................................................................

1-32. 1971 point bathymetry compared to 2007 DEM data in the middle St. Clair River, with uncertainty removed

1-33. 1971 point bathymetry compared to 2007 DEM data in the lower St. Clair River, with uncertainty removed

1-34. 2000 point bathymetry compared to 2007 DEM data in the upper St. Clair River, with uncertainty removed.

1-35. 2000 point bathymetry compared to 2007 DEM data in the middle St. Clair River, with uncertainty removed.

1-36. 2000 point bathymetry compared to 2007 DEM data in the lower St. Clair River, with uncertainty removed...

1-37. 2005-6 high-density point-to-point comparison of elevation change in the upper St. Clair River, with uncertainty removed.

1-38. 2005-7 high-density point-to-point comparison of elevation change in the upper St. Clair River, with uncertainty removed.

1-39. 2006-7 high-density point-to-point comparison of elevation change in the upper St. Clair River, with uncertainty removed.

1-40. Area (outlined in red) where elevation changes dramatically in the 2006-7 comparison (fig. 1-41)

1-41. Area (outlined in red) where elevation changes dramatically from the 2005-6 comparison (fig. 1-40)

1-42. Area highlight of the "sediment tongue" elevation-gain feature in the upper St. Clair River.

1-43. Areas of high geomorphic activity in the upper St. Clair River and spatial relation to selected river features 


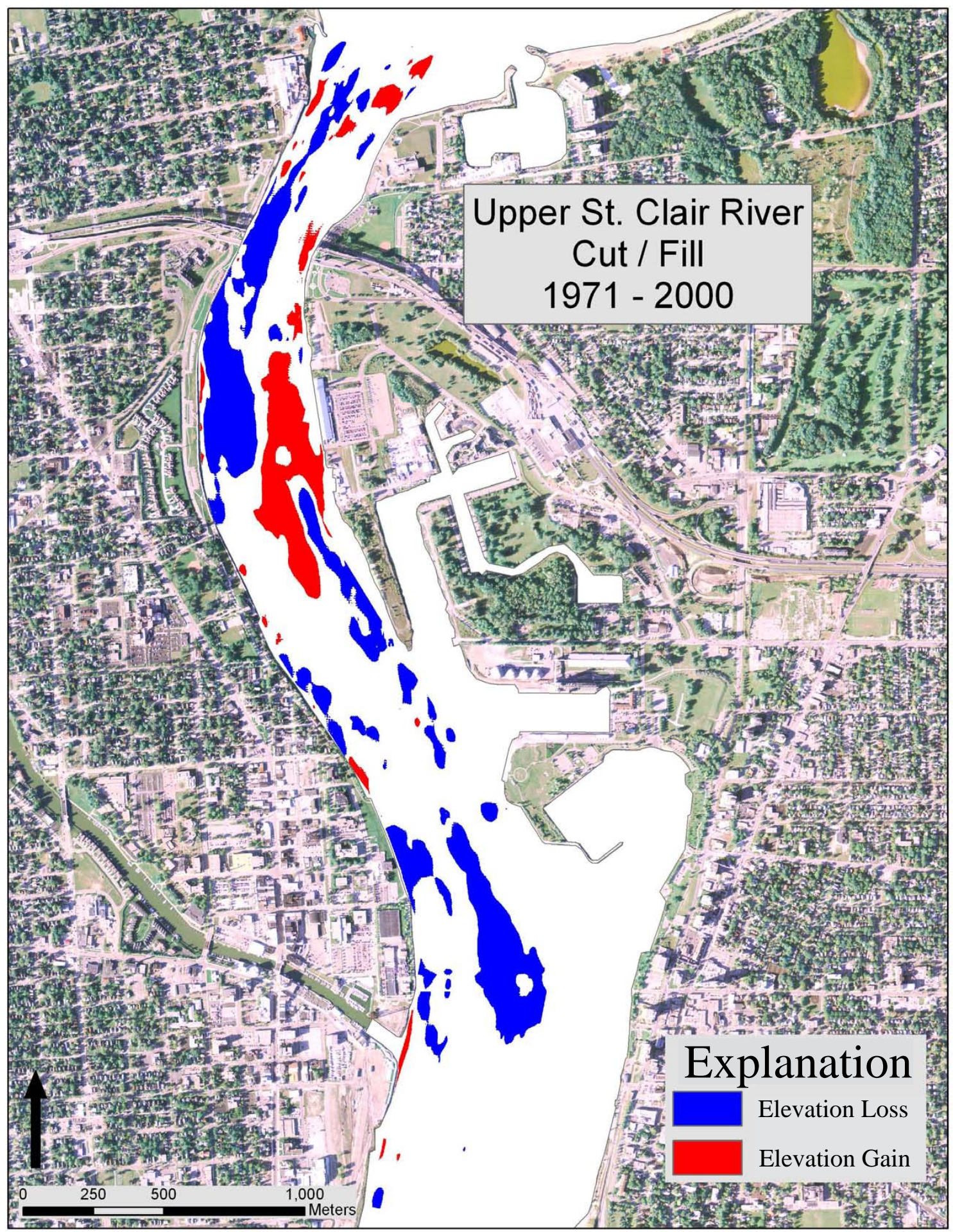

Figure 1-1. Volumetric-change analysis of the upper St. Clair River 1971-2000, with uncertainty removed. 


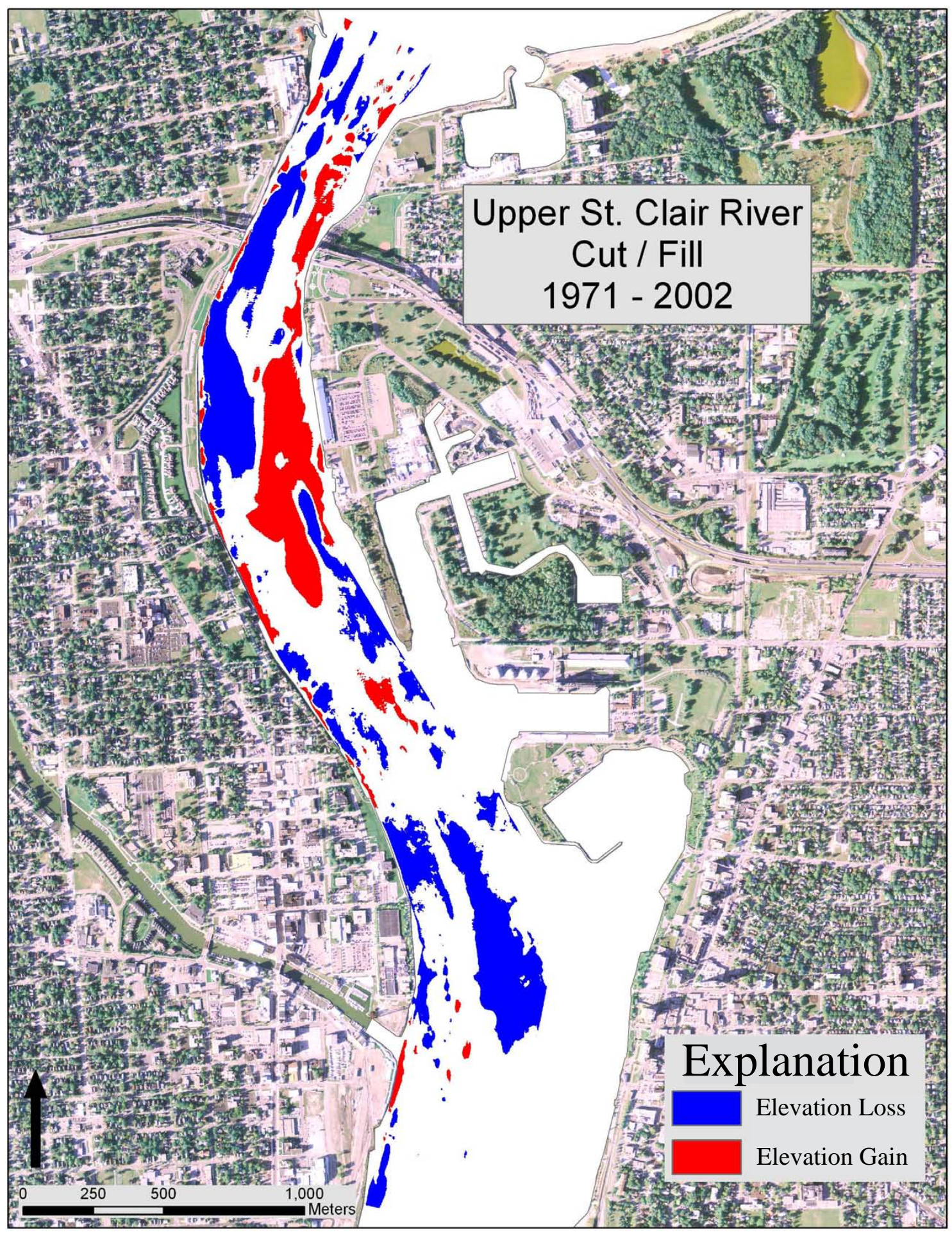

Figure 1-2. Volumetric-change analysis of the upper St. Clair River 1971-2002, with uncertainty removed. 


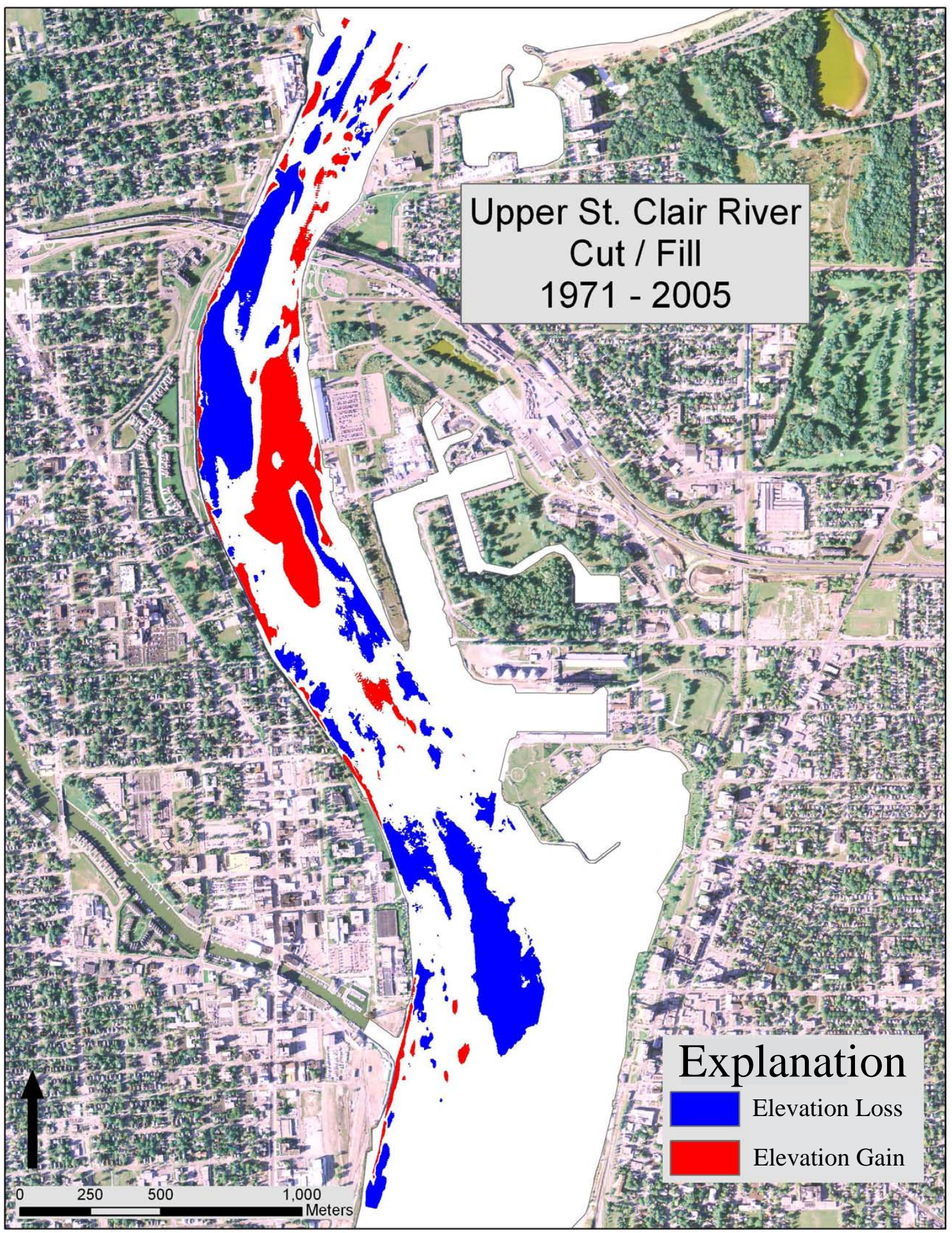

Figure 1-3. Volumetric-change analysis of the upper St. Clair River 1971-2005, with uncertainty removed. 


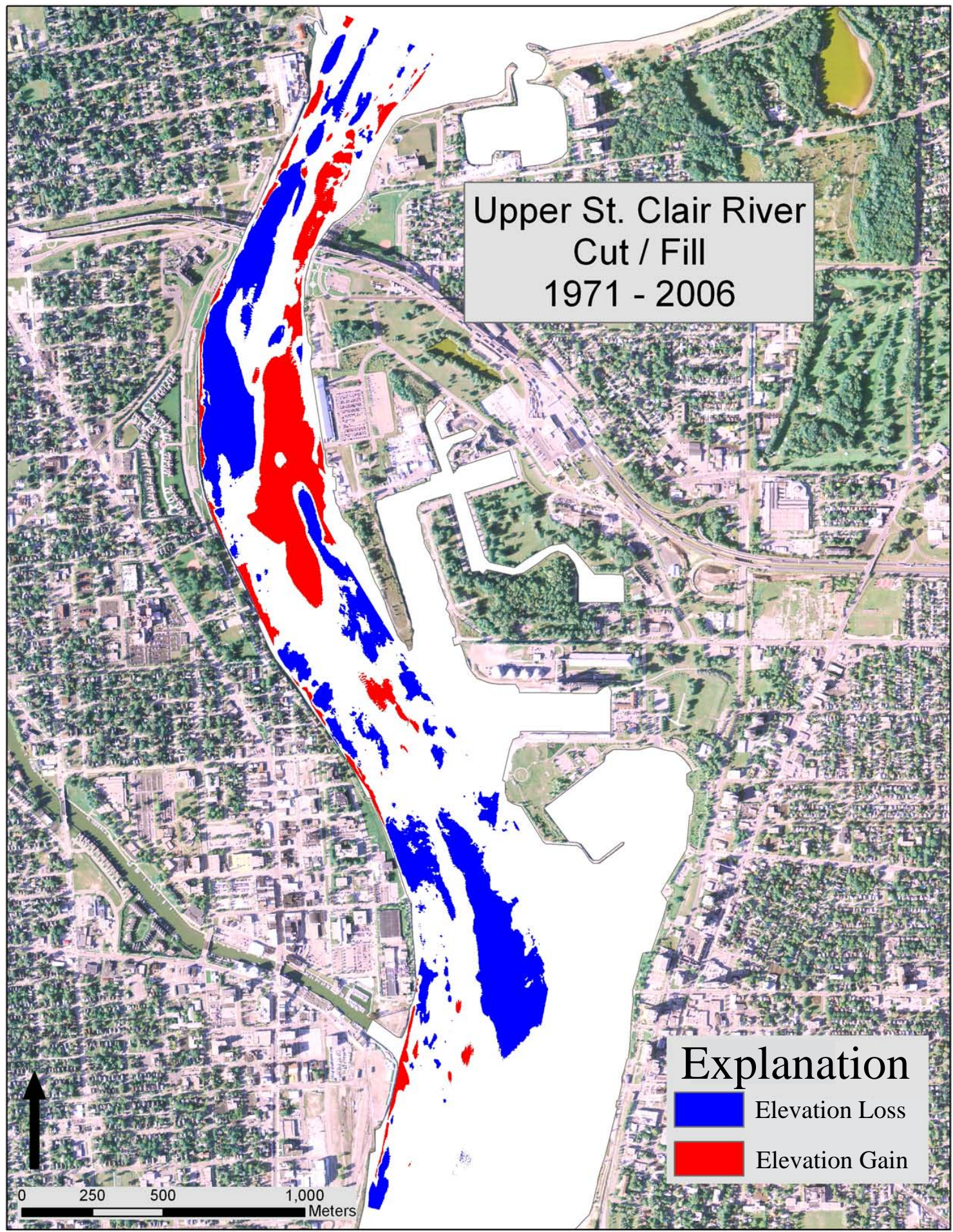

Figure 1-4. Volumetric-change analysis of the upper St. Clair River 1971-2006, with uncertainty removed. 


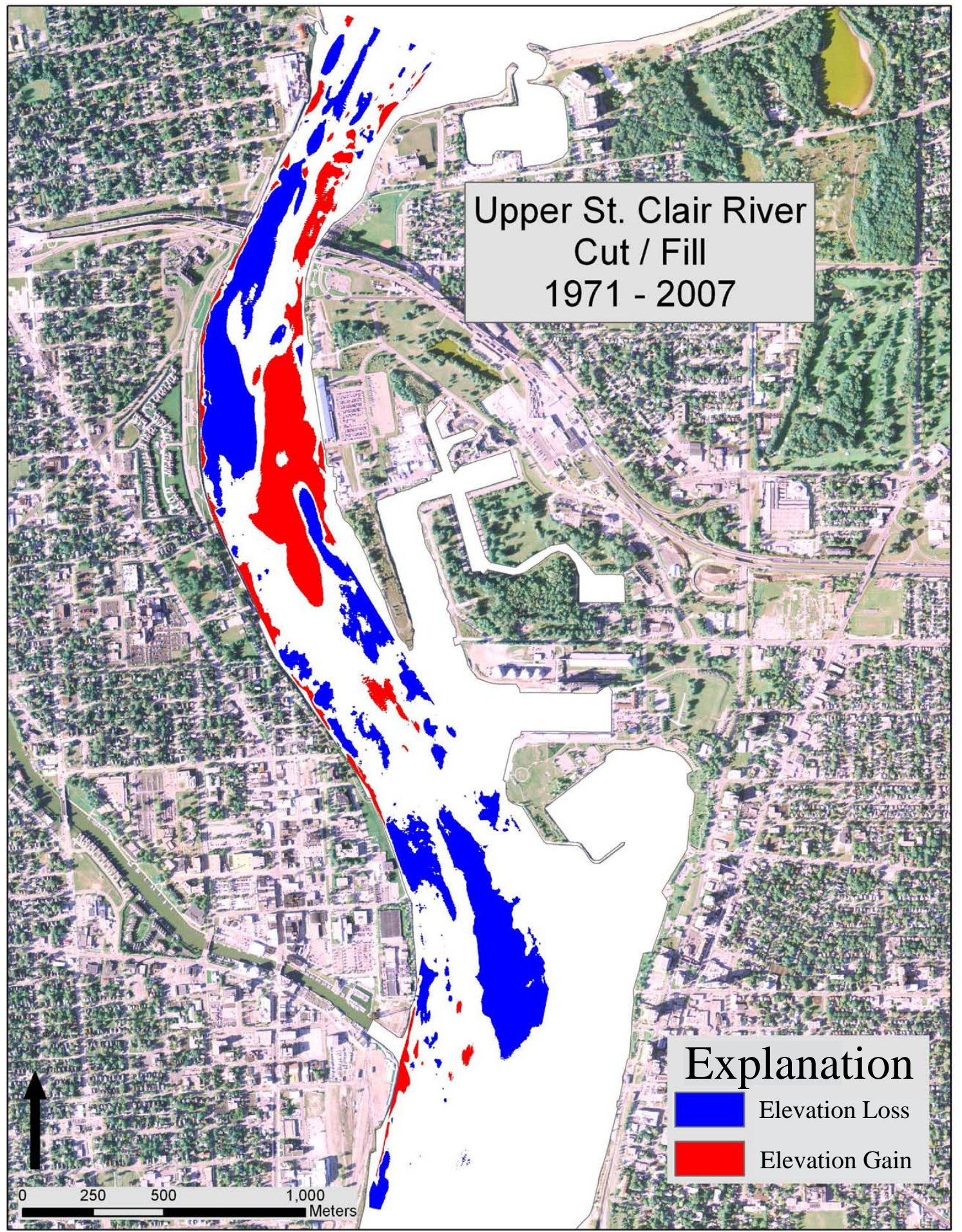

Figure 1-5. Volumetric-change analysis of the upper St. Clair River 1971-2007, with uncertainty removed. 


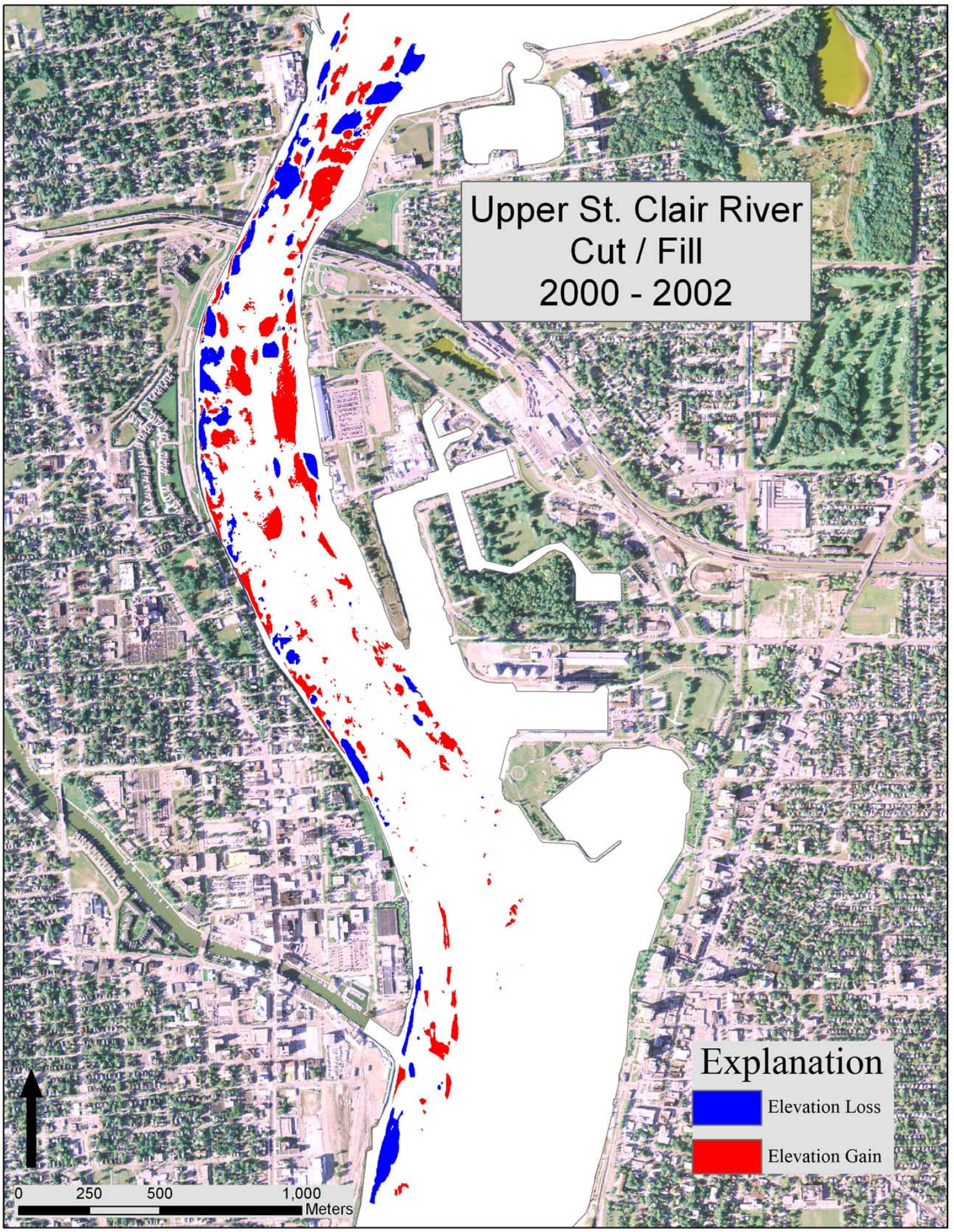

Figure 1-6. Volumetric-change analysis of the upper St. Clair River, 2000-2002, with uncertainty removed. 


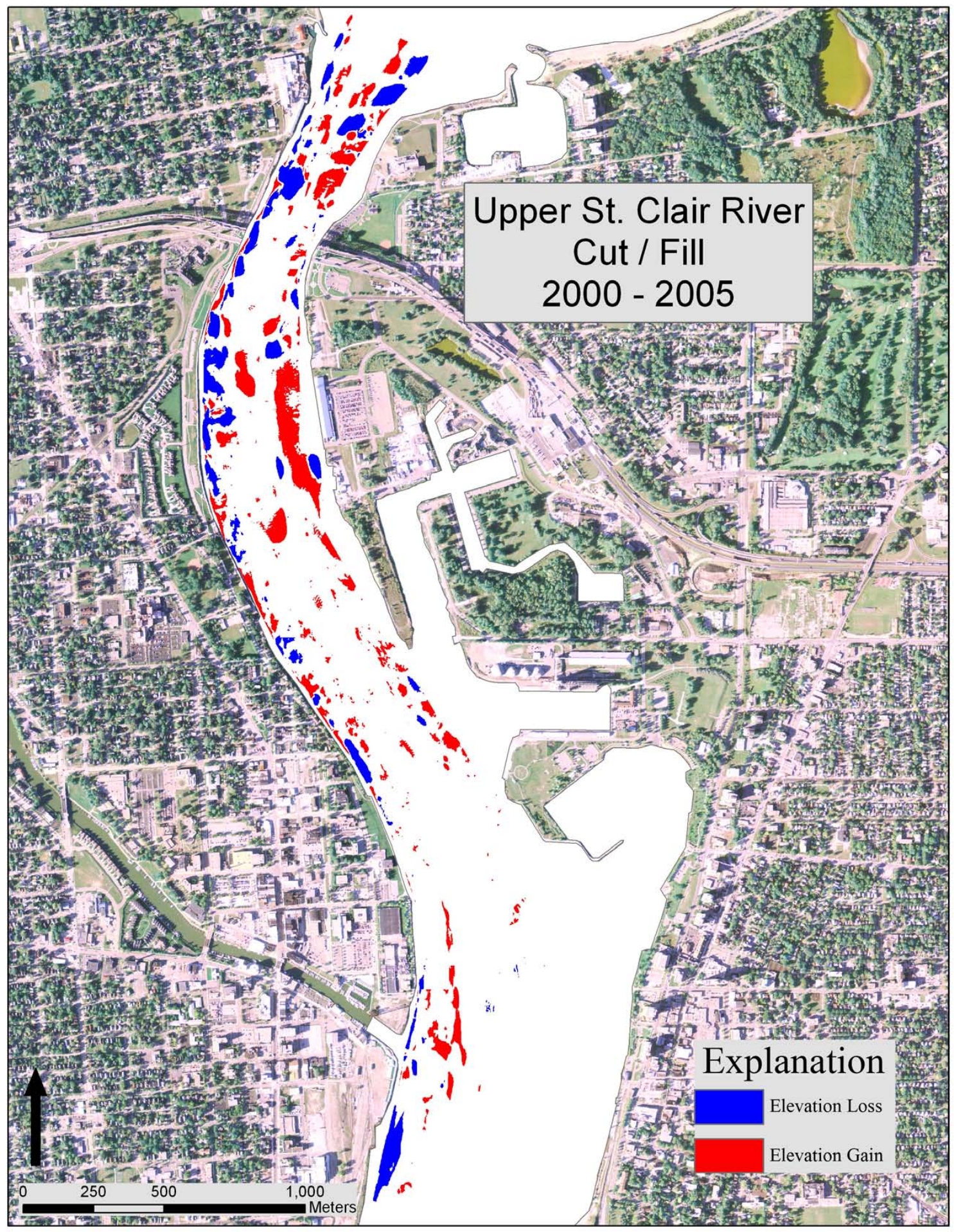

Figure 1-7. Volumetric-change analysis of the upper St. Clair River, 2000-2005, with uncertainty removed. 


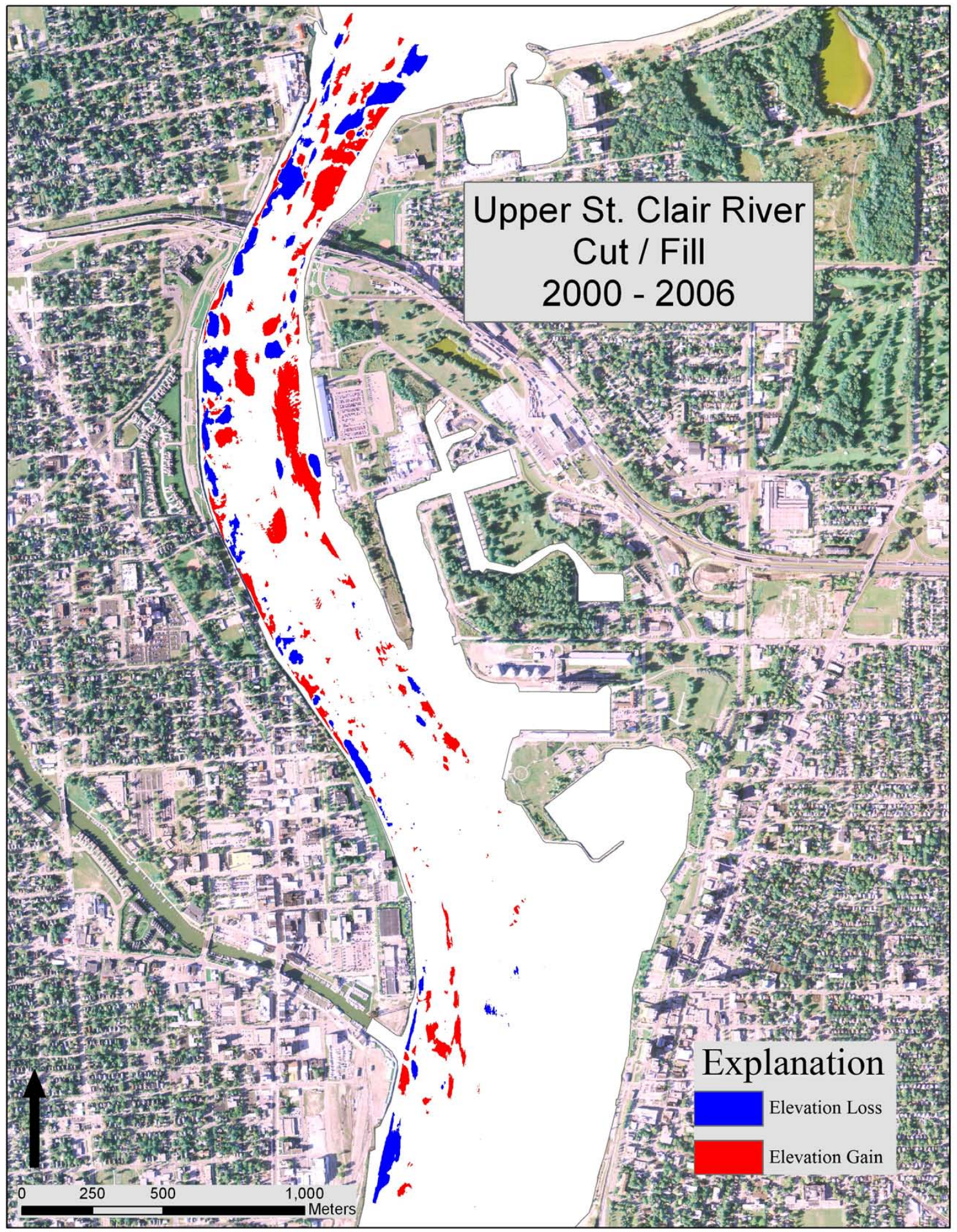

Figure 1-8. Volumetric-change analysis of the upper St. Clair River, 2000-2006, with uncertainty removed. 


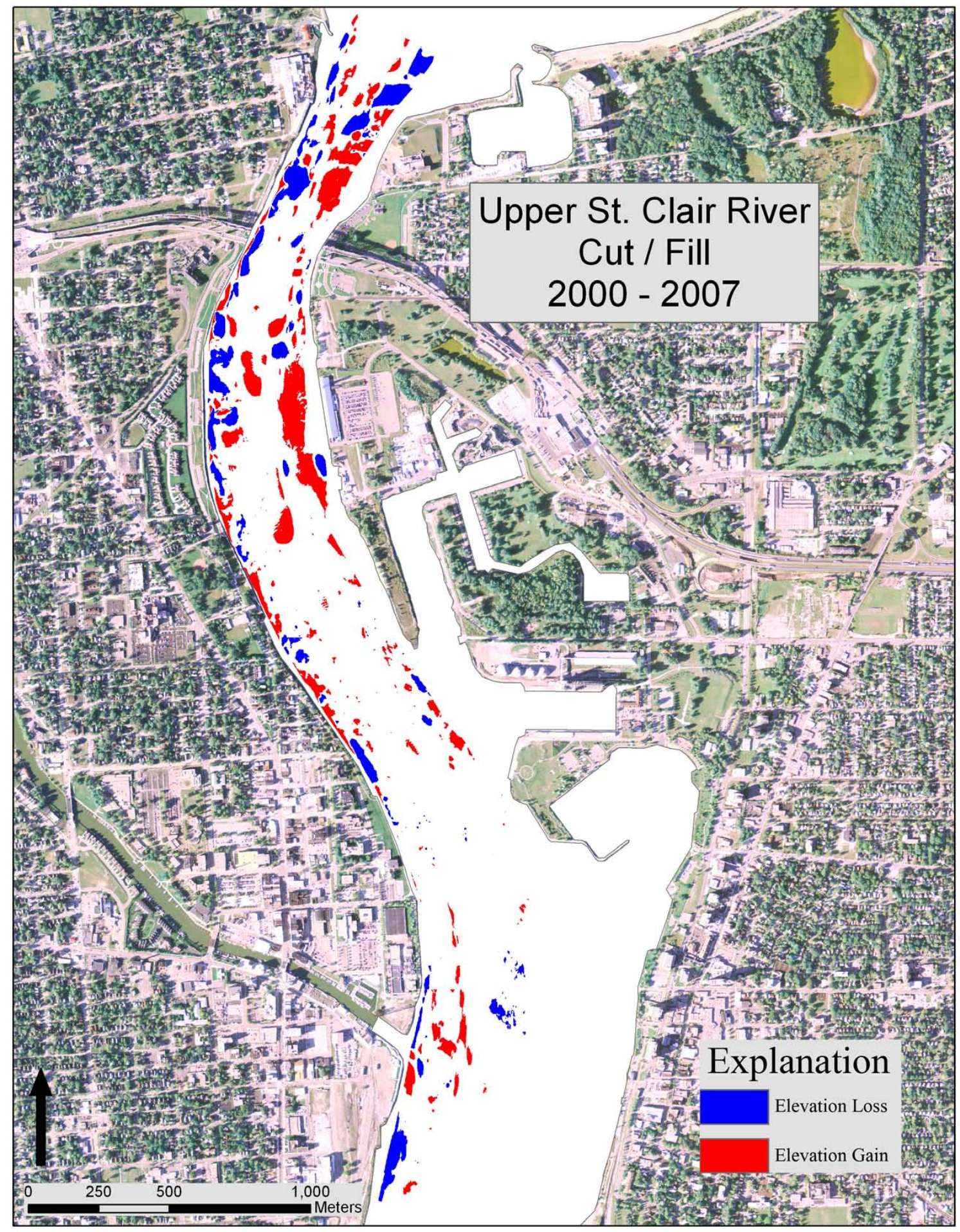

Figure 1-9. Volumetric-change analysis of the upper St. Clair River, 2000-2007, with uncertainty removed. 


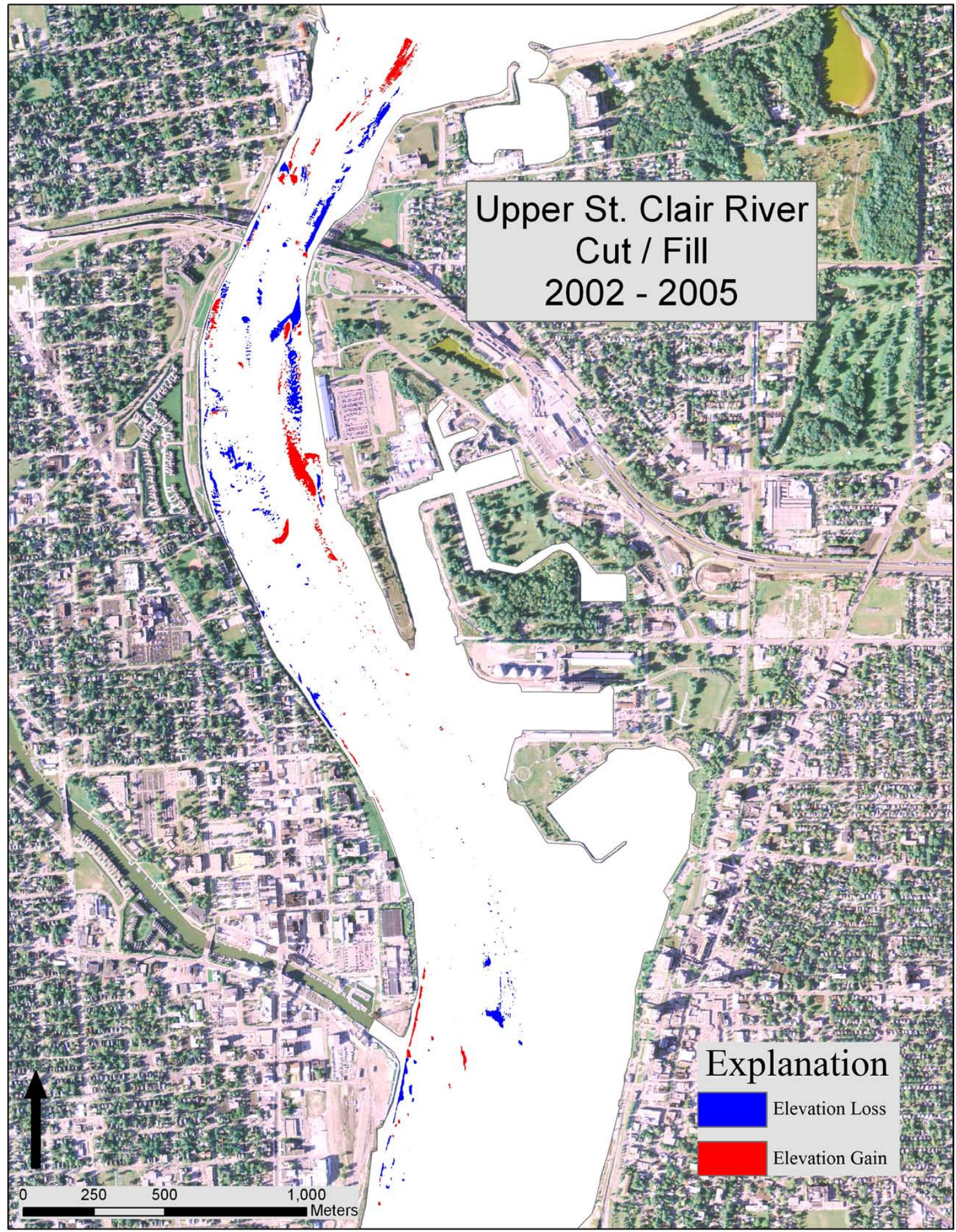

Figure 1-10. Volumetric-change analysis of the upper St. Clair River, 2002-5, with uncertainty removed. 


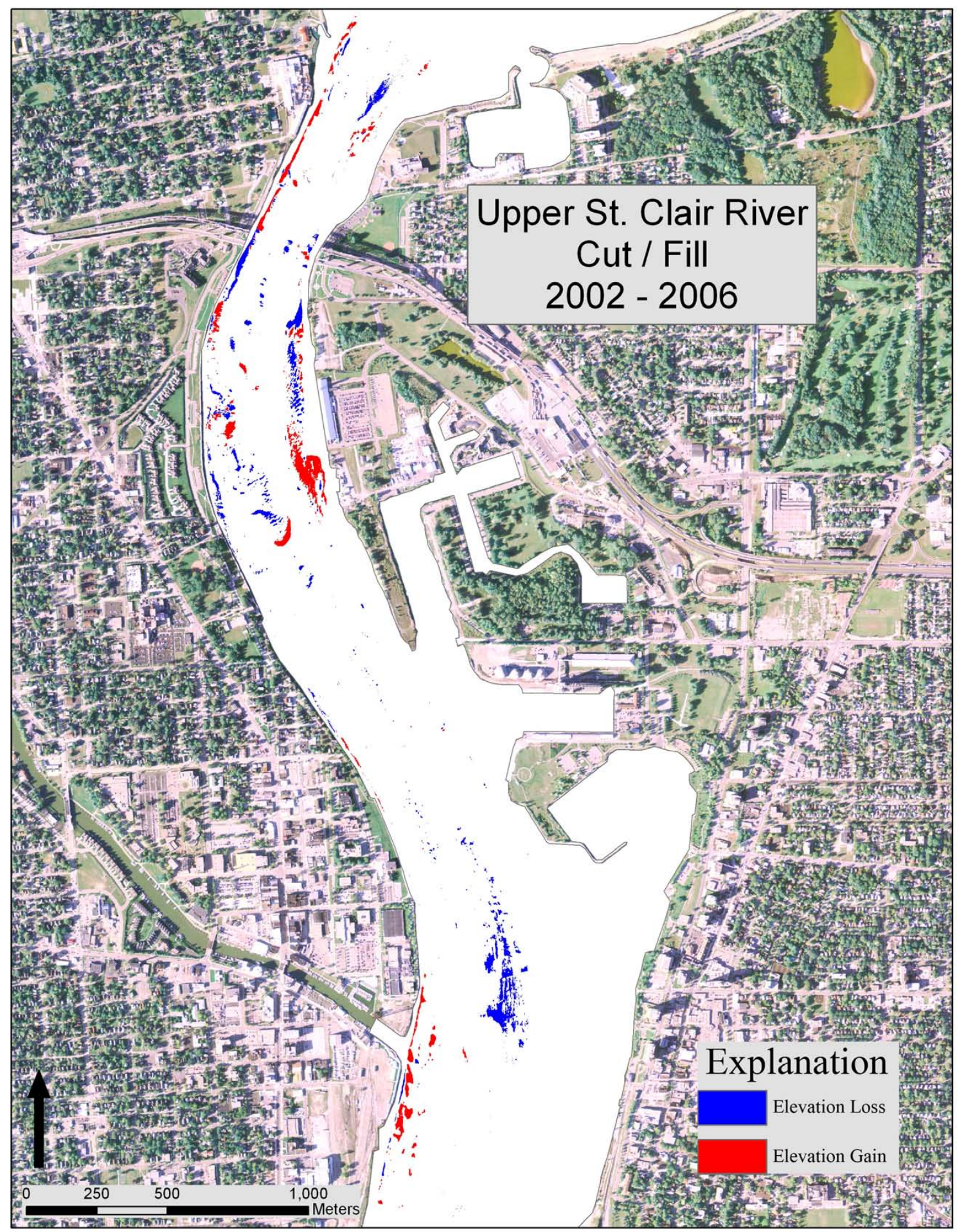

Figure 1-11. Volumetric-change analysis of the upper St. Clair River, 2002-6, with uncertainty removed. 


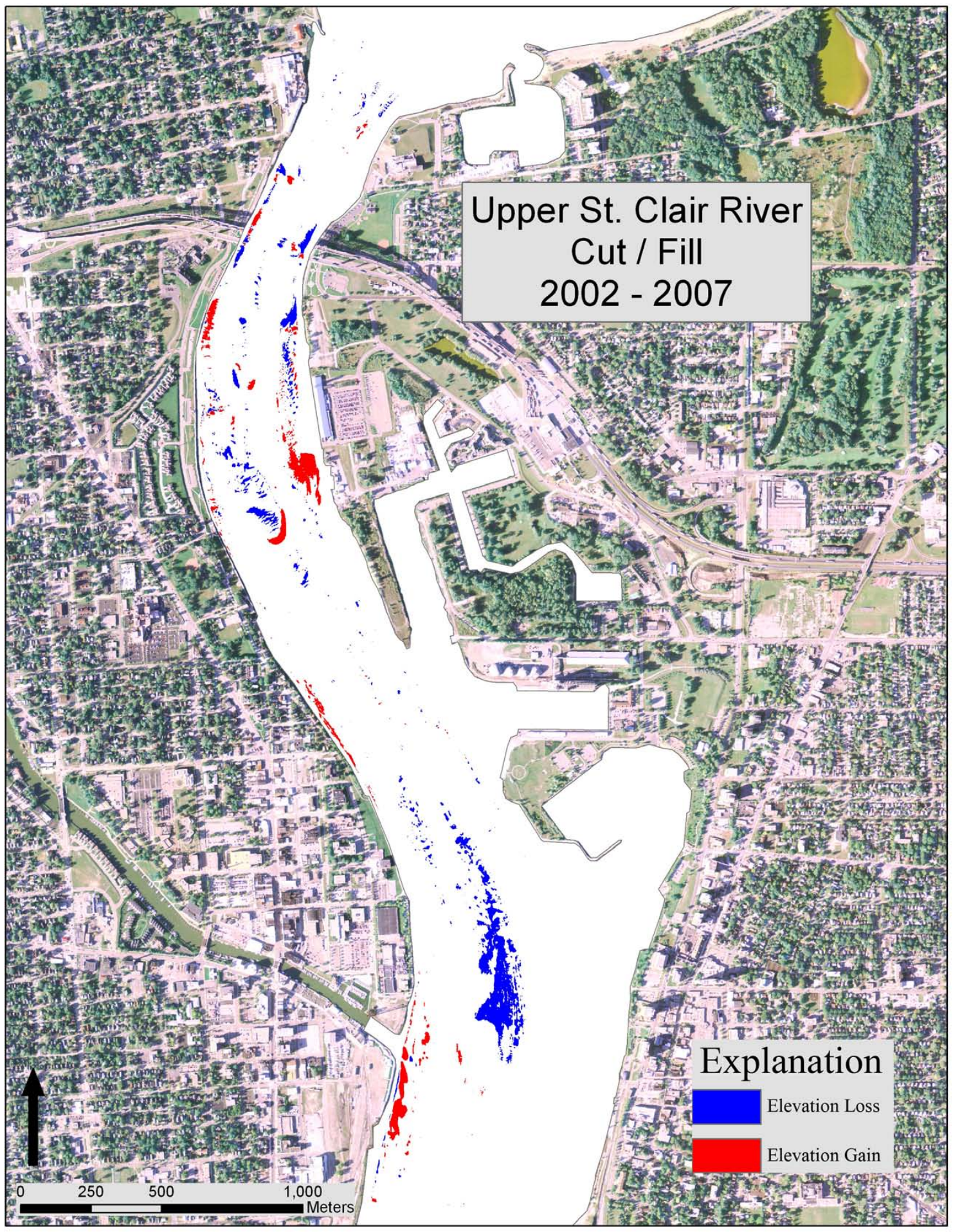

Figure1-12 Volumetric-change analysis of the upper St. Clair River, 2002-7, with uncertainty removed. 


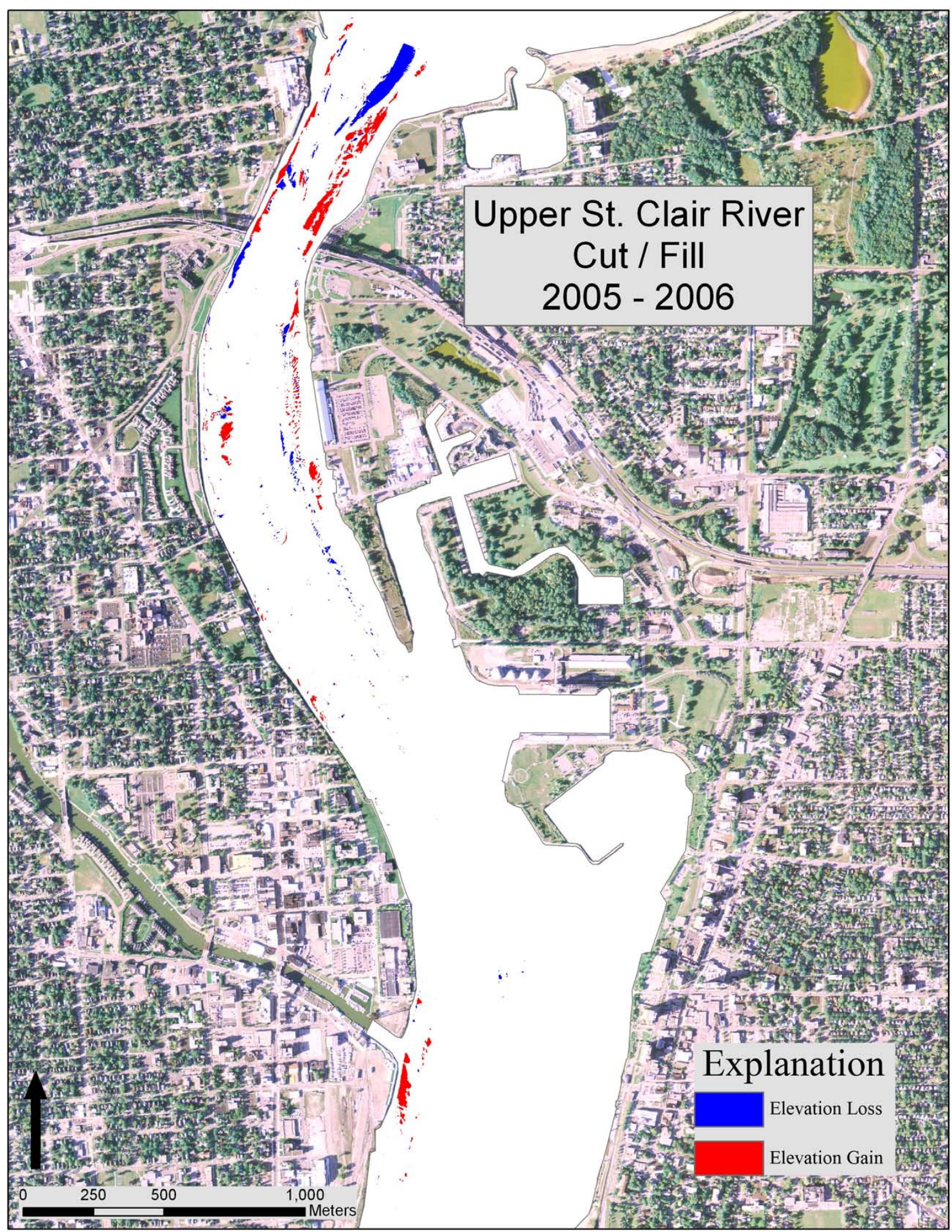

Figure 1-13. Volumetric-change analysis of the upper St. Clair River, 2005-6, with uncertainty removed. 


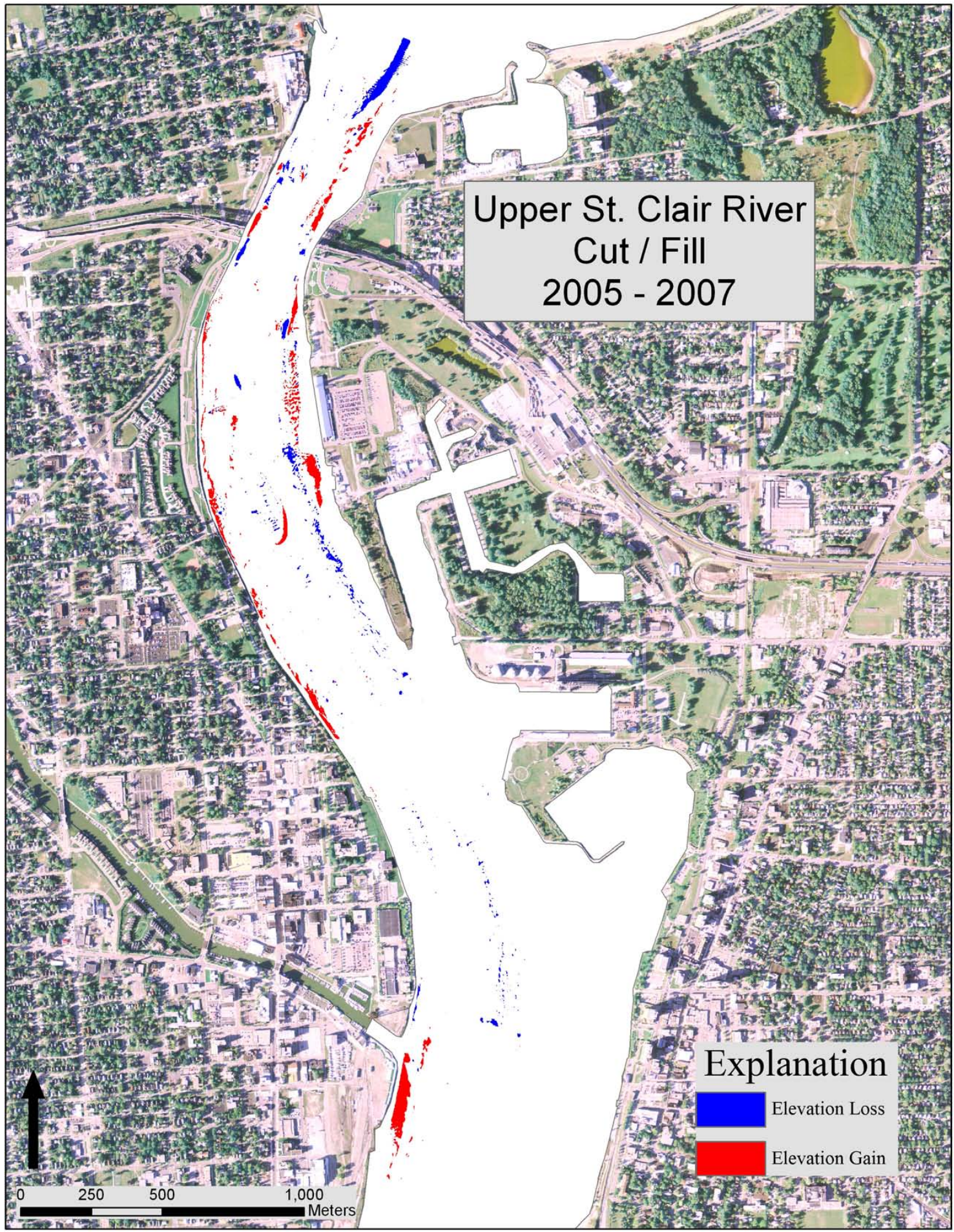

Figure 1-14. Volumetric-change analysis of the upper St. Clair River, 2005-7, with uncertainty removed. 


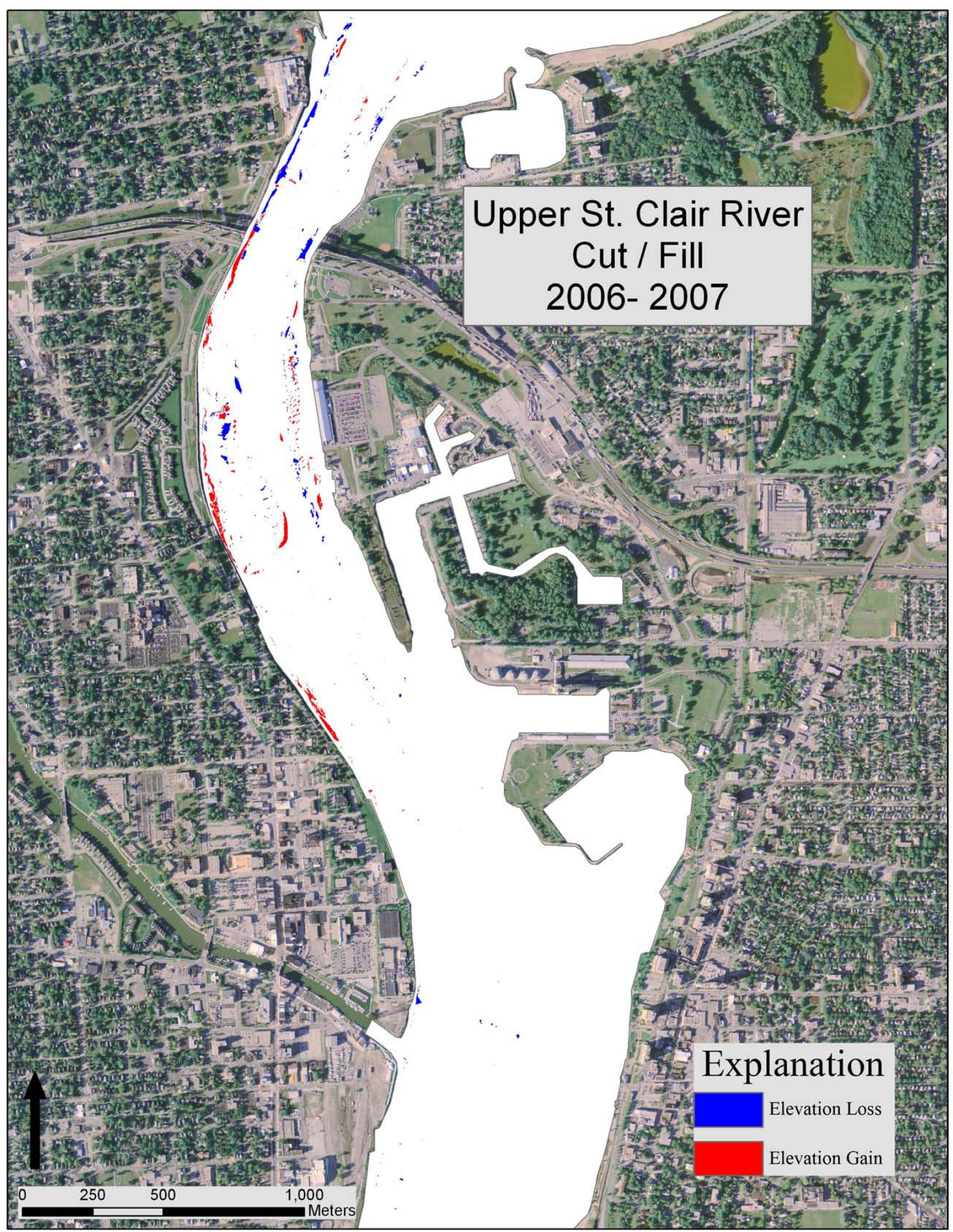

Figure1-15. Volumetric change analysis of the upper St. Clair River, 2006-7, with uncertainty removed. 


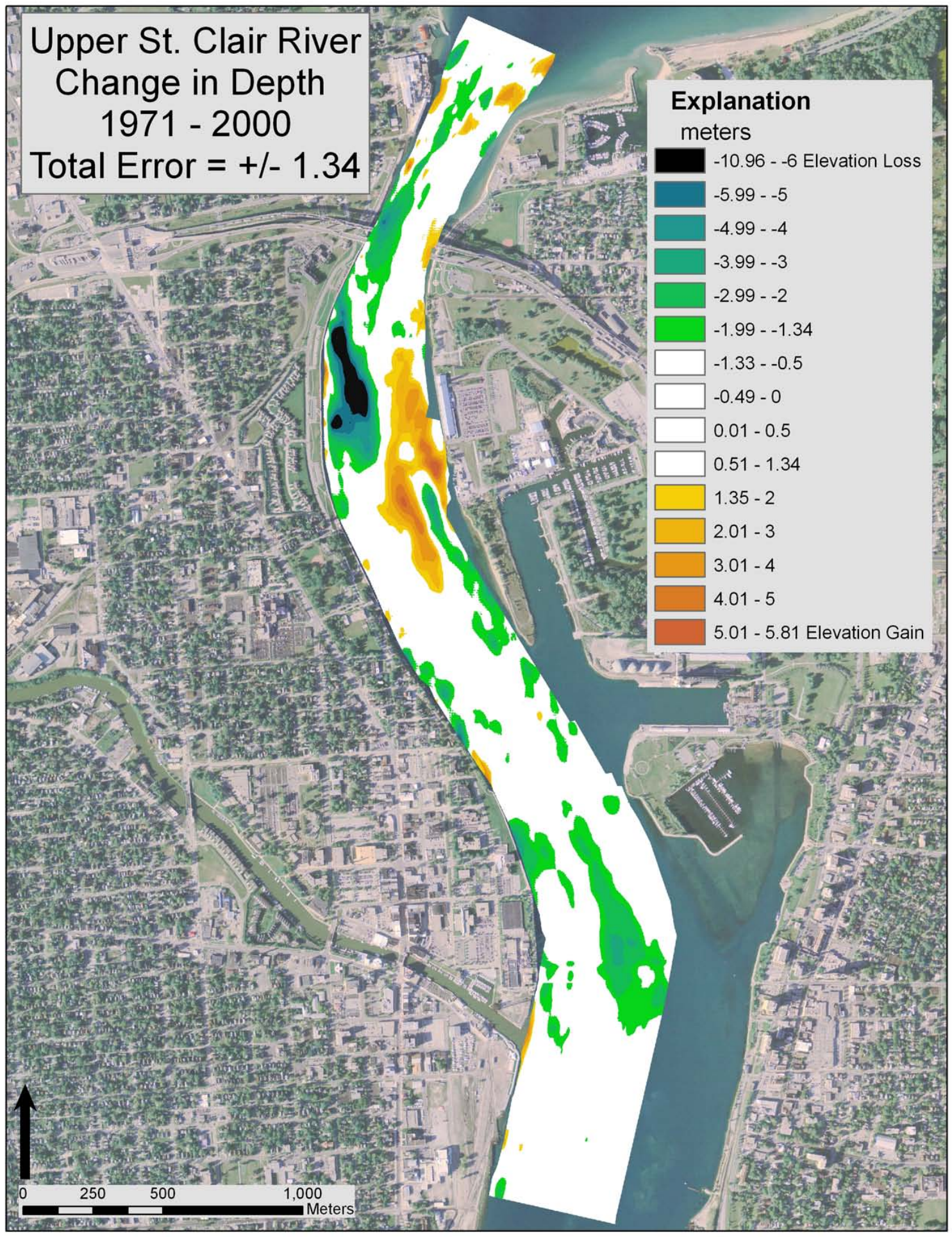

Figure 1-16. DEM file comparison indicating change in riverbed elevation in the upper St. Clair River, 1971-2000, with uncertainty removed. 


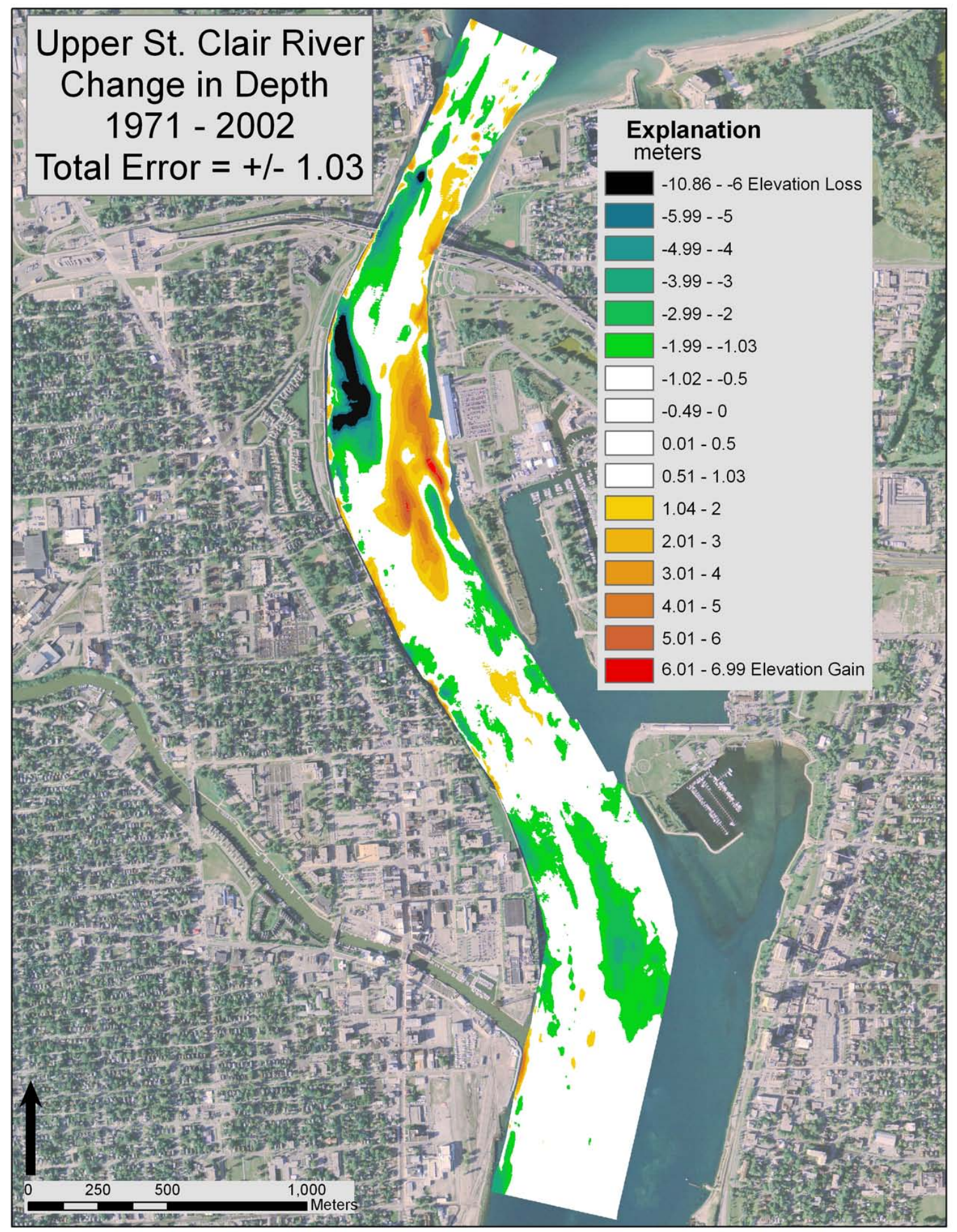

Figure 1-17. DEM file comparison indicating change in riverbed elevation in the upper St. Clair River, 1971-2002, with uncertainty removed. 


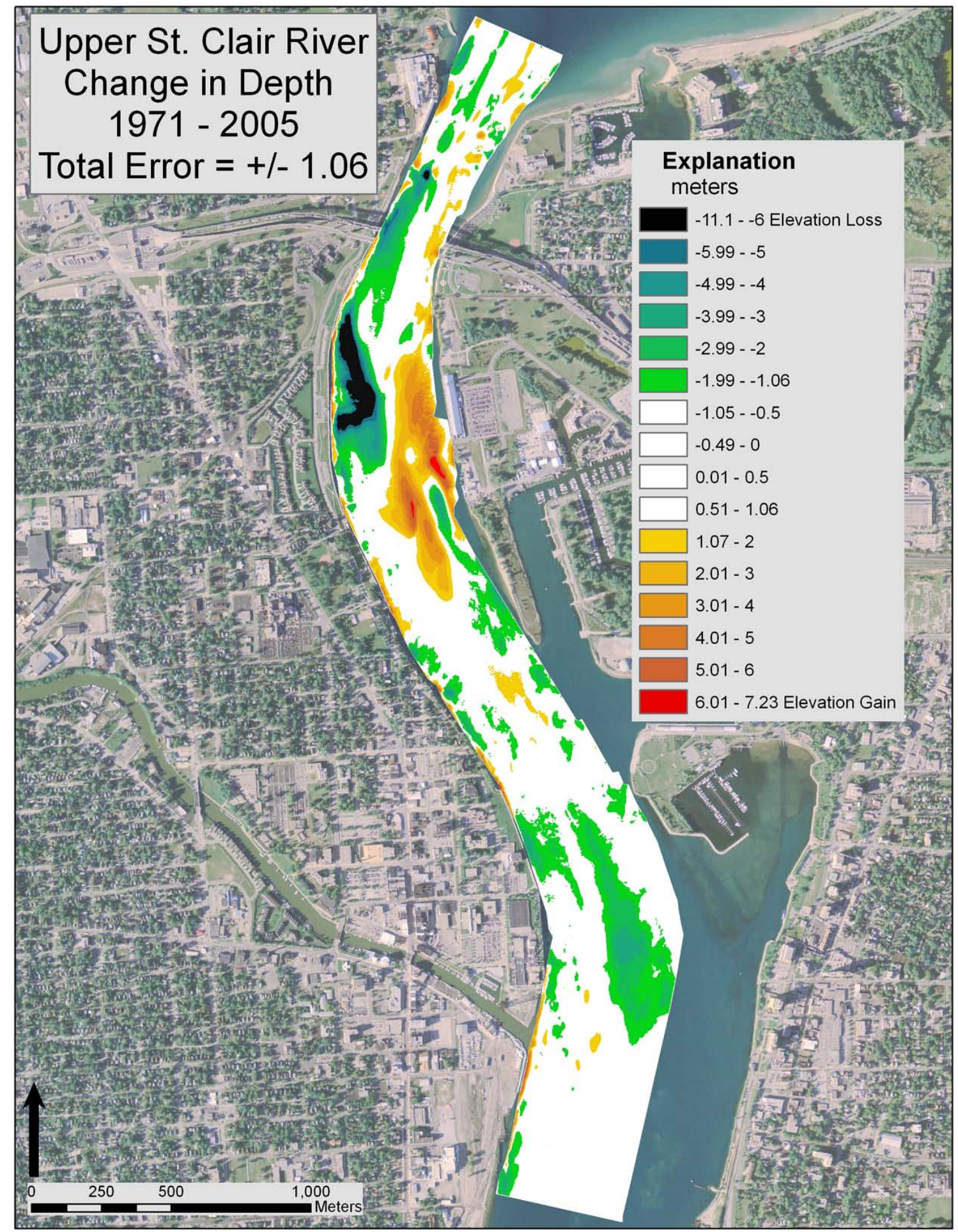

Figure 1-18. DEM file comparison indicating change in riverbed elevation in the upper St. Clair River, 1971-2005, with uncertainty removed. 


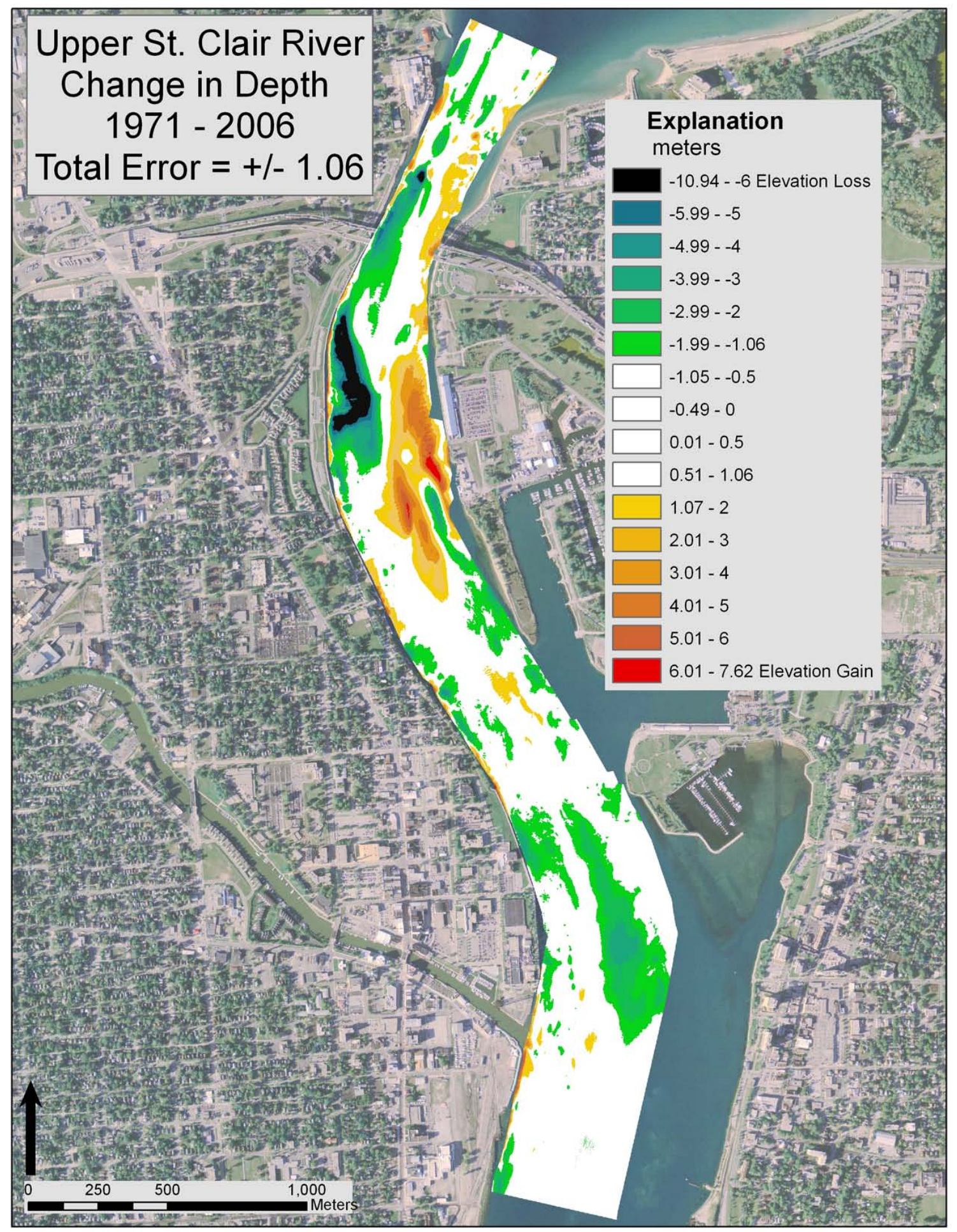

Figure 1-19. DEM file comparison indicating change in riverbed elevation in the upper St. Clair River, 1971-2006, with uncertainty removed. 


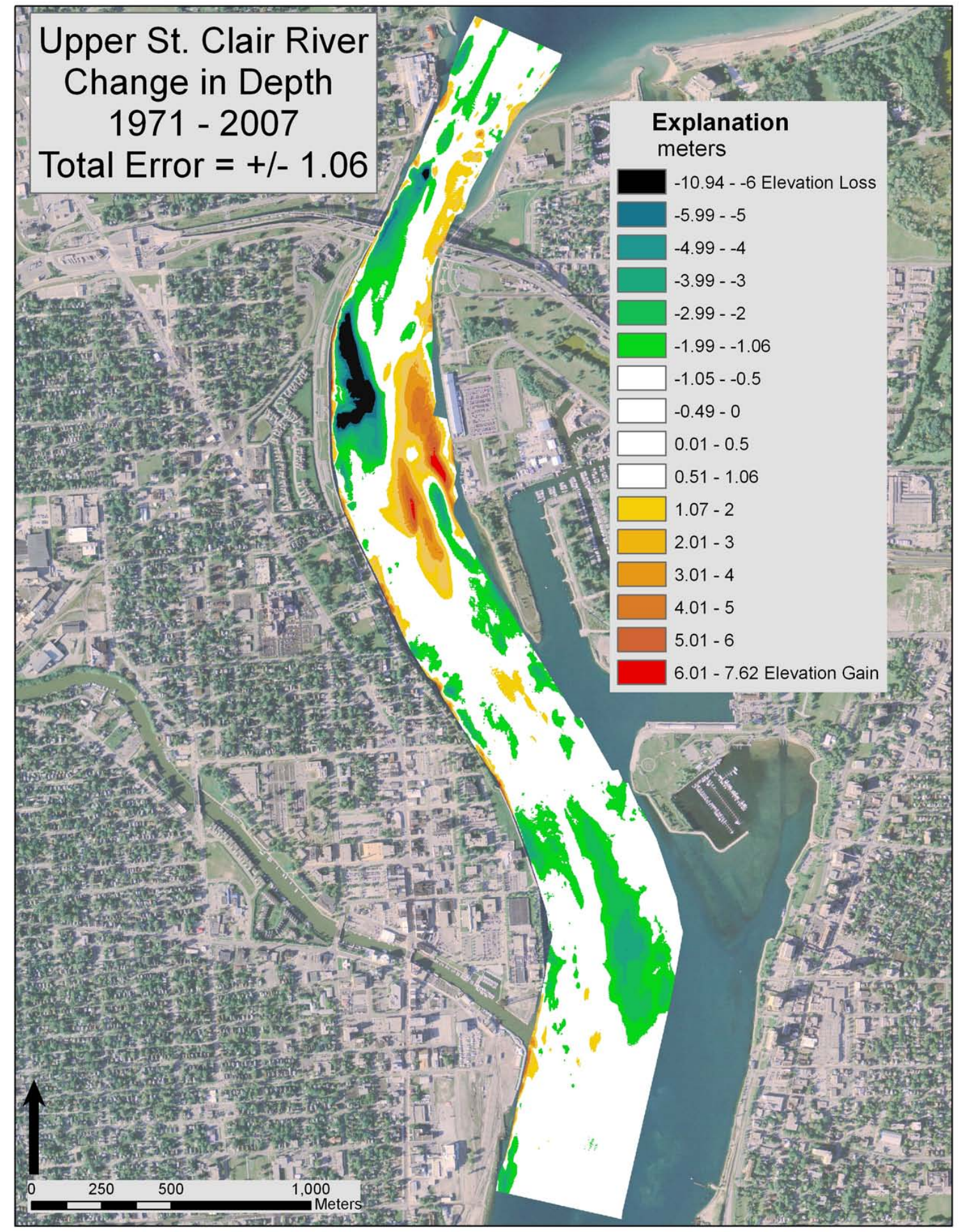

Figure 1-20. DEM file comparison indicating change in riverbed elevation in the upper St. Clair River, 1971-2007, with uncertainty removed. 


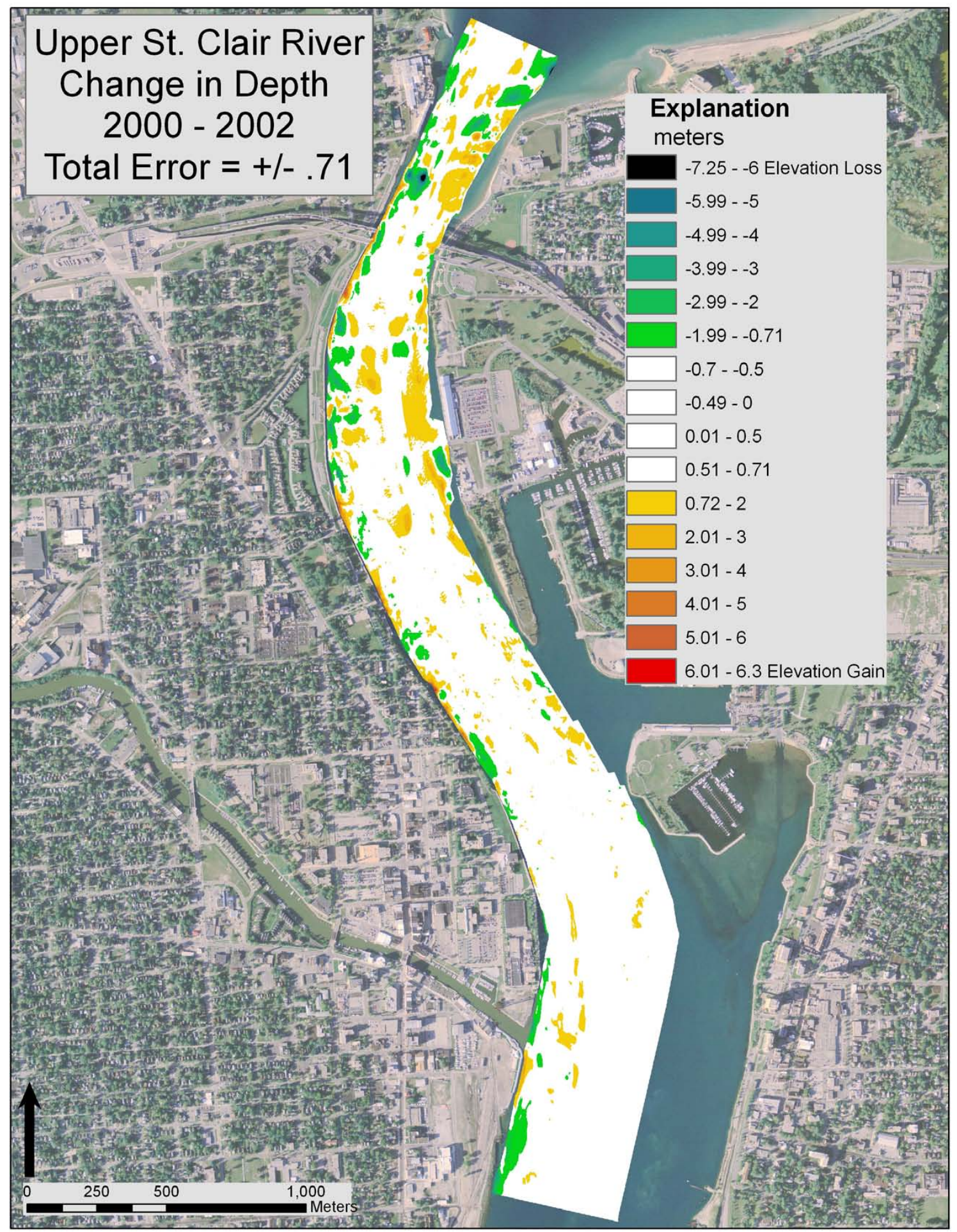

Figure 1-21. DEM file comparison indicating change in riverbed elevation in the upper St. Clair River, 2000-2002, with uncertainty removed. 


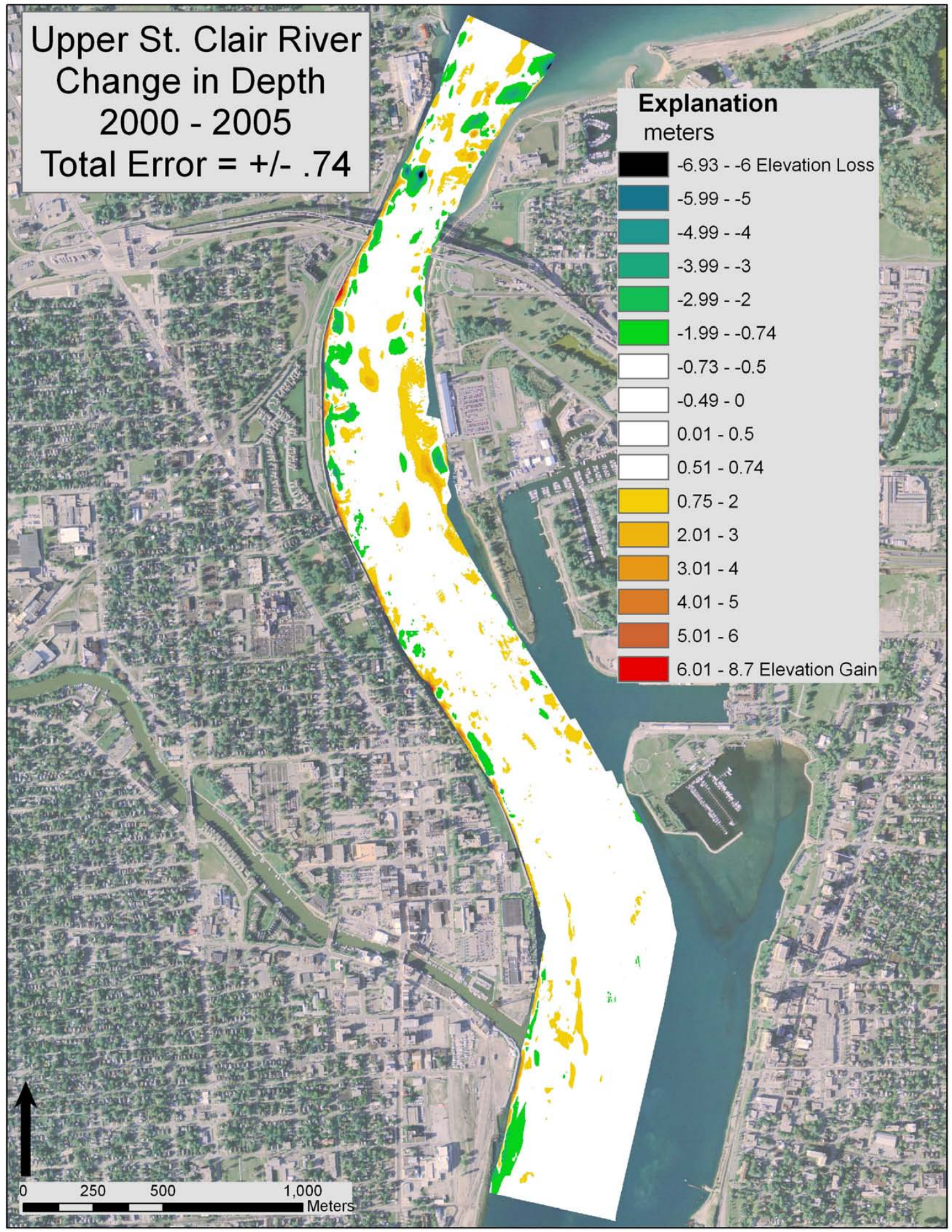

Figure 1-22 DEM file comparison indicating change in riverbed elevation in the upper St. Clair River, 2000-2005, with uncertainty removed. 


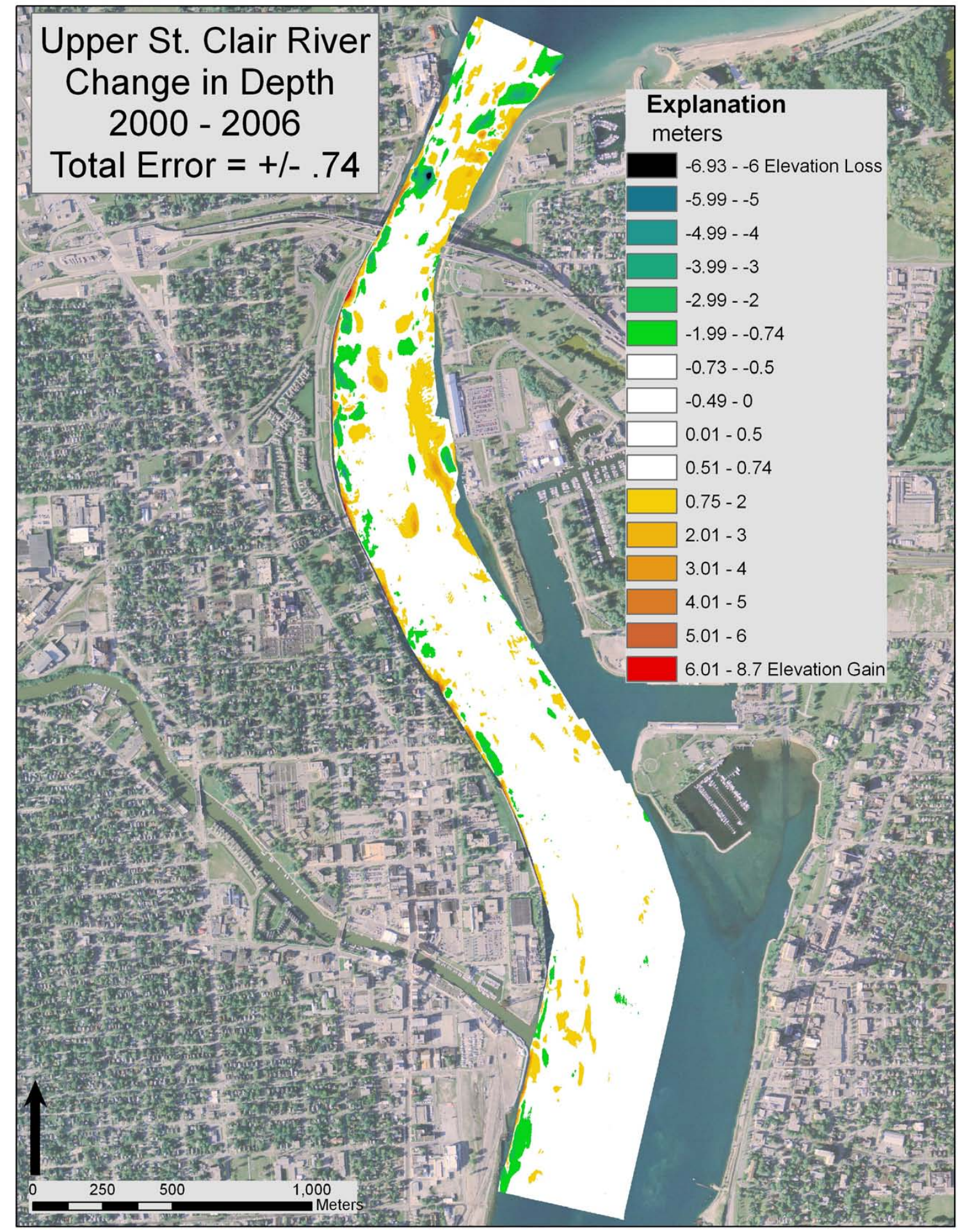

Figure 1-23. DEM file comparison indicating change in riverbed elevation in the upper St. Clair River, 2000-2006, with uncertainty removed. 


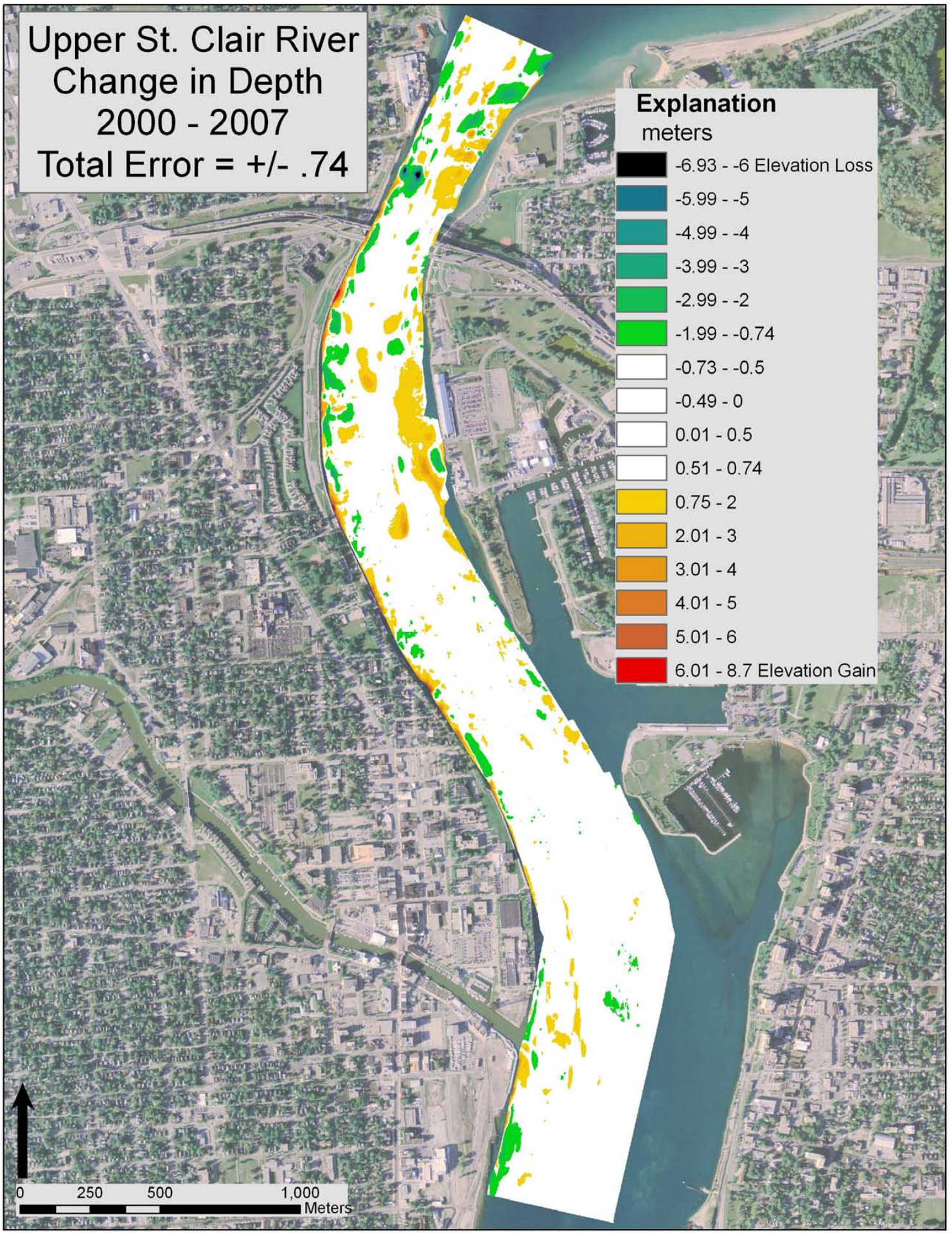

Figure 1-24 DEM file comparison indicating change in riverbed elevation in the upper St. Clair River, 2000-2007, with uncertainty removed. 


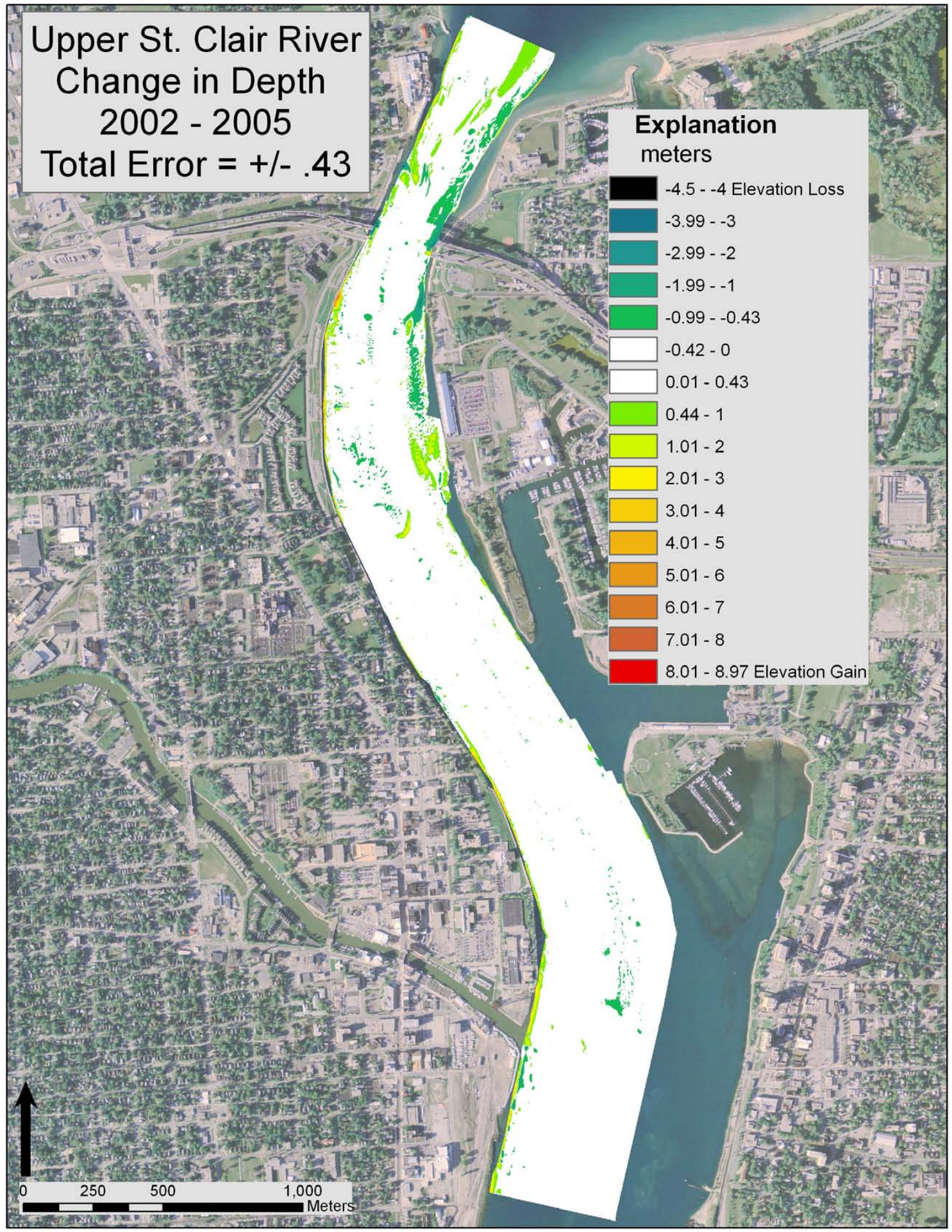

Figure 1-25 DEM file comparison indicating change in riverbed elevation in the upper St. Clair River, 2002-5, with uncertainty removed. 


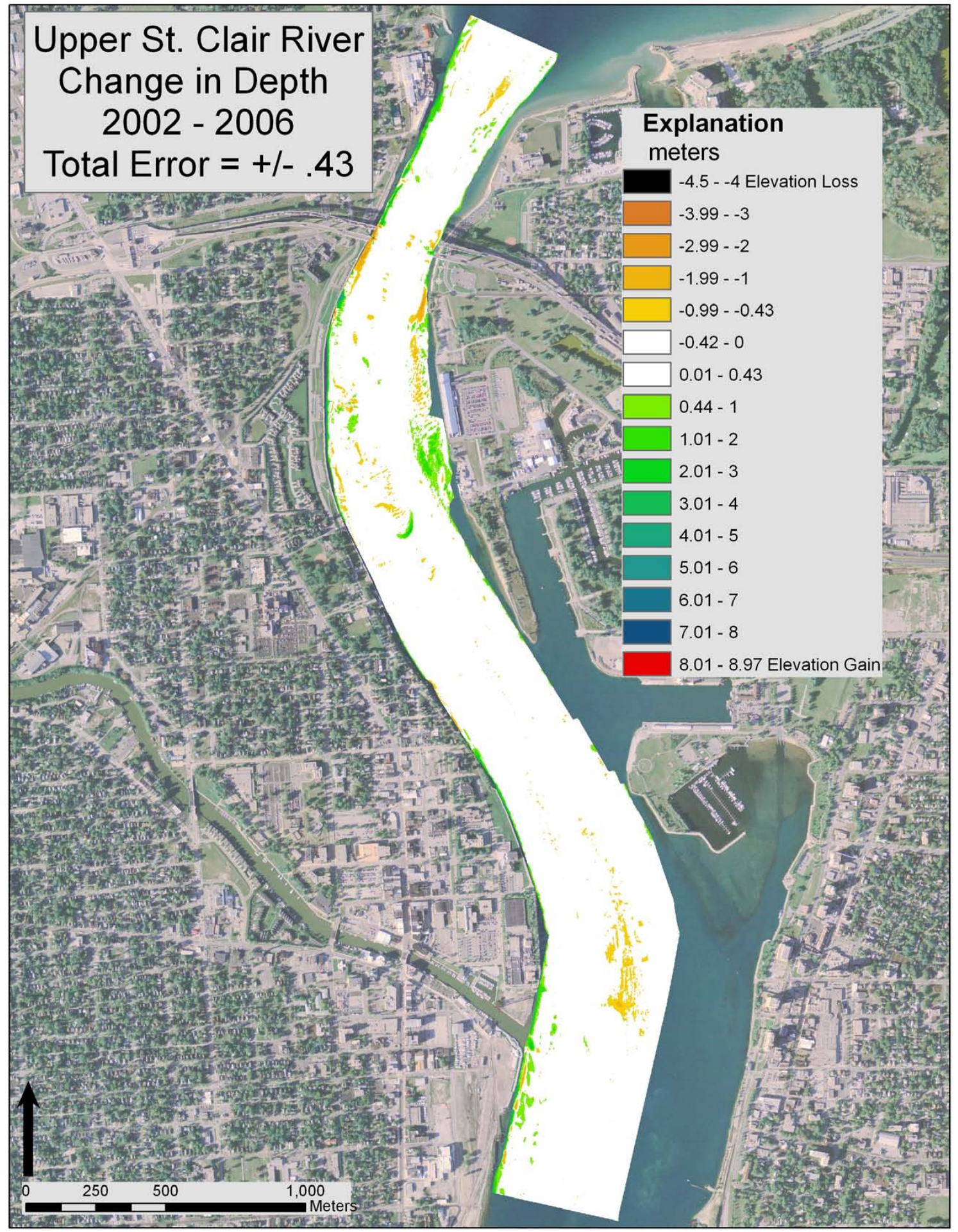

Figure 1-26 DEM file comparison indicating change in riverbed elevation in the upper St. Clair River, 2002-6, with uncertainty removed. 


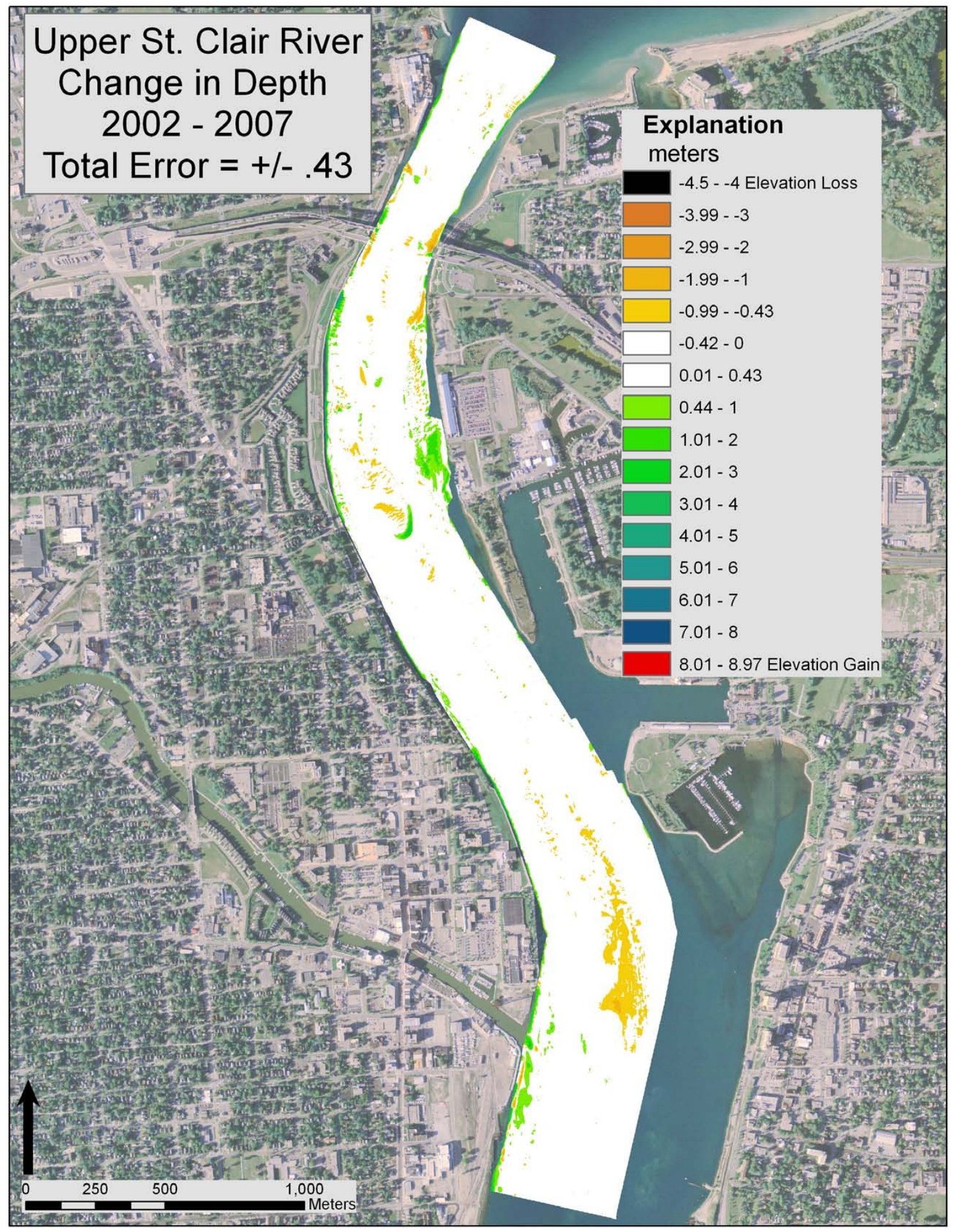

Figure 1-27. DEM file comparison indicating change in riverbed elevation in the upper St. Clair River, 2002-7, with uncertainty removed. 


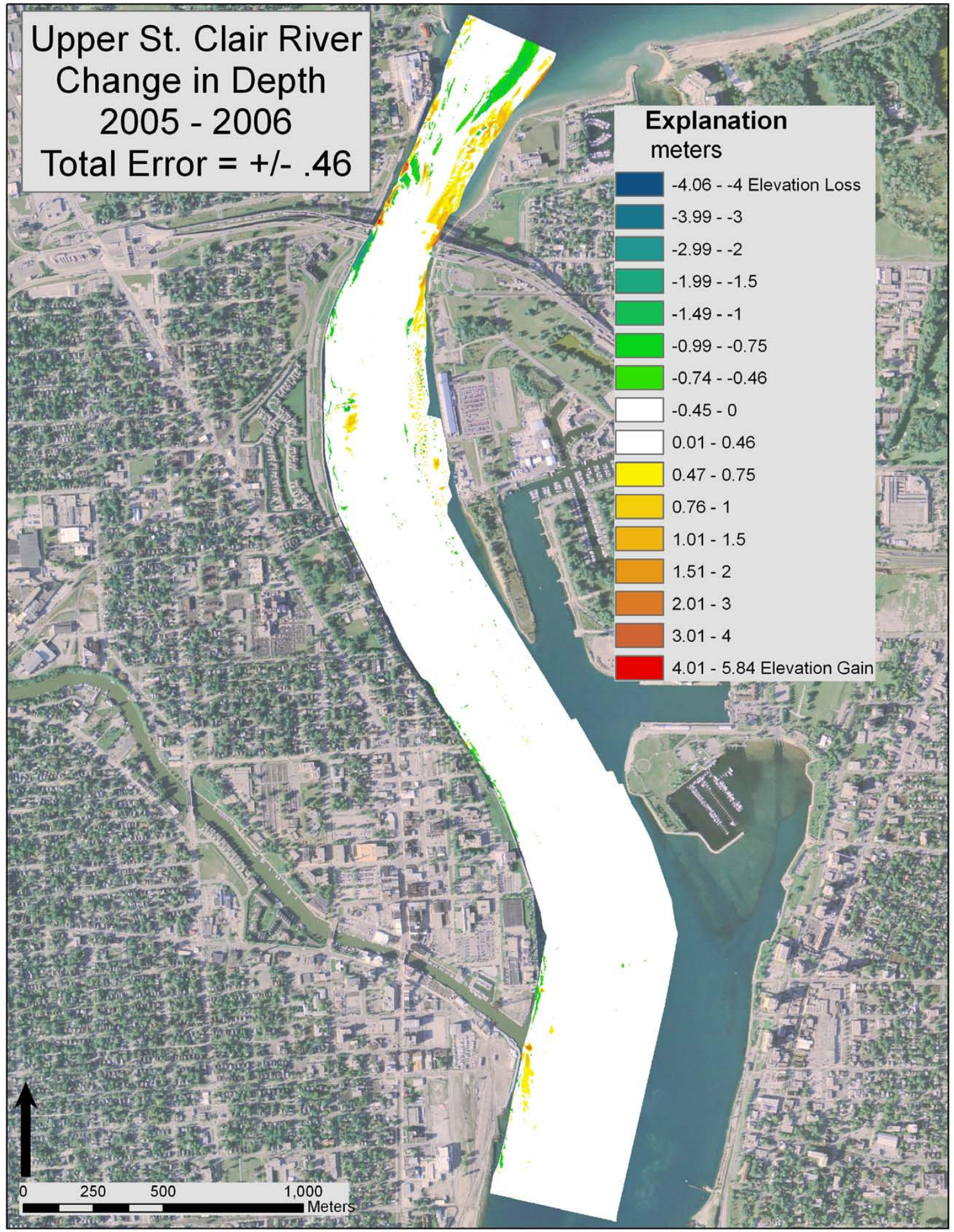

Figure 1-28. DEM file comparison indicating change in riverbed elevation in the upper St. Clair River, 2005-6, with uncertainty removed. 


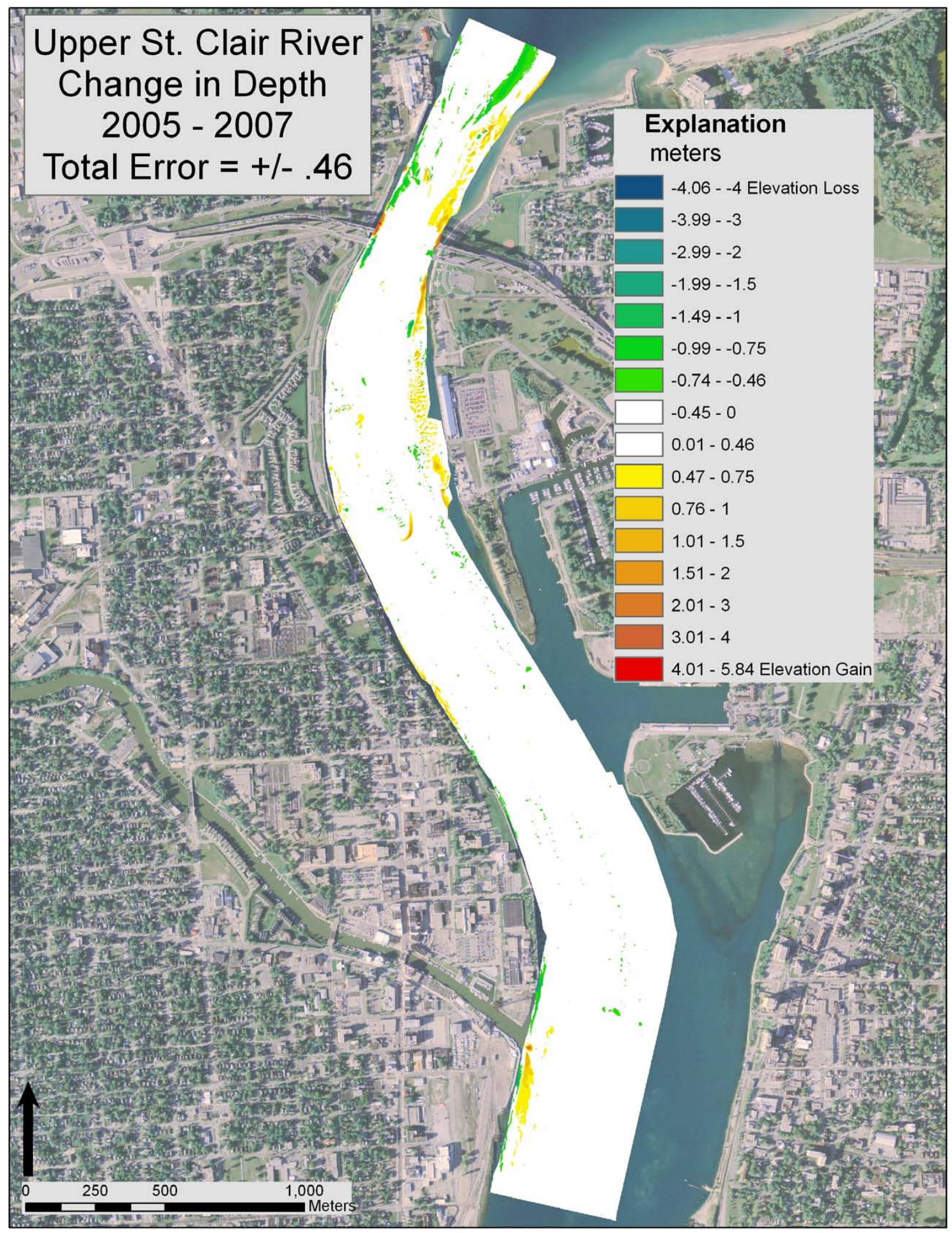

Figure 1-29. DEM file comparison indicating change in riverbed elevation in the upper St. Clair River, 2005-7, with uncertainty removed. 


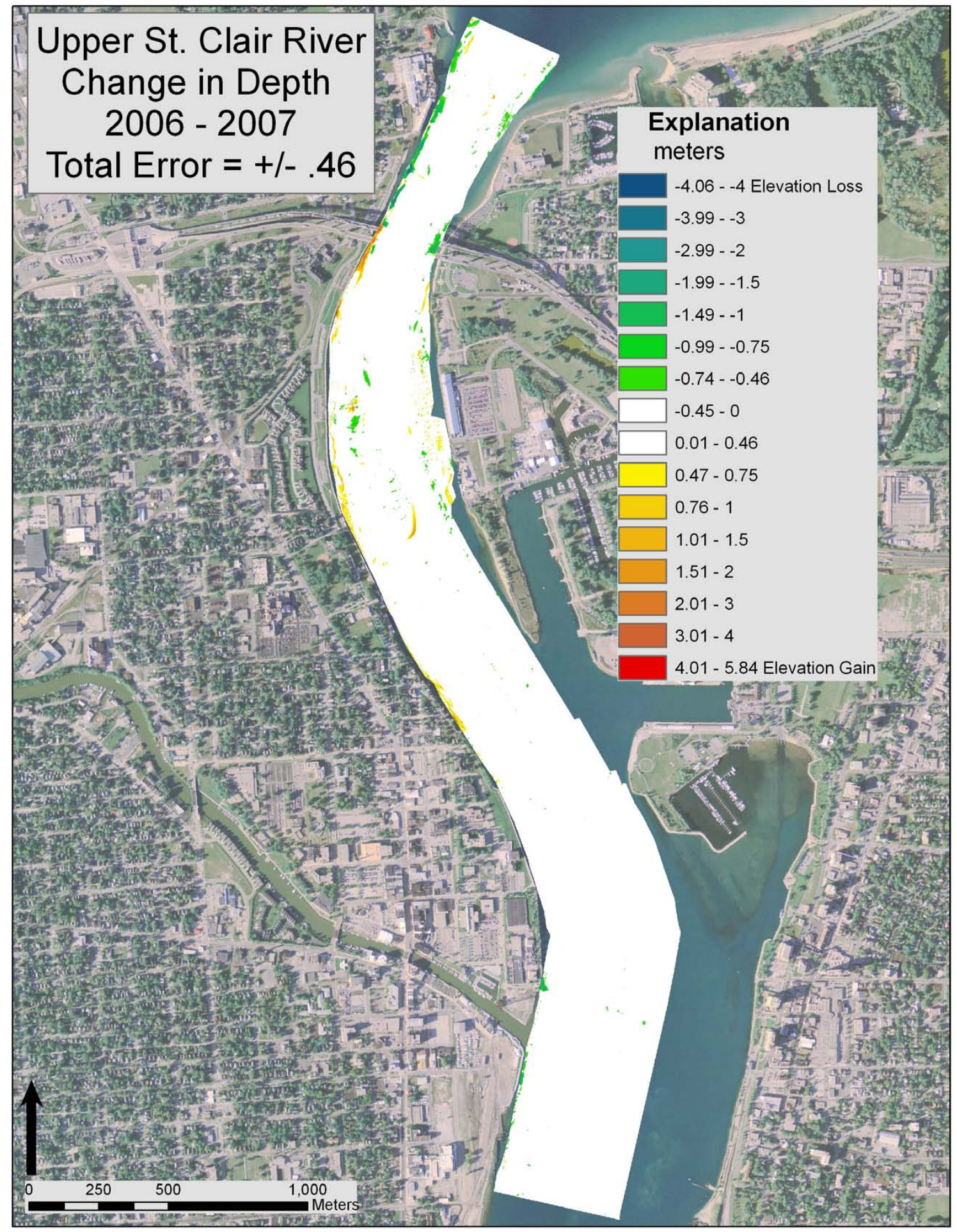

Figure 1-30. DEM file comparison indicating change in riverbed elevation in the upper St. Clair River, 2006-7, with uncertainty removed. 


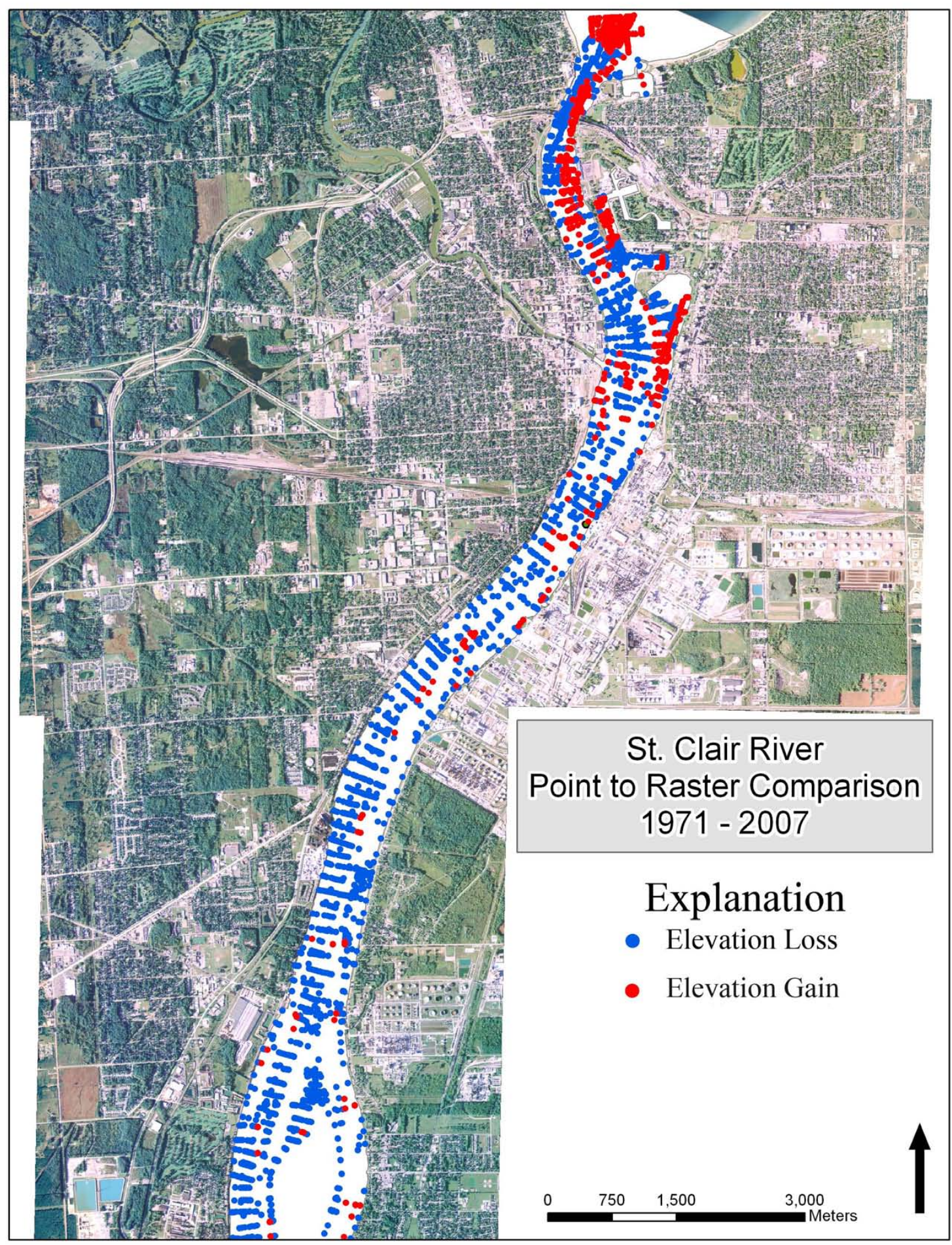

Figure1-31. 1971 point bathymetry compared to 2007 DEM data in the upper St. Clair River, with uncertainty removed. 


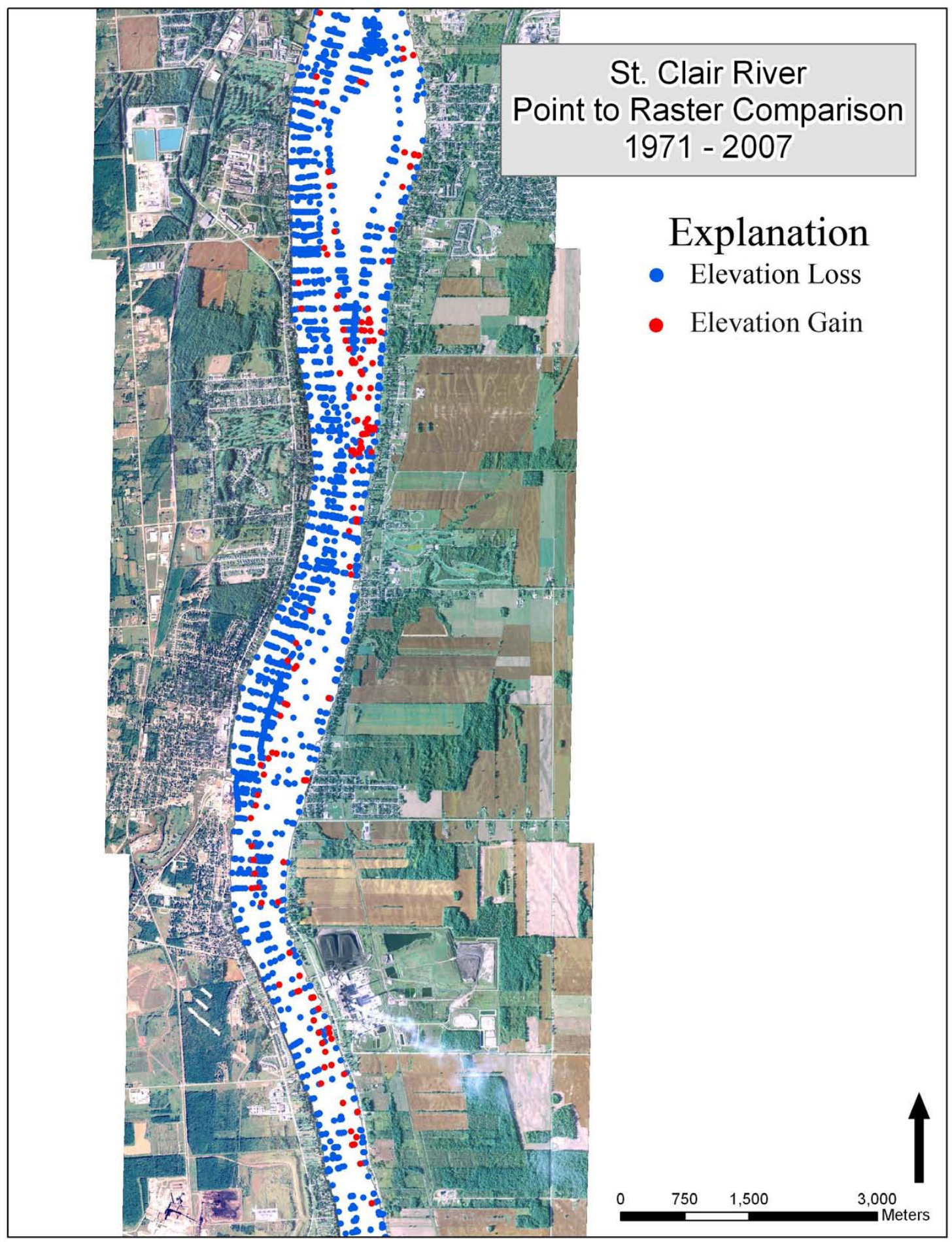

Figure 1-32 1971 point bathymetry compared to 2007 DEM data in the middle St. Clair River, with uncertainty removed. 


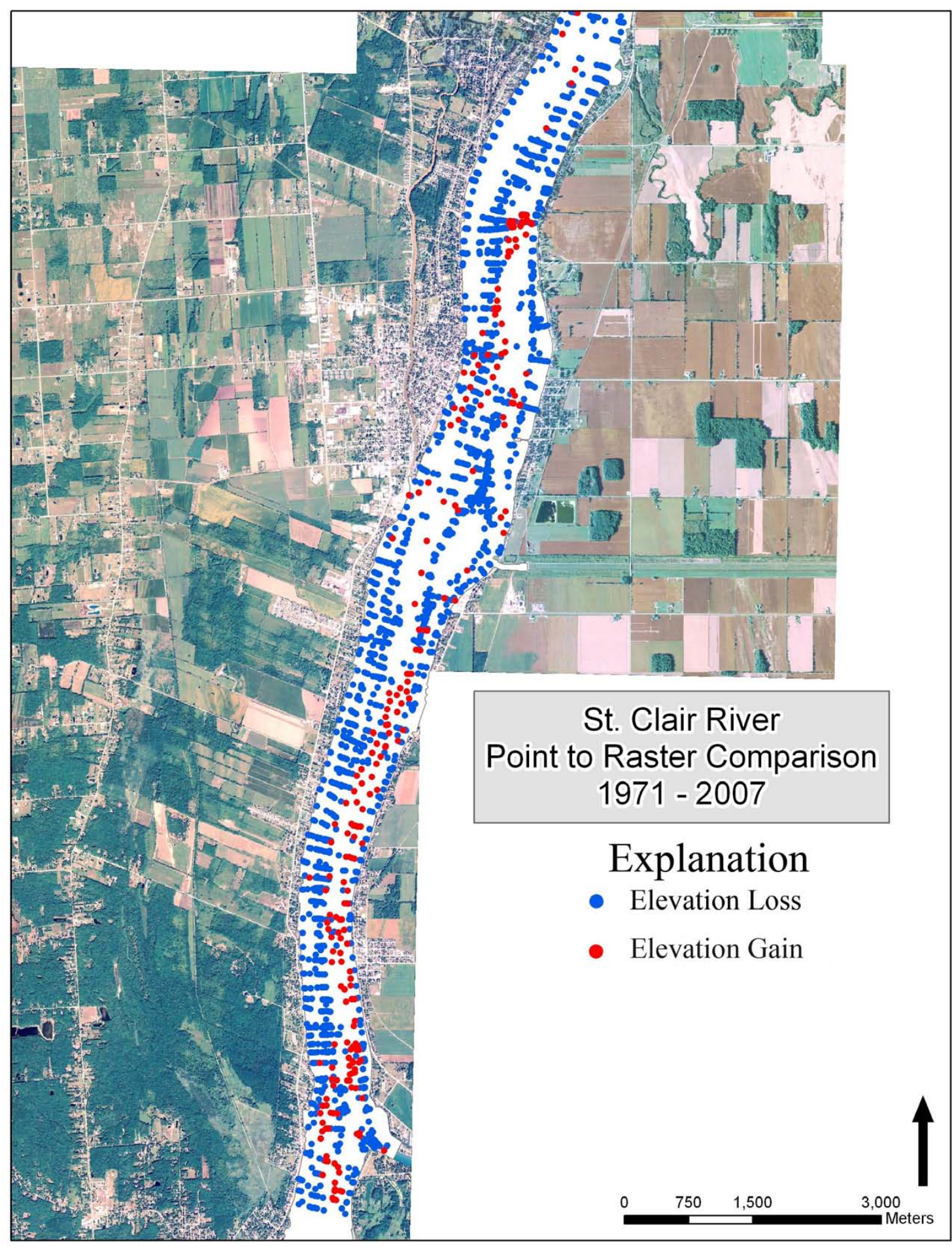

Figure 1-33. 1971 point bathymetry compared to 2007 DEM data in the lower St. Clair River, with uncertainty removed. 


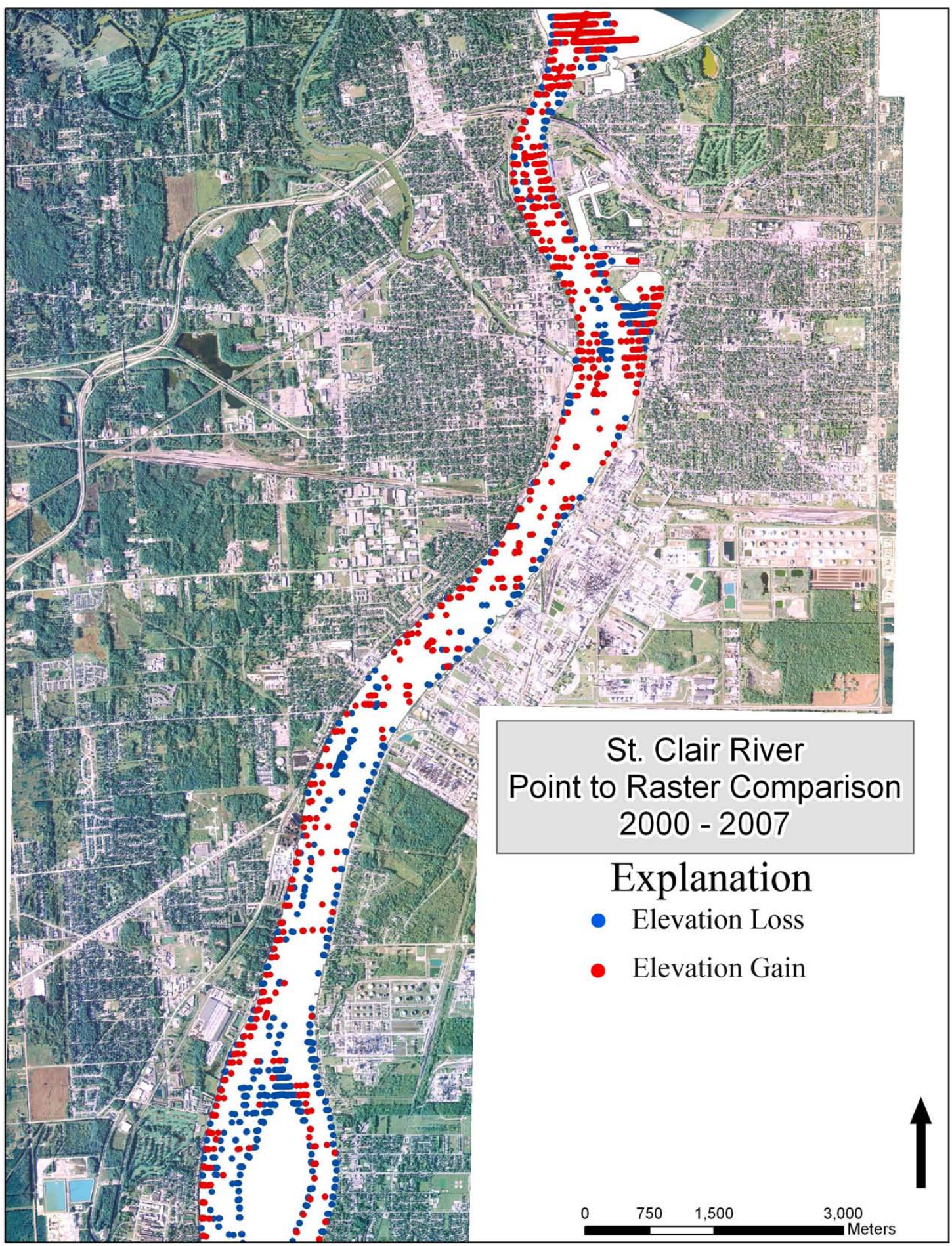

Figure1-34 2000 point bathymetry compared to 2007 DEM data in the upper St. Clair River, with uncertainty removed. 


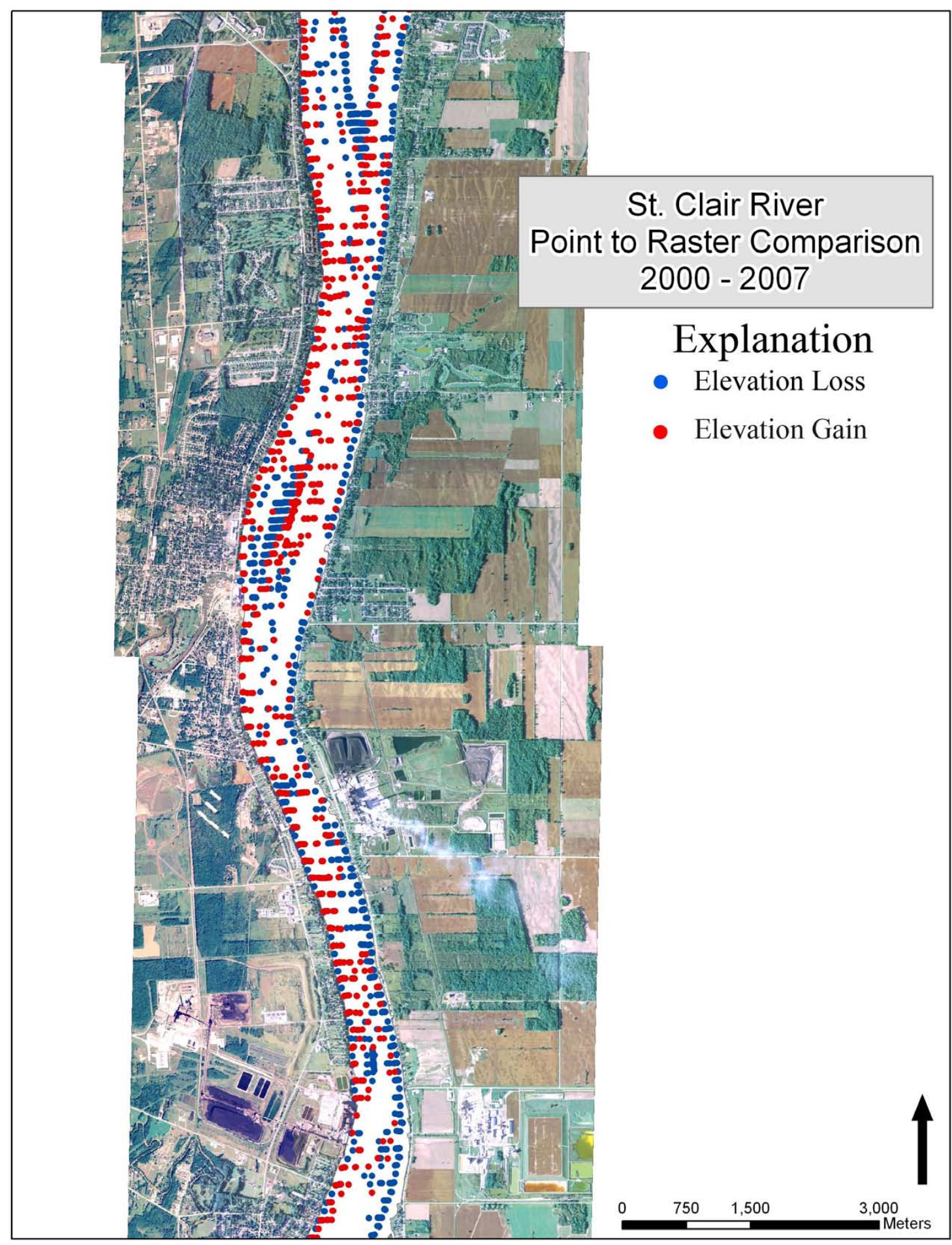

Figure 1-35 2000 point bathymetry compared to 2007 DEM data in the middle St. Clair River, with uncertainty removed. 


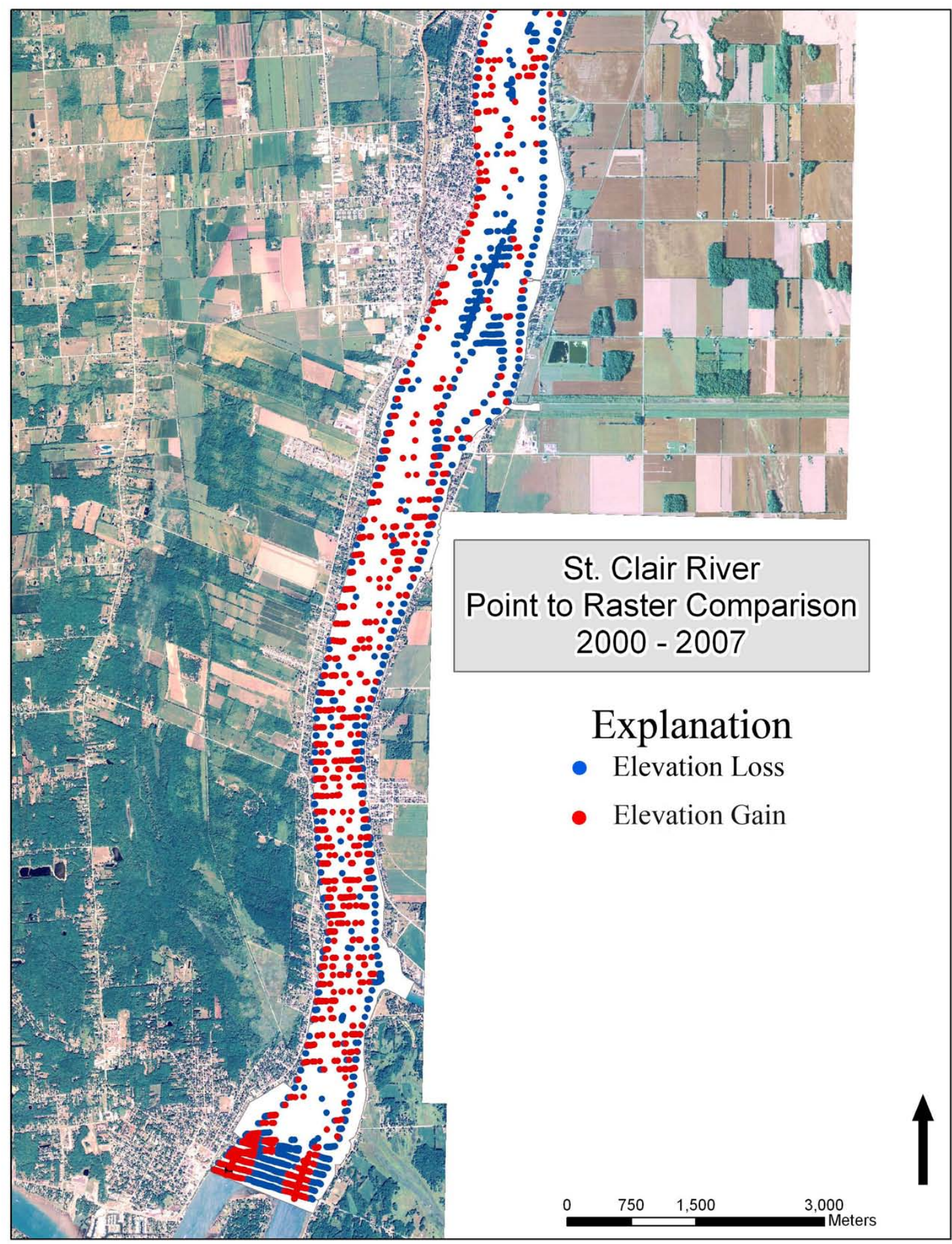

Figure 1-36 2000 point bathymetry compared to 2007 DEM data in the lower St. Clair River, with uncertainty removed. 


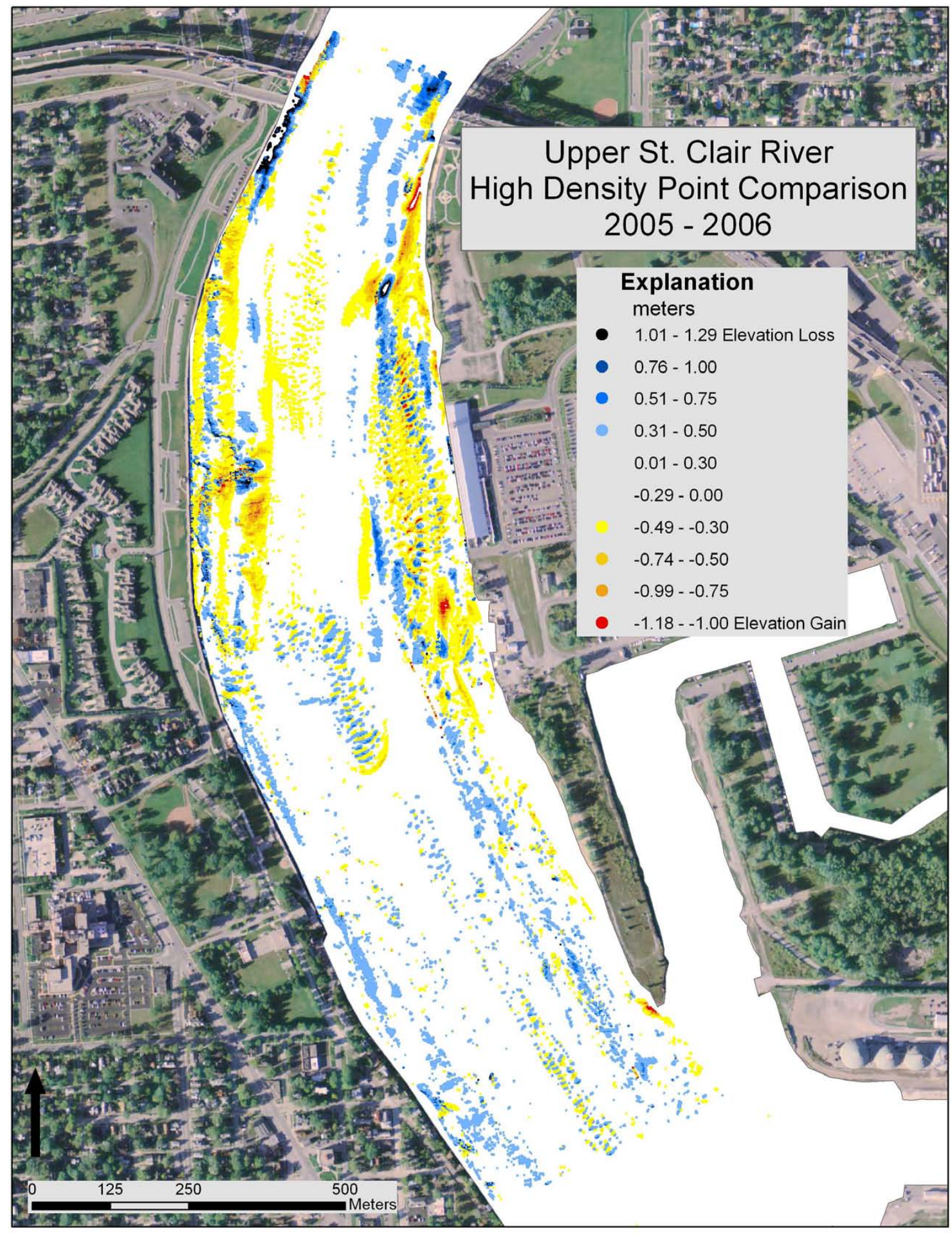

Figure 1-37. 2005-6 high-density point-to-point comparison of elevation change in the upper St. Clair River, with uncertainty removed. 


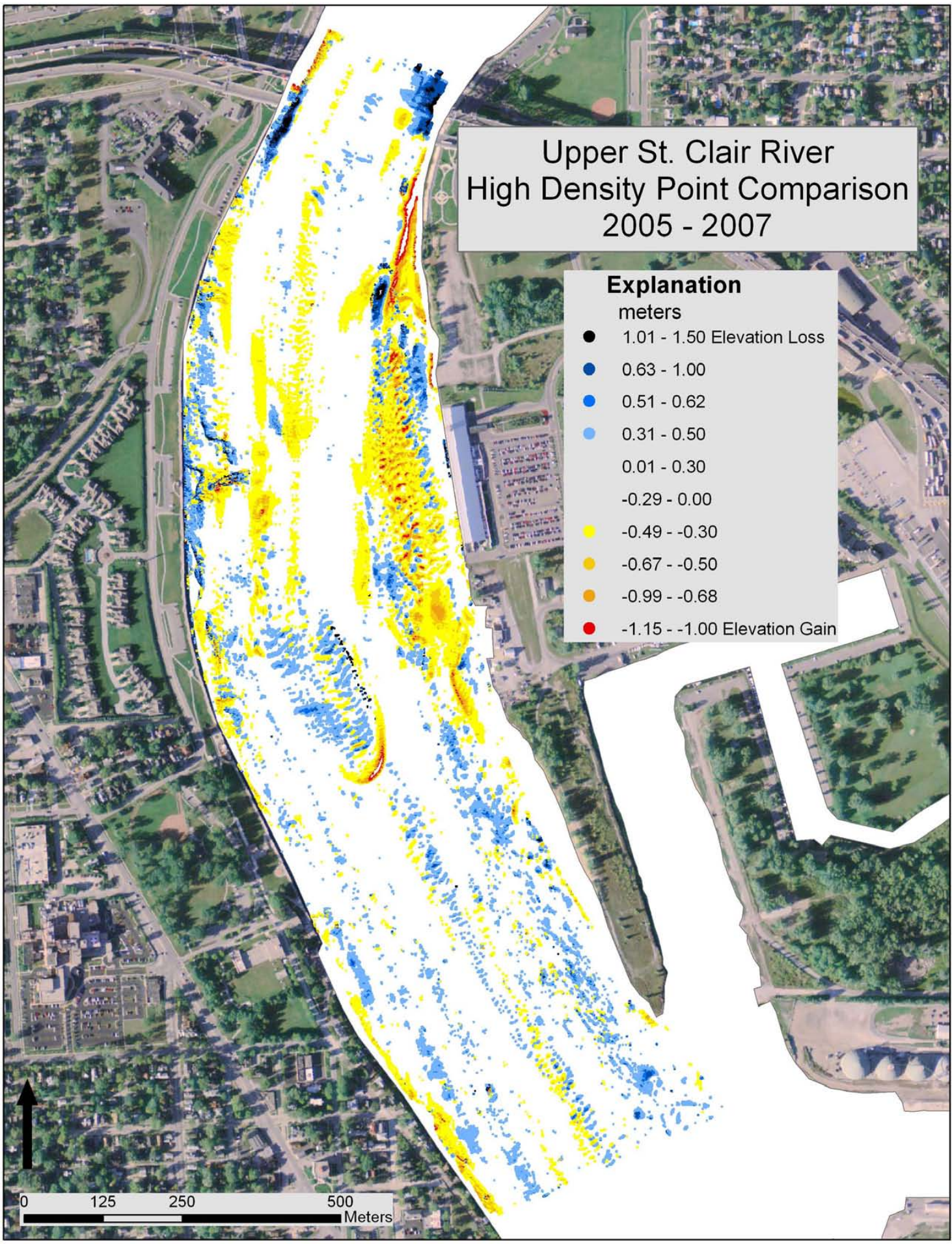

Figure 1-38 2005-7 high-density point-to-point comparison of elevation change in the upper St. Clair River, with uncertainty removed. 


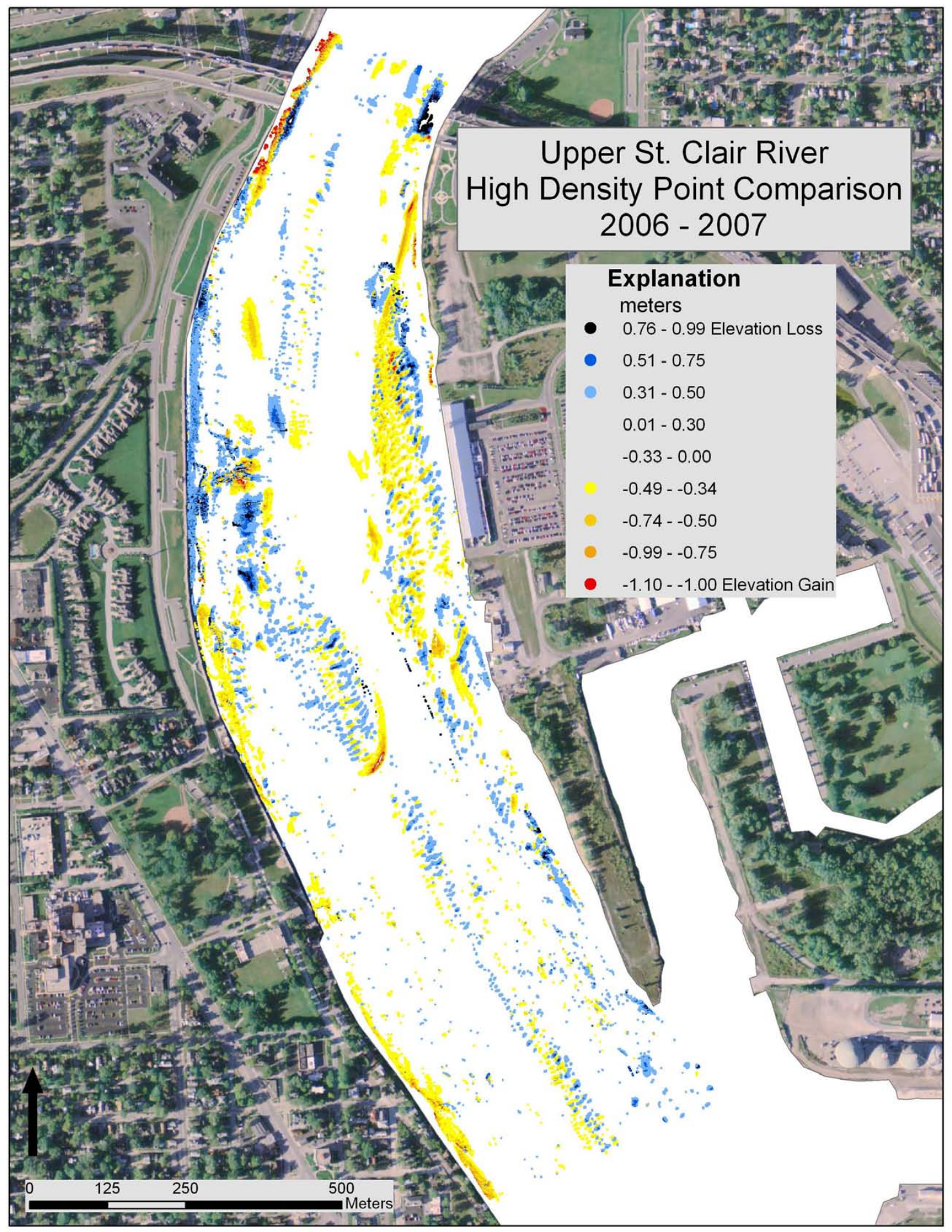

Figure 1-39. 2006-7 high-density point-to-point comparison of elevation change in the upper St. Clair River, with uncertainty removed. 


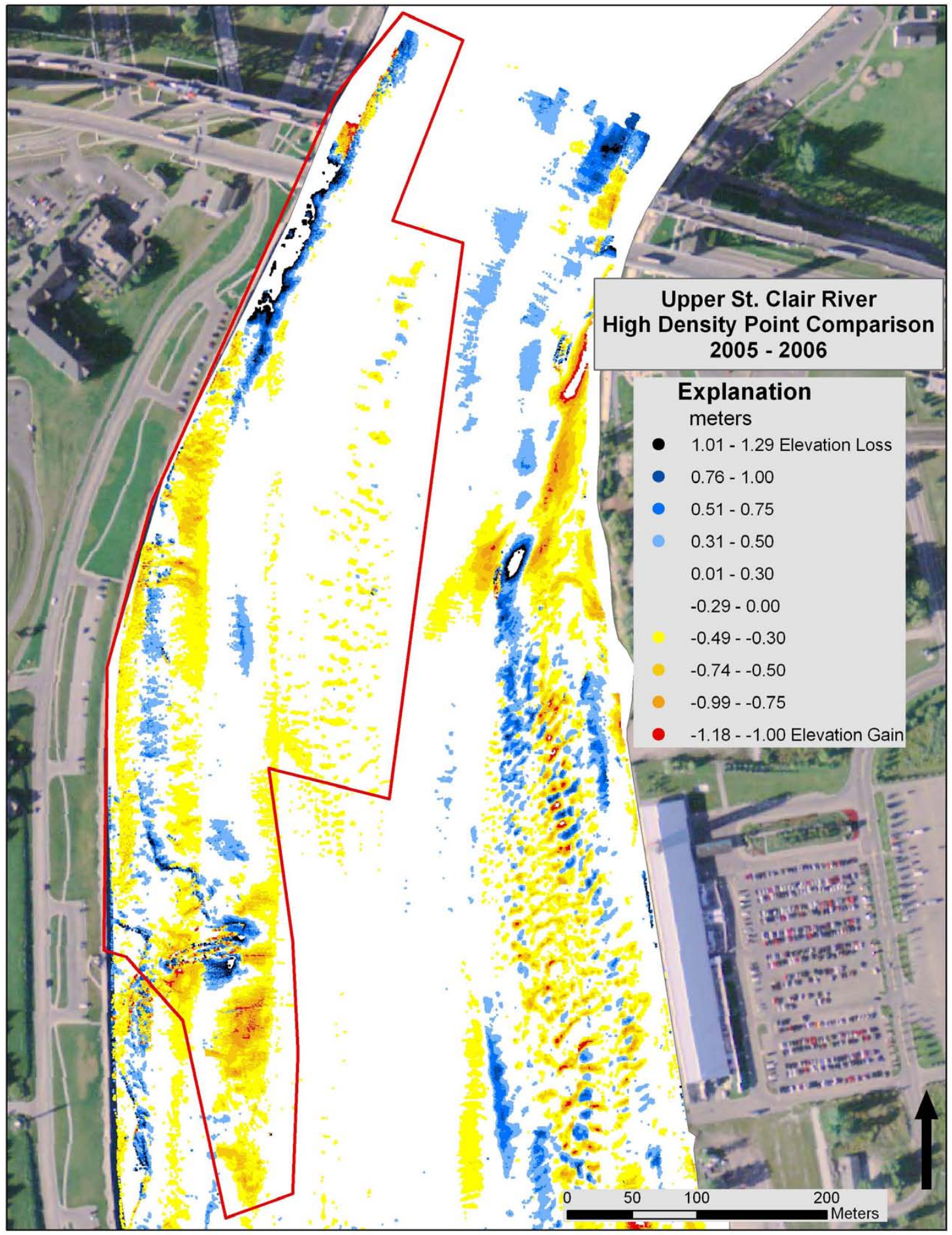

Figure 1-40. Area (outlined in red) where elevation changes dramatically from the 2006-7 comparison (fig. 1-41). 


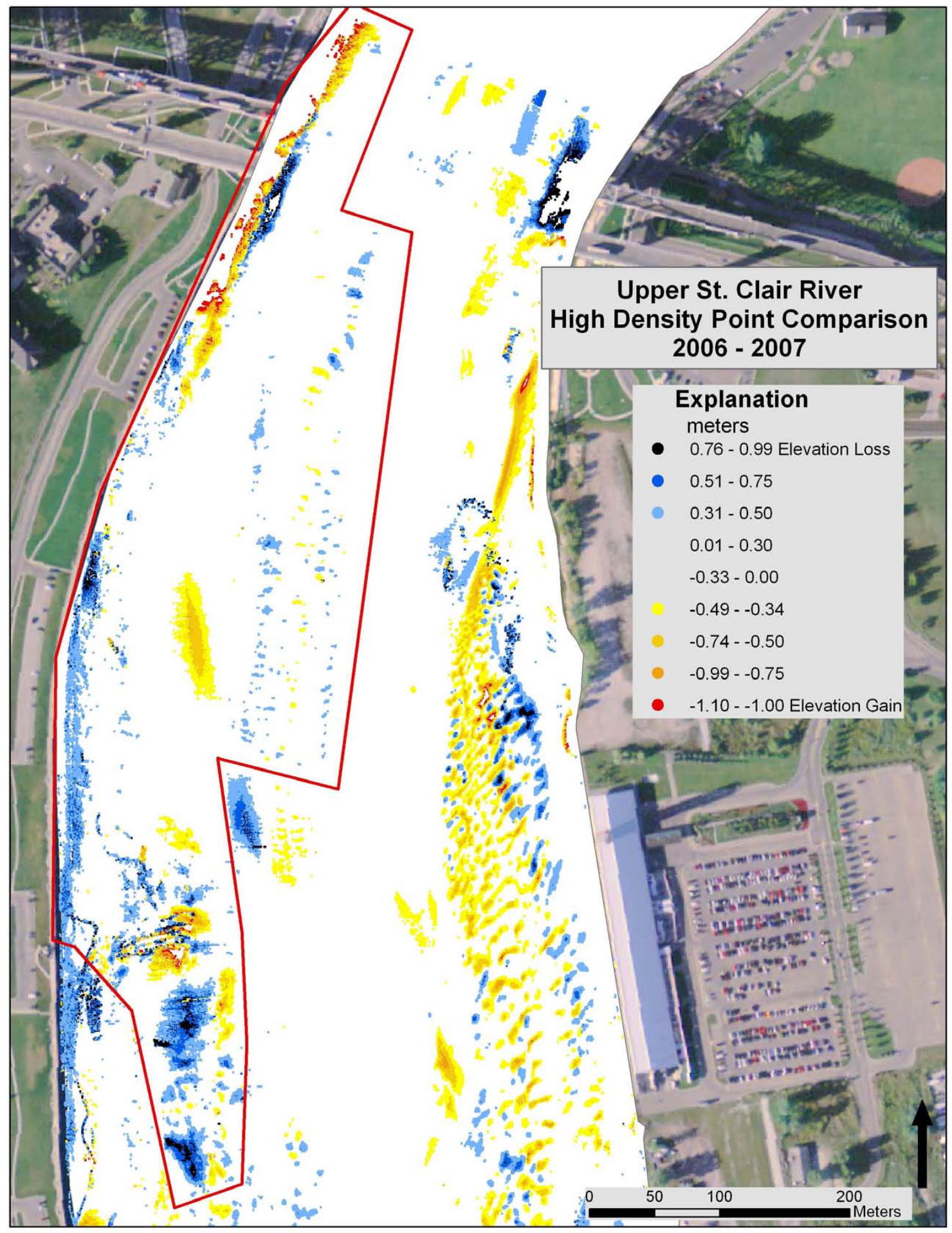

Figure1-41. Area (outlined in red) where elevation changes dramatically from the 2005-6 comparison (fig. 1-40). 


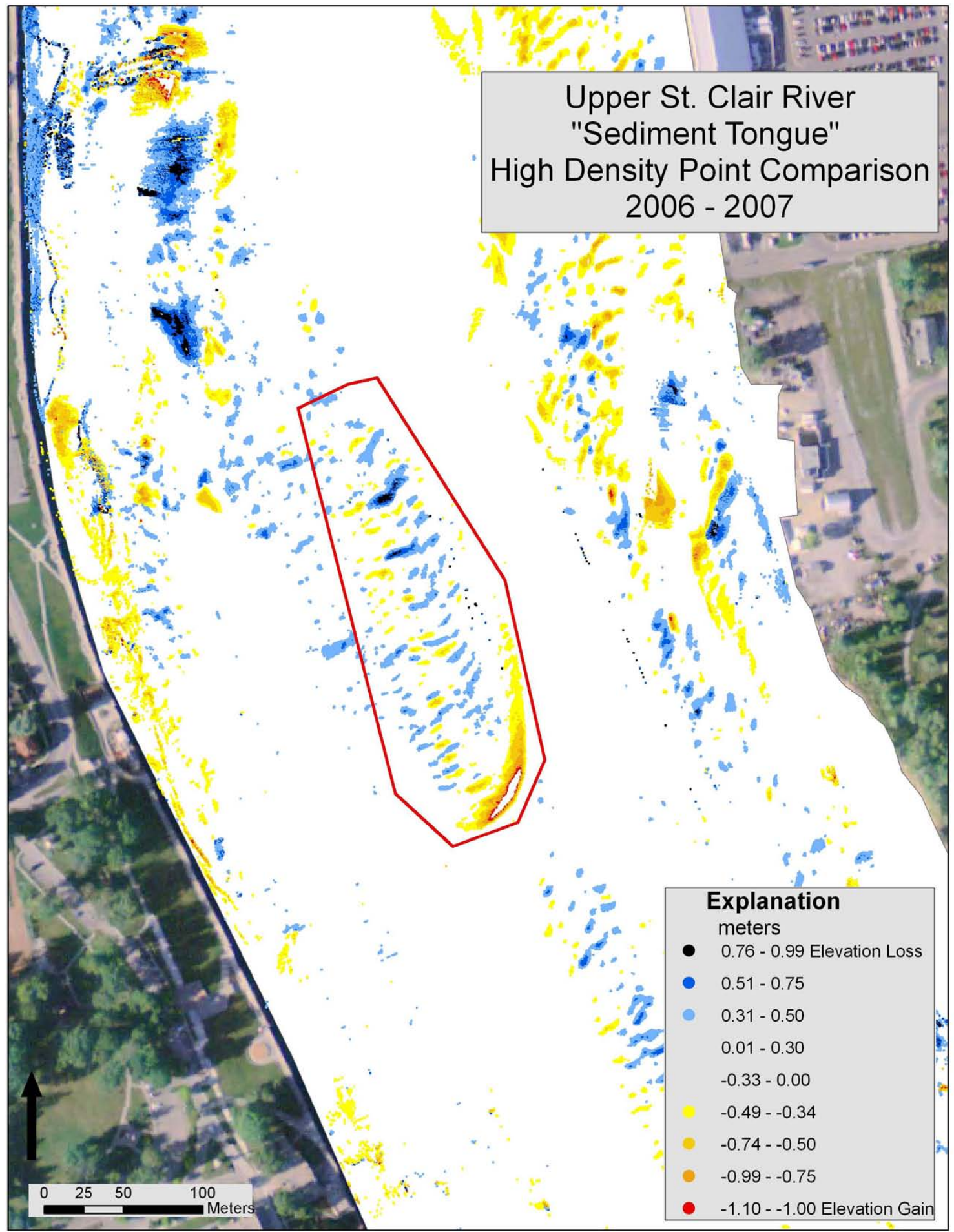

Figure 1-42 Area highlight of the "sediment tongue" elevation-gain feature in the upper St. Clair River. 


\section{Upper St. Clair River Zones of Elevation Loss and Elevation Gain}

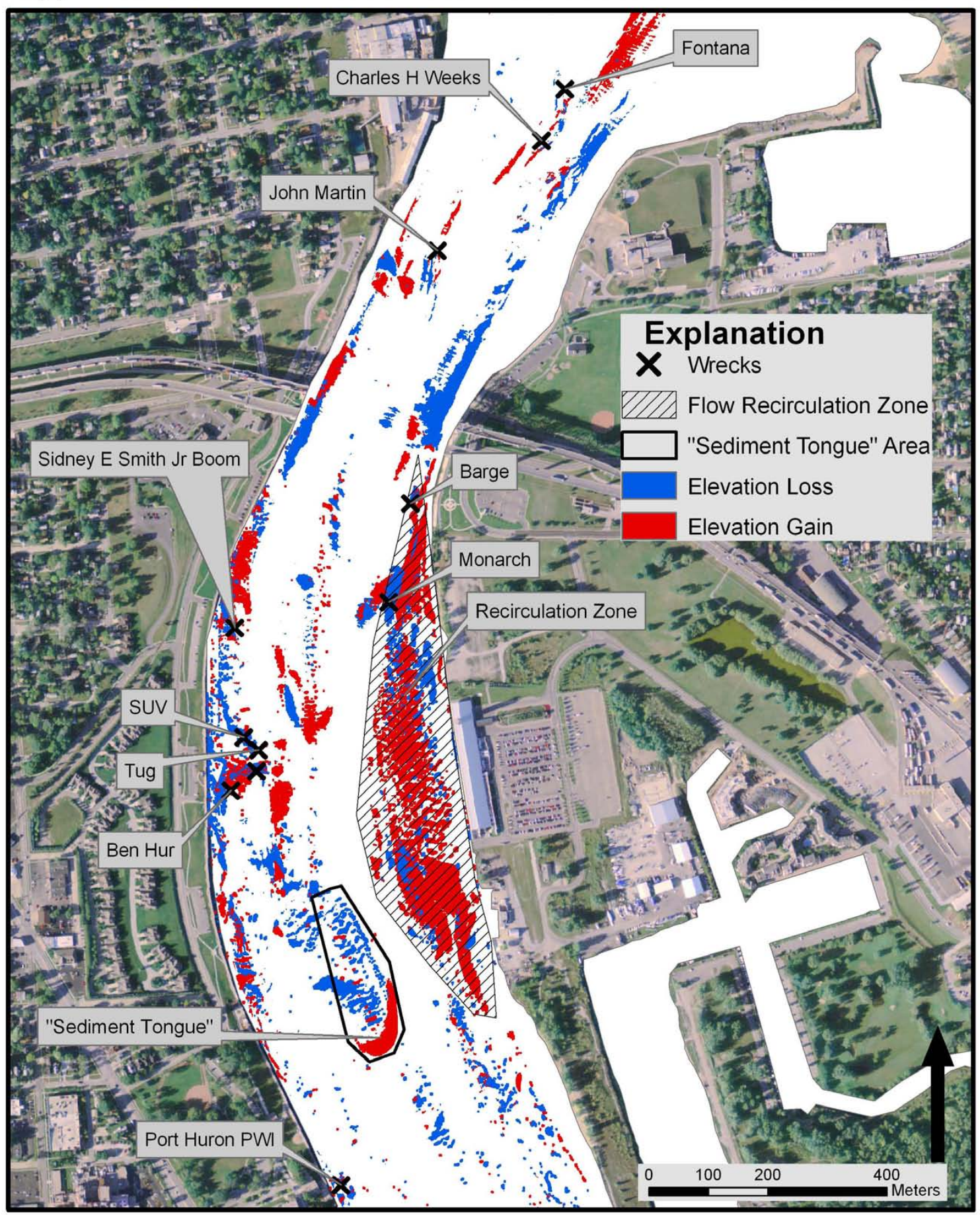

Figure 1-43. Areas of high geomorphic activity in the upper St. Clair River and spatial relation to selected river features. 


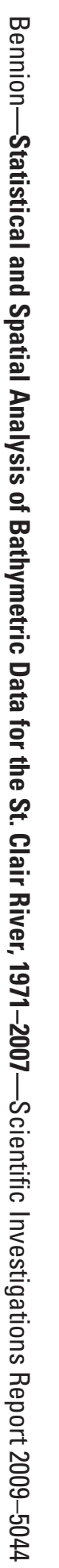

